RAPHAEL QUACHIO

ANÁLISE DO ALGORITMO PLS-PH PARA IDENTIFICAÇÃO DE SISTEMAS

SÃO PAULO

2012 
RAPHAEL QUACHIO

\section{ANÁLISE DO ALGORITMO PLS-PH PARA IDENTIFICAÇÃO DE SISTEMAS}

Dissertação apresentada a Escola Politécnica da Universidade de São Paulo para obtenção do título de Mestre em Ciências

Área de Concentração:

Engenharia de Sistemas

Orientador:

Prof. Dr. Claudio Garcia

\section{SÃO PAULO}


Este exemplar foi revisado e alterado em relação à versão original, sob responsabilidade única do autor e com a anuência de seu orientador.

São Paulo, de fevereiro de 2012.

Assinatura do autor

Assinatura do orientador

FICHA CATALOGRÁFICA

Quachio, Raphael

Análise do algoritmo PLS-PH para identificação de sistemas /

R. Quachio. -- ed.rev. -- São Paulo, 2012.

$100 \mathrm{p}$.

Dissertação (Mestrado) - Escola Politécnica da Universidade de São Paulo. Departamento de Engenharia de Telecomunicações e Controle.

1. Identificação de sistemas 2. Controle preditivo I. Universidade de São Paulo. Escola Politécnica. Departamento de Engenharia de Telecomunicações e Controle II. t. 


\section{AGRADECIMENTOS}

Ao professor Claudio Garcia, pela orientação e apoio, sem os quais esse trabalho dificilmente seria possível.

Aos colegas de laboratório: Alain Segundo Potts, Osmel Reyes Vaillant, Rodrigo Alvite Romano, Rodrigo Juliani Correa de Godoy e Vitor Alex Oliveira Alves, pelas sugestões, que enriqueceram muito esse trabalho.

Aos meus pais, Edson e Valdete, pelo seu apoio incondicional e encorajamento constante, em todos os momentos da minha vida.

A minha noiva, Luana, por toda a compreensão e incentivo ao longo destes anos.

A CHEMTECH, pelo apoio para a realização deste trabalho. 


\section{RESUMO}

O presente texto tem por objetivo avaliar diferentes aplicações do algoritmo PLS-PH (Partial Least Squares - Prediction Horizon), desenvolvido por (LAURI et al., 2010) para a identificação de sistemas, com o objetivo de desenvolvimento de controladores MPC. Desta maneira, é avaliada a capacidade do algoritmo gerar modelos lineares para realizar predições múltiplos passos à frente, para sistemas SISO e MIMO, com dados coletados em malha fechada. É também avaliada a capacidade do algoritmo de identificar modelos não-lineares baseados na estrutura NARX polinomial.

Palavras-Chave: Identificação de Sistemas; Controle Preditivo. 


\begin{abstract}
The objective of this work consists in evaluating different applications of the PLS-PH (Partial Least Squares - Prediction Horizon) algorithm, developed by (LAURI et al., 2010), in order to identify models for MPC controllers. The algorithm's capacity of producing linear models capable of performing multiple steps-ahead prediction for both SISO and MIMO systems, with data collected in closed-loop. The algorithm's capability of identifying non-linear models with the NARX polynomial structure is also evaluated.
\end{abstract}

Keywords: Systems Identification, Predictive Control. 


\section{SUMÁRIO}

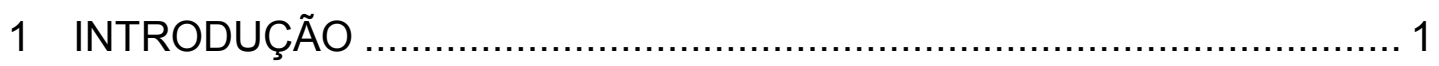

1.1 Identificação de Sistemas .............................................................. 2

1.2 Identificação relevante para controle.................................................. 3

1.2.1 Predição de Horizonte Amplo …………………........................... 4

1.3 Identificação em malha fechada .................................................... 5

1.3.1 Definição do conceito de malha fechada ………............................ 5

1.3.2 Problemas da identificação em malha fechada .................................. 6

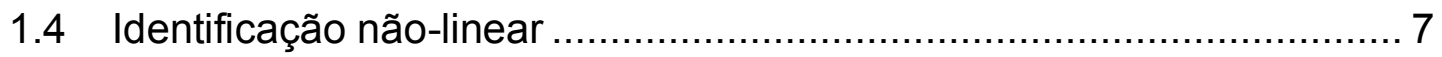

1.5 Motivação e Objetivos ................................................................... 7

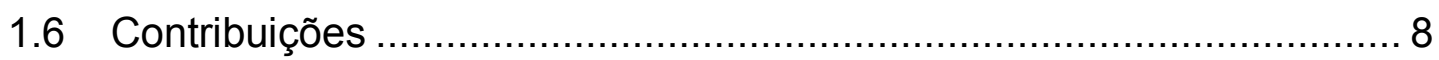

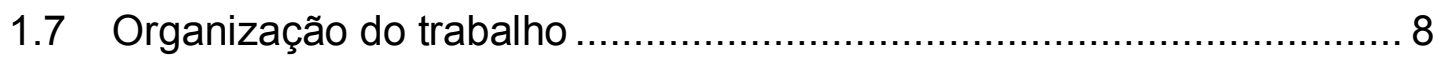

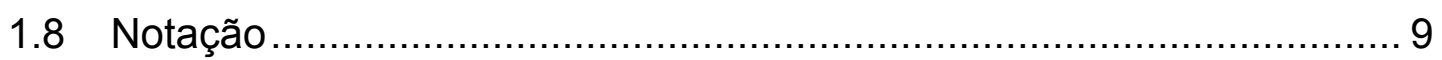

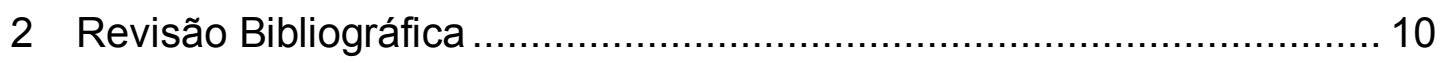

2.1 Model Predictive Control (MPC) …….............................................. 10

2.2 Identificação em malha fechada...................................................... 12

2.3 Identificação de sistemas multivariáveis …………………………... 13

2.4 Predição $k$ passos à frente ........................................................... 14

2.5 MPC Relevant Identification (MRI) ……….................................... 16

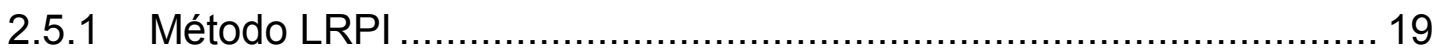

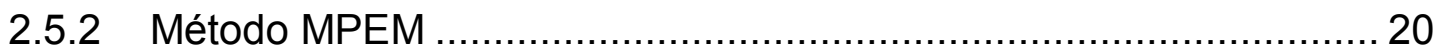

2.5.3 Identificação multi-modelos........................................................... 21

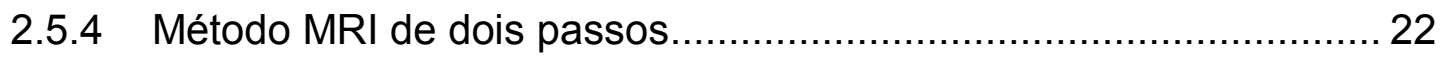

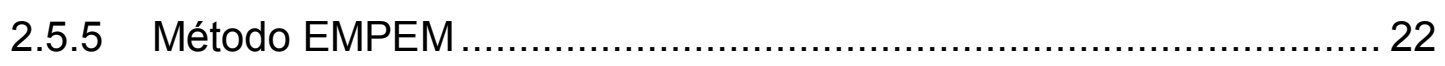

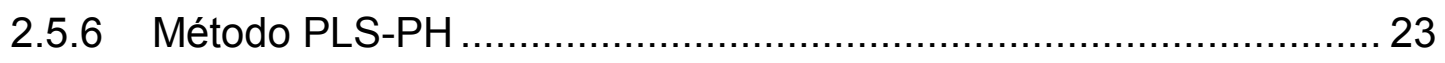


2.6 Regressão Multivariável, Multicolinearidade e PLS .......................... 24

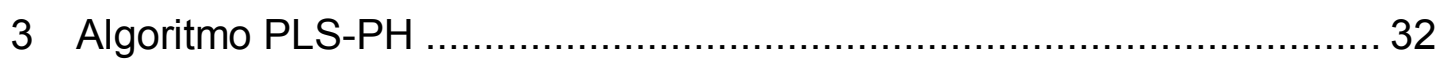

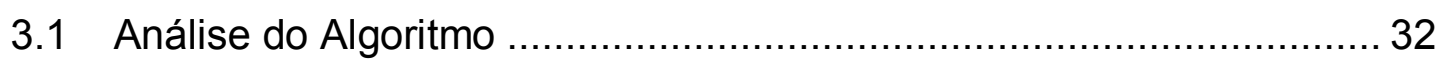

3.2 Regressão linear em malha fechada ....................................... 36

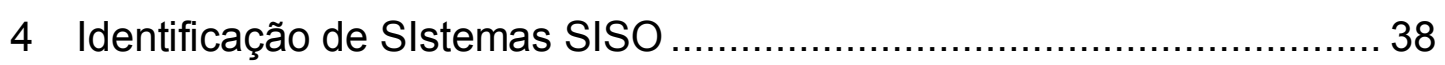

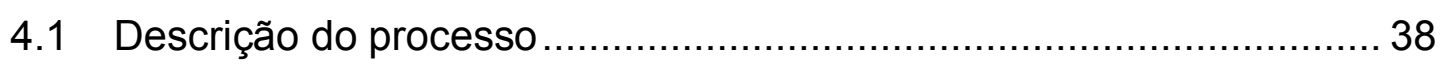

4.2 Identificação utilizando o algoritmo PLS-PH............................... 40

4.2.1 Estimação de tempo morto ............................................. 41

4.2.2 Identificação do fenômeno de multicolinearidade ......................... 41

4.2.3 Comparação entre PLS-PH e MPEM ...................................... 44

4.2.4 Efeito do Erro de Estimação de Tempo Morto .............................. 48

4.2.5 Análise de precisão da identificação ...................................... 49

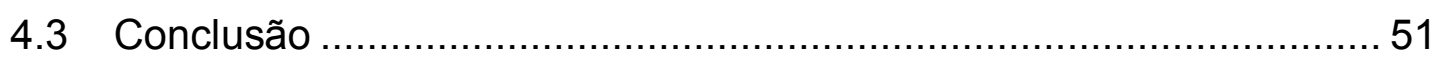

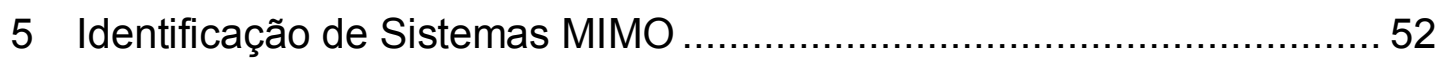

5.1 Coluna de Destilação Binária de Wood and Berry .......................... 52

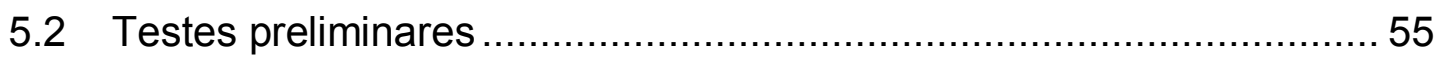

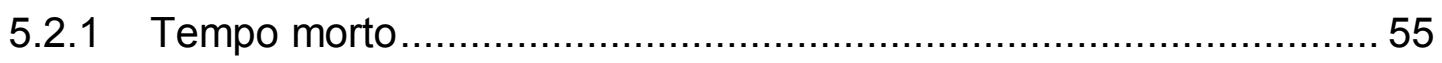

5.2.2 Ordem do Modelo e Número de Componentes Principais ...............58

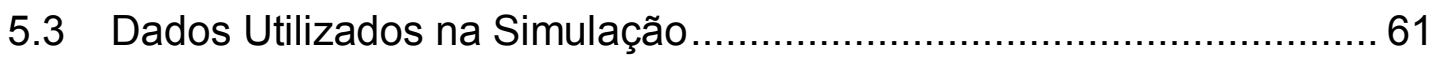

5.4 Identificação em malha fechada ........................................... 63

5.4.1 Desempenho em função da ordem e do horizonte de predição....... 63

5.4.2 Efeito do erro da estimativa de tempo morto .............................68

5.4.3 Análise de Precisão dos Algoritmos.................................... 70

5.5 Identificação da Planta + Controlador PID .................................. 72

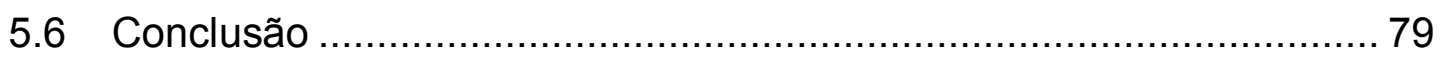

6 identificação de sistemas NARX Polinomiais .................................. 80

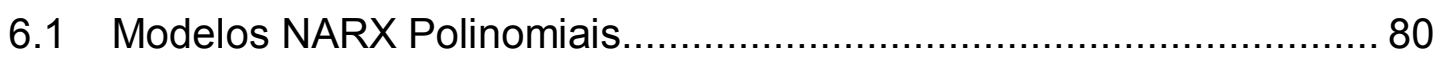


6.2 Métodos de identificação para modelos NARX polinomiais 82

6.2.1 Método dos mínimos quadrados 82

6.2.2 Métodos dos mínimos quadrados ortogonais 82

6.2.3 Métodos baseados em valores singulares.... 83

6.3 Métodos de redução da matriz de regressores 84

6.4 Identificação não-linear com o algoritmo PLS-PH. 85

6.5 Conclusão 94

7 Conclusão. 95

7.1 Perspectivas de Trabalhos Futuros 96

REFERÊNCIAS 98 


\section{INTRODUÇÃO}

O grande emprego de algoritmos de controle em aplicações industriais (notadamente na indústria de processos) é inegável. É comum encontrar, em unidades industriais de diferentes tamanhos, algumas dezenas ou centenas de malhas de controle. De acordo com (ÅSTRÖM; HÄGGLUND, 1995 apud CAMPOS; TEIXEIRA, 2006), em mais de 11000 malhas de controle avaliadas, mais de 97\% utilizavam controladores PID. Isso se deve à simplicidade de configuração deste controlador e a seu desempenho satisfatório. Estes números referem-se ao controle regulatório, cujo principal objetivo é manter a planta no ponto de operação desejado.

Entretanto, surge o problema de como definir os pontos de operação de uma planta. Para a grande maioria das unidades industriais, o plano de produção e o conhecimento (muitas vezes intuitivo) dos operadores acerca da planta são suficientes para que seja realizada a definição de tais valores. O conhecimento que a equipe de operação possui da planta é, de fato, extremamente importante. Porém existem alguns pontos que devem ser ressaltados:

- Por ser uma definição muitas vezes intuitiva, não existe uma métrica objetiva para definir se o conjunto de pontos de operação obtido garante que a produção esteja ocorrendo em seu ponto ótimo.

- A correlação entre diferentes variáveis de processo faz com que a definição dos pontos de operação se torne bastante complicada. Essa situação pode ser encontrada, por exemplo, na distribuição da vazão de um fluido entre os diferentes passes de um forno.

Para sanar tais deficiências utiliza-se outra camada de controle, denominada controle supervisório, que tem por objetivo calcular os valores ótimos para as variáveis de processo a partir de dados de produção desejados para a planta.

Dentre todas as metodologias de controle supervisório existentes, uma muito aplicada na indústria é o controle preditivo por modelo (Model Predictive 
Control - MPC). Em um levantamento realizado junto a fornecedores dessas soluções, apresentado em (QIN; BADGWELL, 2003), existiam na época mais de 4000 aplicações de controladores MPC instalados em diferentes plantas industriais no mundo inteiro.

Para poder operar, o MPC depende de um modelo matemático do sistema a ser controlado. A obtenção deste modelo foi identificada como uma das tarefas que demanda maior esforço para o desenvolvimento do controlador. Existem duas maneiras principais de se obter um modelo para uma planta industrial:

- Modelagem fenomenológica ou caixa branca: um modelo matemático é obtido a partir do cálculo dos balanços de massa e energia e de correlações conhecidas entre as variáveis.

- Identificação de sistemas ou caixa preta: um modelo é inferido a partir de regressão estatística realizada com base nos dados de processos coletados na planta.

Na presente dissertação é analisado um método de identificação de sistemas que tem por premissa gerar modelos ótimos para controladores MPC, utilizando como base a regressão de mínimos quadrados parciais.

\subsection{Identificação de Sistemas}

Identificação de sistemas é o nome dado à família de algoritmos utilizados para a obtenção de modelos matemáticos para a representação de sistemas dinâmicos. Existe uma grande diversidade de métodos para a construção de modelos, conforme apresentado em (LJUNG, 1999) e (AGUIRRE, 2007). Uma classe de métodos que apresenta um grande interesse acadêmico engloba os métodos paramétricos de identificação, nos quais o objetivo é a obtenção de um modelo dinâmico, na forma de função de transferência ou espaço de estados, que explique satisfatoriamente o conjunto de dados observados. 
A identificação de parâmetros com base em um conjunto de dados de entrada e saída do sistema pode ser interpretada como um problema de regressão em estatística, que pode ser apresentado como:

$$
\boldsymbol{y}=f(\boldsymbol{X}, \boldsymbol{\epsilon}, \boldsymbol{\theta})
$$

em que:

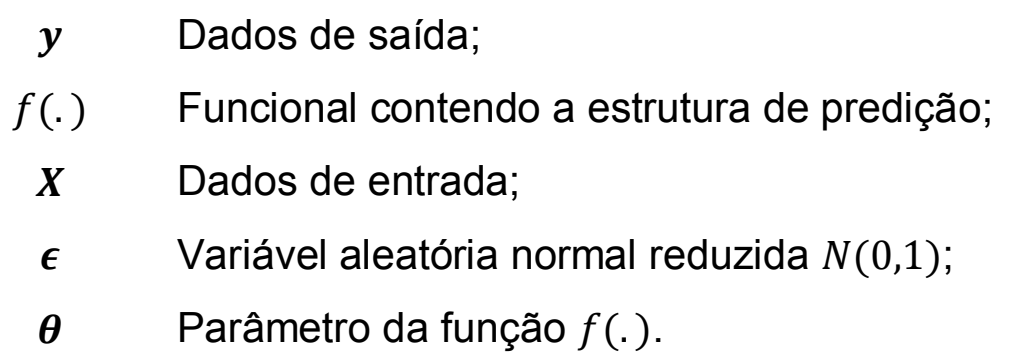

Neste problema, o objetivo é determinar o vetor $\boldsymbol{\theta}$ de modo a se obter uma estimativa ótima, segundo alguma métrica, da saída a partir de dados de entrada.

Por se tratar de um problema de regressão estatística, todo procedimento de identificação de sistemas pode utilizar-se de um conjunto bem estabelecido de ferramentas para determinar a confiança e a validade dos modelos estimados. Ou seja, ao tratar o problema de identificação de sistemas é possível estimar, por exemplo, qual o intervalo de confiança de um certo parâmetro com $99 \%$ de certeza.

\subsection{Identificação relevante para controle}

A necessidade da obtenção de modelos matemáticos para o desenvolvimento de algoritmos de controle não é uma exclusividade dos algoritmos MPC. De fato, um caso crítico ocorre com os algoritmos de controle robusto nos quais, além do modelo da planta, é necessário conhecer uma estimativa do erro de modelagem. Em uma revisão apresentada em (GEVERS, 2002), um dos grandes desafios existentes no início da década de 1990 era a existência de divergências entre as estruturas de modelos obtidos pelos métodos tradicionais 
de identificação de sistemas e as estruturas de modelos demandadas para o projeto de controladores.

Conforme mencionado na seção 1.1, pelo fato de poder ser visto como um problema de regressão, todo procedimento de identificação de sistemas dispõe automaticamente de todos os intervalos de confiança associados aos parâmetros estimados. Ora, a existência deste intervalo de confiança pode ser visto como a incerteza do modelo buscada pelos projetistas de controle robusto.

Caso se analise, por exemplo, a teoria assintótica apresentada em (LJUNG, 1999), observa-se que o elipsóide de confiança de um modelo, e consequentemente sua incerteza, é dado pela integral de uma função do espectro de potência dos sinais. Tal integral não possui a estrutura correta para o projeto de controlador robusto (GEVERS, 2002). Por este motivo, na década de 1990 iniciaram-se diversas linhas de pesquisa com o objetivo de determinar métodos de identificação que gerassem informações relevantes para o projeto de controladores robustos.

\subsubsection{Predição de Horizonte Amplo}

Dentre as diversas linhas originadas nessa época, deve ser dada especial atenção ao trabalho desenvolvido em (SHOOK; MOHTADI; SHAH, 1991). Nos métodos tradicionais de identificação de sistemas, notadamente o método do erro de predição (PEM) e os métodos não paramétricos, o objetivo é obter um modelo tal que o erro entre a estimativa da saída para um passo de tempo no futuro e o valor efetivamente observado seja mínimo. Ora, para o desenvolvimento de controladores MPC, é interessante que o modelo do sistema seja capaz de gerar boas estimativas para todos os passos de tempo $i=1, \ldots, N_{2}$ no futuro. Deste modo, (SHOOK; MOHTADI; SHAH, 1991) apresentaram um método em que o objetivo era a obtenção de um modelo que gerasse uma boa predição da resposta para todos os passos de tempo $i=1, \ldots, N_{2}$ à frente. 
Este trabalho originou uma linha de pesquisa conhecida como MRI (MPC Relevant Identification), na qual podem ser citados os trabalhos desenvolvidos por (HUANG; WANG, 1999), (GOPALUNI; PATWARDHAN; SHAH, 2004) e (LAURI et al., 2010), dentre outros. Este último apresenta um método eficiente para a identificação de sistemas numericamente mal condicionados, conhecido como PLS-PH (Partial Least Squares - Prediction Horizon), que será analisado no presente trabalho.

\subsection{Identificação em malha fechada}

\subsubsection{Definição do conceito de malha fechada}

Antes de se discutir identificação em malha fechada, é importante definir claramente o conceito de malha fechada.

Apesar de simplesmente ser dito que o sistema opera em malha fechada, na topologia mais usual de aplicação do MPC existem pelo menos duas malhas de controle operando, conforme pode ser observado na Figura 1.1.

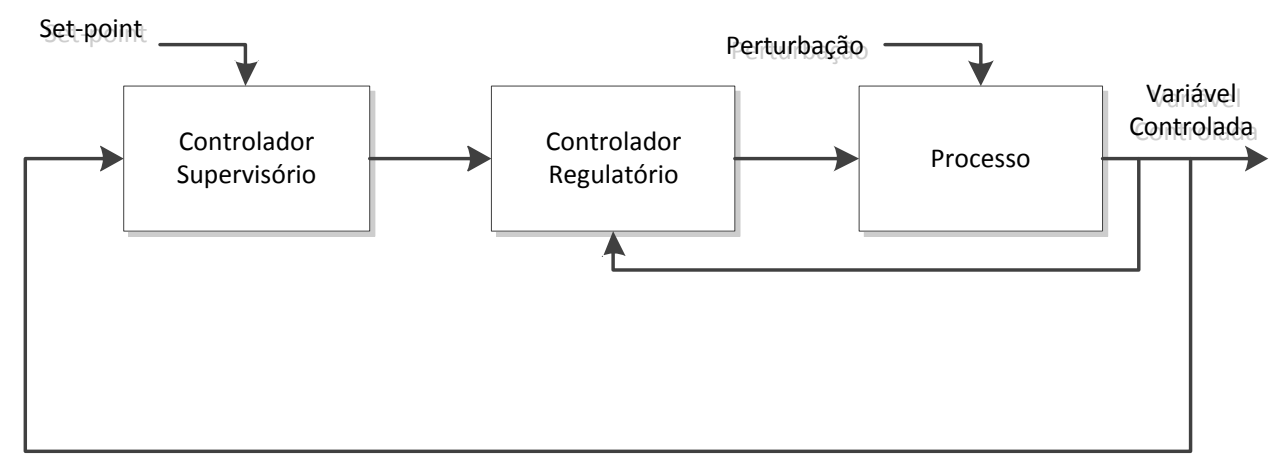

Figura 1.1 - Malhas de controle. (Autor)

A malha interior, conhecida como malha de controle regulatório, é composta geralmente por controladores PID. Estas malhas se caracterizam por serem críticas à estabilidade e segurança do processo e, caso estejam bem 
sintonizadas, dificilmente são desligadas. A malha exterior, conhecida como malha de controle supervisório, normalmente consiste de um controlador MPC e/ou outro sistema de otimização do processo, que não interfere na estabilidade do sistema.

Utilizar as expressões malha aberta e malha fechada, sem qualquer menção referência a qual malha está sendo analisada pode gerar confusões. A fim de evitar este problema, no corpo do presente texto as expressões malha aberta e malha fechada sempre farão referência às malhas de controle regulatório fechadas e de controle MPC desligadas, exceto quando explicitamente indicado.

\subsubsection{Problemas da identificação em malha fechada}

Os métodos tradicionais de regressão estatística normalmente consideram que não exista correlação entre sinais de perturbação e dados de entrada do processo, pois isso pode interferir na qualidade dos parâmetros obtidos.

Quando o sistema opera em malha fechada, a saída, e consequentemente a perturbação, são realimentadas na entrada do sistema. Assim, a utilização de dados coletados em malha fechada pode resultar na criação de regressores numericamente mal-condicionados. Para se trabalhar com esses dados, conhecidos como regressores multicolineares, é necessário que o algoritmo de regressão apresente alguma robustez a esse fenômeno. Em (KIERS; SMILDE, 2007) é apresentada uma revisão de métodos estatísticos que possuem essa propriedade, dentre eles a regressão por meio do método PLS.

Pelo fato da multicolinearidade poder estar presente na identificação em malha fechada, é possível que o algoritmo PLS-PH (por ser baseado na regressão PLS) apresente um bom desempenho para identificação múltiplos passos à frente para um sistema operando em malha fechada. 


\subsection{Identificação não-linear}

Os controladores MPC normalmente utilizados na indústria são baseados em modelos lineares, que tem aplicabilidade limitada em torno do ponto de operação da planta. Entretanto, existem sistemas que possuem elevado grau de não-linearidade, para os quais o desempenho destes controladores é insatisfatório. Para estes casos, são utilizados controladores NMPC (Nonlinear MPC), fundamentados em modelos não-lineares do processo. Convencionalmente, são utilizados modelos fenomenológicos, ou modelos de regressão não-linear 1 passo à frente, não existindo nenhum método MRI capaz de identificar modelos não-lineares.

Analisando alguns métodos de identificação não-linear, apresentados em (AGUIRRE, 2007), é possível verificar que a identificação de modelos com estrutura NARX polinomial possui uma configuração de regressores similar àquela explorada pelo algoritmo PLS-PH. Assim, uma possível maneira de obter um método MRI para a identificação de modelos não-lineares seria utilizar o algoritmo PLS-PH para a identificação de modelos com estrutura NARX polinomial.

\subsection{Motivação e Objetivos}

Com base na constatação que o fenômeno de multicolinearidade pode ser verificado em uma identificação em malha fechada e na possibilidade de aplicar o algoritmo PLS-PH para gerar modelos não-lineares, resolveu-se analisar o desempenho do algoritmo PLS-PH para estas situações, originalmente não previstas em (LAURI; et al., 2010).

Desta maneira, os objetivos do presente trabalho consistem em:

- Implementar o algoritmo PLS-PH;

- Avaliar o desempenho deste algoritmo para identificar sistemas com os dados coletados em malha fechada; 
- Analisar o desempenho para identificação de modelos lineares para plantas SISO e MIMO;

- Avaliar o desempenho dos modelos obtidos em controladores MPC;

- Avaliar a capacidade do algoritmo PLS-PH em identificar modelos não lineares com estrutura NARX polinomial.

\subsection{Contribuições}

Dentre as contribuições realizadas neste trabalho devem ser destacadas:

- Avaliação do algoritmo PLS-PH para realizar a identificação de sistemas com dados coletados em malha fechada, cujos resultados são apresentados em (QUACHIO; GARCIA; 2011b);

- Proposta de um método MRI para a identificação de modelos nãolineares baseados na estrutura NARX polinomial, cujos resultados são apresentados em (QUACHIO; GARCIA; 2011a).

\subsection{Organização do trabalho}

O presente trabalho está organizado da seguinte maneira: no primeiro capítulo é realizada uma breve apresentação sobre o problema da identificação relevante para MPC. No segundo capítulo é feita uma revisão bibliográfica, onde são apresentados os temas relevantes para o desenvolvimento do algoritmo PLS-PH. O terceiro capítulo é dedicado à apresentação do algoritmo PLS-PH e análises preliminares do mesmo. No quarto capítulo, o algoritmo PLS-PH é utilizado para identificar uma planta SISO com os dados coletados em malha fechada. O quinto capítulo é dedicado à identificação de plantas MIMO e a aplicação dos modelos em controladores MPC. O sexto capítulo apresenta uma aplicação do algoritmo PLS-PH para a identificação de modelos não lineares com estrutura NARX polinomial. Finalmente, o sétimo capítulo é consagrado às conclusões e perspectivas de trabalhos futuros. 


\subsection{Notação}

No presente trabalho, será utilizada a seguinte convenção para representar as equações:

- As variáveis representadas por letras maiúsculas em negrito representam matrizes;

- As variáveis representadas por letras minúsculas em negrito representam vetores coluna;

- As variáveis representadas por letras maiúsculas ou minúsculas representam valores escalares. 


\section{REVISÃO BIBLIOGRÁFICA}

Neste capítulo são apresentados os principais conceitos teóricos que são utilizados ao longo deste texto.

\subsection{Model Predictive Control (MPC)}

A importância do MPC (Model Predicitive Control) em controle de processos industriais, notadamente nos setores de Óleo, Gás e Petroquímica, é citada por diversos autores tanto em trabalhos sobre MPC quanto em trabalhos acerca de identificação de sistemas. Uma descrição sobre as aplicações do MPC, bem como os principais algoritmos nele empregados, pode ser vista em CAMACHO; BORDONS (2004). Apesar de existir grande quantidade de algoritmos de MPC, todos eles têm como objetivo a minimização de uma função custo da forma:

$$
\begin{gathered}
J_{M P C}=\sum_{t=N_{1}}^{N_{2}} f\left(\left[\boldsymbol{y}_{\boldsymbol{s} \boldsymbol{p}}-\widehat{\boldsymbol{y}}(\boldsymbol{u}(t), t)\right], \boldsymbol{u}(t)\right) \\
\boldsymbol{y}_{\min } \leq \widehat{\boldsymbol{y}}(\boldsymbol{u}(t), t) \leq \boldsymbol{y}_{\max } \\
\boldsymbol{u}_{\min } \leq \boldsymbol{u}(t) \leq \boldsymbol{u}_{\max }
\end{gathered}
$$

em que:

$\left[N_{1}, N_{2}\right] \quad$ Intervalo de predição;

$\boldsymbol{y}_{\boldsymbol{s} \boldsymbol{p}} \quad$ Valor esperado para as variáveis controladas;

$\widehat{\boldsymbol{y}}(\boldsymbol{u}(t), t) \quad$ Valor das variáveis controladas obtidas pelo modelo;

$\boldsymbol{u}(t) \quad$ Valor da variáveis manipuladas;

$f($. $) \quad$ Função objetivo de controlador;

$\boldsymbol{y}_{\min } \quad$ Vetor de valores mínimos das variáveis controladas;

$\boldsymbol{y}_{\max } \quad$ Vetor de valores máximos das variáveis controladas; 
$\boldsymbol{u}_{\min } \quad$ Vetor de valores mínimos das variáveis manipuladas;

$\boldsymbol{u}_{\max } \quad$ Vetor de valores máximos das variáveis manipuladas.

É usual escolher uma função custo quadrática, de maneira que o problema de otimização seja convexo. Deste modo, eventuais problemas com mínimos locais são eliminados. Outra característica dos algoritmos MPC usualmente utilizados na indústria é o fato de que o intervalo de predição normalmente é da forma $\left[1, N_{2}\right]$, sendo necessário definir exclusivamente o horizonte de predição $N_{2}$. Deste modo, a função custo do MPC normalmente assume a forma:

$$
\begin{gathered}
J_{M P C}=\sum_{t=1}^{N_{2}}\left\{\left[\boldsymbol{y}_{\boldsymbol{s} \boldsymbol{p}}-\widehat{\boldsymbol{y}}(\boldsymbol{u}(t), t)\right]^{T} \boldsymbol{Q}\left[\boldsymbol{y}_{\boldsymbol{s} \boldsymbol{p}}-\widehat{\boldsymbol{y}}(\boldsymbol{u}(t), t)\right]+\boldsymbol{u}(t)^{T} \boldsymbol{R} \boldsymbol{u}(t)\right\} \\
\boldsymbol{y}_{\min } \leq \widehat{\boldsymbol{y}}(\boldsymbol{u}(t), t) \leq \boldsymbol{y}_{\max } \\
\boldsymbol{u}_{\min } \leq \boldsymbol{u}(t) \leq \boldsymbol{u}_{\max }
\end{gathered}
$$

em que:

$Q \quad$ Matriz de ponderação das saídas;

$\boldsymbol{R} \quad$ Matriz de ponderação das entradas.

Com base em (2-1) e (2-2), é possível perceber que o controlador MPC depende de um modelo capaz de gerar boas estimativas $\hat{y}(u(t), t)$. Assim, a fim de gerar boas predições, diversos métodos de identificação de sistemas podem ser utilizados em função da forma do modelo esperada pelo algoritmo MPC. Por exemplo, os algoritmos DMC e QDMC utilizam modelos na forma de resposta ao degrau. Os algoritmos da classe GPC empregam modelos na forma de matrizes de transferência (CAMACHO; BORDONS, 2004).

O presente texto concentra atenção em uma classe específica de métodos de identificação, o MRI (MPC Relevant Identification). 


\subsection{Identificação em malha fechada}

A identificação em malha fechada é um tema que foi profundamente explorado em (FORSSELL; LJUNG, 1999). Neste trabalho, é mostrado que um dos grandes problemas gerados quando a identificação ocorre em malha fechada é o fato da fonte de perturbação ser correlacionada com a entrada do sistema. Consequentemente, a hipótese de não correlação entre as colunas da matriz de regressores e a perturbação deixa de ser válida.

Em (FORSSELL; LJUNG, 1999) é informado que a identificação em malha fechada pode ser realizada de três maneiras distintas, considerando o sistema em malha fechada apresentado na Figura 2.1.

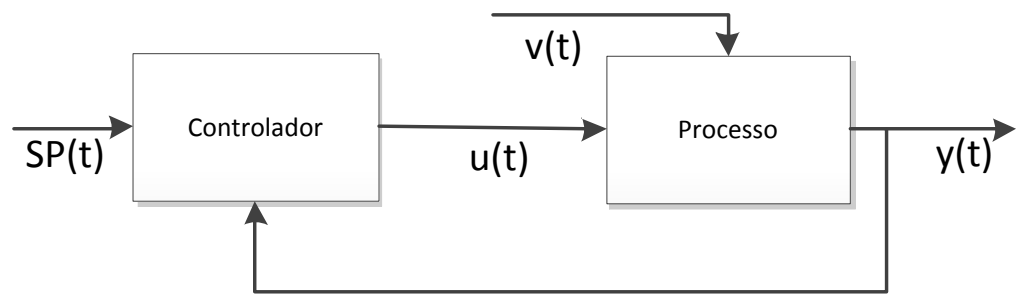

Figura 2.1 - Sistema em malha fechada. (Autor)

As abordagens de identificação de sistemas em malha fechada são:

1. Identificação Direta: Utilizar como entrada $u(t)$ e como saída $y(t)$. Este método consiste em ignorar o fato da malha estar fechada.

2. Identificação Indireta: Utilizar como entrada $S P(t)$ e como saída $y(t)$, utilizando conhecimento da estrutura do controlador para levantar a função de transferência do processo.

3. Identificação conjunta entrada-saída: este método consiste em considerar $u(t)$ e $y(t)$ como saídas do sistema e $S P(t)$ e $v(t)$ como entradas. Realiza-se a identificação do sistema aumentado, utilizando técnicas de identificação em malha aberta. 
Em (AMJAD; AL-DUWAISH, 2003) é apresentado um trabalho onde são comparados diversos métodos para identificar um sistema em malha fechada controlado por um MPC. Os autores afirmam que dentre os métodos de identificação propostos por (FORSSELL; LJUNG, 1999), apenas a identificação direta pode ser utilizada para este controlador. Isso se deve ao fato que o controlador MPC consiste na resolução de um problema de otimização, geralmente com restrições, dificultando assim quaisquer manipulações algébricas necessárias para realizar a identificação indireta ou a identificação conjunta entrada-saída.

\subsection{Identificação de sistemas multivariáveis}

Na presente seção são propostas algumas considerações sobre a identificação de sistemas multivariáveis. Para a obtenção de modelos multivariáveis, é necessário considerar que os modelos se encontrem na forma MFD (Matrix Fraction Description) descrita em detalhes em (KAILATH, 1980). Nesse modelo, os elementos da diagonal principal das matrizes polinomiais representam os denominadores das funções de transferência SISO. Um modelo com a estrutura ARX MIMO sem acoplamento entre as saídas apresenta a seguinte estrutura:

$$
\begin{aligned}
{\left[\begin{array}{ccc}
A_{11}\left(q^{-1}\right) & \ldots & 0 \\
\vdots & \ddots & \vdots \\
0 & \ldots & A_{n n}\left(q^{-1}\right)
\end{array}\right]\left[\begin{array}{c}
y_{1}(t+1 \mid t) \\
\vdots \\
y_{n}(t+1 \mid t)
\end{array}\right] } \\
\quad=\left[\begin{array}{ccc}
B_{11}\left(q^{-1}\right) & \ldots & B_{1 m}\left(q^{-1}\right) \\
\vdots & \ddots & \vdots \\
B_{n 1}\left(q^{-1}\right) & \ldots & B_{n m}\left(q^{-1}\right)
\end{array}\right]\left[\begin{array}{c}
u_{1}(t+1) \\
\vdots \\
u_{m}(t+1)
\end{array}\right]+\left[\begin{array}{c}
e_{1}(t+1) \\
\vdots \\
e_{n}(t+1)
\end{array}\right]
\end{aligned}
$$

Apesar desta estrutura ser restrita apenas aos modelos em que não ocorre o acoplamento entre as saídas, ela é suficiente para representar grande parte dos sistemas observados. 
Essa característica faz com que um modelo MIMO $m X n$ possa ser compreendido como $n$ modelos MISO, $m X 1$. Para os casos em que é possível utilizar regressão linear, os algoritmos para a identificação MISO possuem exatamente a mesma estrutura dos algoritmos usados para a identificação SISO.

Neste trabalho todos os modelos multivariáveis são identificados como múltiplos modelos MISO.

\subsection{Predição $k$ passos à frente}

Conforme apresentado em (LJUNG, 1999), as principais razões para se obter um modelo são:

- Simular o comportamento de um sistema a uma dada excitação;

- Obter estimativas para variáveis não observadas;

- Prever as próximas saídas do sistema a partir do conjunto de entradas e saídas do sistema.

Quando se projeta um controlador MPC, é necessário dispor de um modelo que seja capaz de realizar predições com pequeno erro, independente do desempenho para a realização de simulações ou para a construção de observadores. Desta maneira, na presente seção são apresentados os preditores para o caso SISO. Este raciocínio pode ser generalizado para o caso MISO.

Considere que o processo a ser identificado apresenta a seguinte forma:

$$
y(t)=G(q) u(t)+H(q) e(t)
$$

em que $G(q)$ e $H(q)$ são sistemas lineares invariantes no tempo que representam, respectivamente, o modelo do processo e o modelo de perturbação. Suponha que o inverso do modelo de perturbação $H^{-1}(q)$ exista. Assume-se que $G(q), H(q)$ e $H^{-1}(q)$ sejam estáveis. 
Por serem lineares e invariantes no tempo, estes modelos podem ser expressos por:

$$
\begin{aligned}
& G(q)=\sum_{k=0}^{\infty} g_{k} q^{-k} \\
& H(q)=\sum_{k=0}^{\infty} h_{k} q^{-k}
\end{aligned}
$$

É importante notar que a possibilidade de representar o sistema por meio de respostas impulsivas não implica em que os modelos do processo e da perturbação sejam polinomiais.

Sejam $u(s)$ e $y(s)$ conhecidos para todo $s \leq t-k$. A predição da saída $k$ instantes de tempo no futuro $\hat{y}(t \mid t-k)$ é dada por (LJUNG, 1999):

$$
\hat{y}(t \mid t-k)=W_{k}(q) G(q) u(t)+\left[1-W_{k}(q)\right] y(t)
$$

com:

$$
\begin{gathered}
W_{k}(q)=\bar{H}_{k}(q) H^{-1}(q) \\
\bar{H}_{k}(q)=\sum_{l=0}^{k-1} h_{l} q^{-l} \\
h_{0}=1
\end{gathered}
$$

É interessante notar que o preditor definido pelas equações (2-7), (2-8) e (2-9) é diferente das predições normalmente calculadas pelo MPC. Isso se deve ao fato das aplicações tradicionais de MPC ignorarem o modelo de perturbação. 


\subsection{MPC Relevant Identification (MRI)}

Uma das principais famílias de métodos de identificação de sistemas, os métodos de predição de erro (Prediction Error Methods, PEM), têm por objetivo a minimização do erro de predição um passo à frente (One Step Ahead Prediction Identification). Isto é, o objetivo é minimizar o funcional dado por:

$$
J_{O S A P I}(t+1)=\|\boldsymbol{y}(t+1)-\widehat{\boldsymbol{y}}(t+1 \mid t)\|_{2}^{2},
$$

em que:

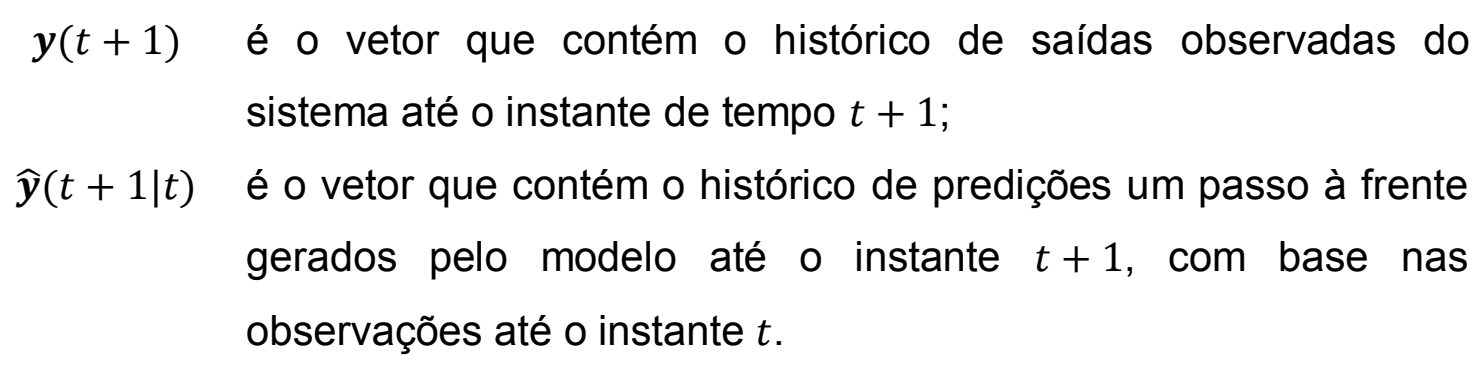

Para realizar o cálculo das predições, usualmente utilizam-se diferentes estruturas de modelos lineares. Ljung (1999) apresenta uma equação geral que engloba um conjunto de 32 estruturas lineares distintas. Esta equação geral é apresentada em (2-12).

$$
A\left(q^{-1}\right) \hat{y}(t+1 \mid t)=\frac{B\left(q^{-1}\right)}{F\left(q^{-1}\right)} u(t)+\frac{C\left(q^{-1}\right)}{D\left(q^{-1}\right)} e(t),
$$

em que:

$q^{-1} \quad$ Operador de atraso unitário;

$A, C, D, F$ São polinômios mônicos que têm como variável o operador de atraso unitário;

$B \quad$ É um polinômio qualquer que têm como variável o operador de atraso unitário;

$e(t) \quad$ Ruído branco gaussiano. 
Das estruturas apresentadas em (2-12), apenas as estruturas ARX (Auto Regressive with eXogenous input) e FIR (Finite Impulse Response) podem ser obtidas por métodos de Regressão Linear.

Apesar de ser possível encontrar 32 estruturas distintas, algumas estruturas recebem nomes específicos por serem comumente encontradas na literatura. Estas estruturas são apresentadas na Tabela 2.1.

Tabela 2.1 - Modelos clássicos lineares.

\begin{tabular}{|c|c|}
\hline Modelo & Restrição \\
\hline FIR & $A\left(q^{-1}\right)=1, C\left(q^{-1}\right)=1, D\left(q^{-1}\right)=1$ e $F\left(q^{-1}\right)=1$ \\
\hline ARX & $C\left(q^{-1}\right)=1, D\left(q^{-1}\right)=1$ e $F\left(q^{-1}\right)=1$ \\
\hline Output Error (OE) & $A\left(q^{-1}\right)=1, C\left(q^{-1}\right)=1$ e $D\left(q^{-1}\right)=1$ \\
\hline ARMAX & $D\left(q^{-1}\right)=1$ e $F\left(q^{-1}\right)=1$ \\
\hline Box-Jenkins (BJ) & $A\left(q^{-1}\right)=1$ \\
\hline
\end{tabular}

O fato de poderem ser resolvidos a partir de um método de regressão linear implica que apenas os modelos FIR e ARX apresentam uma solução analítica, obtida a partir do método dos mínimos quadrados. Para todas as demais estruturas, é necessária a utilização de métodos de otimização não-linear, que não possuem garantia de convergência para o mínimo global.

Uma apresentação detalhada sobre as demais famílias de métodos de identificação de sistemas pode ser encontrada em (LJUNG, 1999) e (AGUIRRE, 2007).

No artigo (SHOOK; MOHTADI; SHAH, 1991) foi apresentada a predição de horizonte amplo (Long Range Prediction Identification), cuja função custo é dada por:

$$
J_{L R P I}\left(t+N_{2}\right)=\sum_{i=1}^{N_{2}}\|\boldsymbol{y}(t+i)-\widehat{\boldsymbol{y}}(t+i \mid t)\|_{2}^{2}
$$

A diferença entre as funções custo (2-11) e (2-13) é o fato de que enquanto a minimização da primeira fornece um modelo ótimo para a predição um passo à 
frente, a segunda fornece um modelo que é ótimo para todos os passos de predição à frente $i=1, \ldots, N_{2}$. Assim, os modelos fornecidos pela minimização de (2-13) supõem apresentar melhor desempenho quando aplicados em controladores MPC (LAURI et al., 2010). Por esta razão, a minimização desta função custo é a base para os algoritmos do tipo MRI. Uma desvantagem da função custo (2-13) em relação à (2-11) é que, independente da estrutura escolhida para o modelo, não é possível garantir a convexidade do funcional. Assim, a minimização desta função custo implicará na resolução de um problema de programação não-linear, que não possui solução analítica e pode assumir mínimos locais.

Em (STOICA; NEHORAI, 1989) foi realizada uma comparação entre modelos de séries temporais sem entradas exógenas, obtidos para a predição um passo à frente (análogos aos métodos PEM) e para múltiplos passos à frente (análogos aos métodos MRI). Apesar desta análise ter utilizado modelos com estrutura ARMA, este trabalho mostrou que para predições múltiplos passos à frente, o desempenho obtido pelos métodos um passo à frente ou múltiplos passos à frente são equivalentes, quando a ordem do modelo é correta ou superdimensionada. Entretanto, nas análises onde a ordem do modelo foi subdimensionada, as identificações para predições múltiplos passos à frente apresentaram melhores resultados.

Apesar do trabalho de (STOICA; NEHORAI, 1989) levantar hipóteses de que não existem ganhos em utilizar algoritmos de identificação do tipo MRI, deve-se lembrar que as plantas de processos químicos em geral consistem em modelos não-lineares, que só seriam perfeitamente representados por um modelo de ordem infinita. Ora, com base nessa premissa, pode-se afirmar que qualquer modelo possui ordem subdimensionada. Assim, existem fortes indícios que o desempenho dos algoritmos MRI seja superior aos métodos PEM para a obtenção de modelos para controladores MPC. Por este motivo, optou-se por restringir a análise exclusivamente entre diferentes algoritmos MRI.

Alguns dos principais métodos de identificação MRI são apresentados a seguir. 


\subsubsection{Método LRPI}

O método LRPI (Long Range Prediction Identification) apresentado em (SHOOK; MOHTADI; SHAH, 1991) é uma estratégia MRI que pode ser classificado como método de pré-filtro. Assim como em todos os métodos MRI, o objetivo é obter um modelo tal que o funcional (2-13) seja minimizado. Seja o modelo do processo SISO dado na forma:

$$
A\left(q^{-1}\right) \hat{y}(t+1 \mid t)=B\left(q^{-1}\right) u(t)+\frac{T\left(q^{-1}\right)}{D\left(q^{-1}\right)} e(t)
$$

em que o modelo de perturbação $T\left(q^{-1}\right) / D\left(q^{-1}\right)$ é fornecido como parâmetro de entrada ao algoritmo. A partir da função de predição $k$ passos à frente (2-7) é possível definir uma função

$$
E_{k}\left(q^{-1}\right)=\frac{W_{k}\left(q^{-1}\right)}{A\left(q^{-1}\right)}
$$

A partir desta função, é possível calcular o filtro $L\left(q^{-1}\right)$, definido como:

$$
L\left(q^{-1}\right)=\frac{L_{1}\left(q^{-1}\right) D\left(q^{-1}\right)}{T\left(q^{-1}\right)}
$$

em que $L_{1}\left(q^{-1}\right)$ é dado pela equação (2-17), que pode ser resolvida através de fatoração espectral.

$$
L_{1}\left(q^{-1}\right) L_{1}(q)=\left(\sum_{j=1}^{N_{2}} E_{j}\left(q^{-1}\right) E_{j}(q)\right)
$$

Em (SHOOK; MOHTADI; SHAH, 1991) é demonstrado que o modelo de processo com a estrutura dada por (2-14) que minimiza (2-13) pode ser obtido utilizando uma identificação ARX se os dados de entrada e saída, $(u(t)$ e $y(t))$, forem substituídos respectivamente por $y_{f}(t)=L\left(q^{-1}\right) y(t)$ e $u_{f}(t)=$ $L\left(q^{-1}\right) u(t)$. 
Uma das desvantagens desse método é que ele exige que o projetista forneça um modelo de perturbação para o sistema. Além disso, a solução obtida é ótima para o modelo de perturbação escolhido, de maneira que não se pode garantir que o modelo seja globalmente ótimo.

\subsubsection{Método MPEM}

Um segundo método MRI, também baseado em pré-filtros, é apresentado em (HUANG; WANG, 1999). Diferente do método LRPI apresentado na subseção 2.5.1, o método MPEM (Multistep Prediction Error Method) é capaz de obter sua própria estimativa do modelo de perturbação. O método MPEM para o caso SISO consiste na resolução das seguintes etapas:

1. Com os dados de entrada e saída $u(t)$ e $y(t)$, execute uma identificação utilizando o método do erro de predição (PEM) para obter um modelo da planta $G\left(q^{-1}\right)$ e um modelo de perturbação $H\left(q^{-1}\right)$.

2. Obtenha as novas entradas e saídas $u_{f}(t)=L\left(q^{-1}\right) u(t)$ e $y_{f}(t)=$ $L\left(q^{-1}\right) y(t)$, onde o filtro $L\left(q^{-1}\right)$ é dado pela equação (2-18). Este filtro pode ser calculado utilizando algum algoritmo de fatoração espectral.

$$
L\left(q^{-1}\right)=\sum_{k=1}^{N_{2}} \bar{H}_{k}\left(q^{-1}\right)
$$

em que $\bar{H}_{k}\left(q^{-1}\right)$ é dado pela equação (2-9).

3. Execute a identificação de um modelo com estrutura Output Error utilizando os dados filtrados $u_{f}(t)$ e $y_{f}(t)$ para determinar o modelo da planta $G\left(q^{-1}\right)$ que minimize a função (2-13) .

Segundo (HUANG; WANG, 1999), pelo fato de ser fundamentado no método de erro de predição, o método MPEM apresenta modelos com desempenho satisfatório mesmo quando existe correlação entre a entrada e a perturbação, (identificação em malha fechada). Os autores afirmam ainda que o método 
LRPI (apresentado na subseção anterior) possui bom desempenho exclusivamente para identificações em malha aberta.

É importante citar que os dois métodos MRI abordados até o momento foram analisados exclusivamente para o caso SISO, podendo ser facilmente generalizados para casos MISO. No entanto, (SHOOK; MOHTADI; SHAH, 1991), afirmam ser possível realizar a extensão do algoritmo para o caso MIMO.

\subsubsection{Identificação multi-modelos}

O método de identificação multi-modelos foi proposto em (ROSSITER; KOUVARITAKIS, 2001). Diferentemente dos métodos apresentados até 0 momento (cujo objetivo é obter um modelo que minimize a função custo (2-13)), este trabalho propõe a obtenção de um modelo distinto para cada passo de predição entre 1 e $N_{2}$. O argumento para a utilização desta técnica reside no fato que o $k$-ésimo modelo é capaz de gerar a predição ótima para $k$ passos à frente, enquanto ao tentar otimizar o somatório dos erros de predição é encontrado um modelo sub-ótimo, que pode introduzir erros de predição. É importante notar que o desenvolvimento desse algoritmo é realizado diretamente para o caso MIMO.

A desvantagem desse método, entretanto, consiste no fato de que os algoritmos MPC utilizados convencionalmente não estão adaptados para a abordagem multi-modelo. Um segundo argumento contra esta abordagem é apresentado em (LAURI et al., 2010), trabalho em que se ressalta o fato de que a variância assintótica dos parâmetros do modelo é função da razão entre o número de parâmetros estimados e o número de amostras. Ora, a estimação de um modelo MIMO para cada passo de predição, implica em um número elevado de parâmetros. Deste modo, os modelos obtidos por esse método exibirão elevada variância. 


\subsubsection{Método MRI de dois passos}

O método MRI de dois passos, proposto por (GOPALUNI; PATWARDHAN; SHAH, 2004), tem por objetivo apresentar um método de identificação em que o modelo da planta minimiza a polarização do erro de identificação, enquanto o modelo de perturbação minimiza a variância o erro. Neste trabalho, ressalta-se a importância do modelo de perturbações para a identificação MRI. Mostra-se que, caso o modelo de perturbação não seja considerado, a identificação MRI apresenta os mesmos resultados que a identificação um passo à frente.

Outra análise apresentada no referido artigo constata que a polarização do erro de um modelo pode ser minimizada quando a estrutura do modelo da planta é do tipo FIR. (GOPALUNI; PATWARDHAN; SHAH, 2004).

Com base nisto o método MRI de dois passos obtém o modelo de perturbação ótimo. $\mathrm{O}$ algoritmo é executado nas seguintes etapas:

1. Fixa-se o modelo de perturbação $H(q)=1$ e identifica-se um modelo da planta com estrutura FIR de alta ordem;

2. Com o modelo da planta determinado, o modelo de perturbação que minimiza o erro de variância do sistema é identificado.

O modelo final obtido pelo método MRI de dois passos consiste em uma variante da estrutura BJ, com o polinômio $F(q)=1$.

\subsubsection{Método EMPEM}

O Método EMPEM (Enhanced MPEM) apresentado em (POTTS; ROMANO; GARCIA, 2012) ${ }^{1}$ consiste em um novo método que combina características do método MPEM (HUANG; WANG, 1999) e do método MRI de dois passos

\footnotetext{
${ }^{1}$ POTTS, A.S.; ROMANO, R.A.; GARCIA, C. Enhancement in performance and stability of MRI methods. In: $16^{\text {th }}$ IFAC Symposium on Systems Identification, 2012, Bruxelas. Artigo Submetido.
} 
(GOPALUNI; PATWARDHAN; SHAH, 2004), incluindo algumas melhorias nos algoritmos originais.

Na subseção 2.5.2, foi possível observar que o método MPEM necessita de um modelo de pertrubação para realizar a filtragem dos dados de entrada e saída da planta. Por outro lado, na subseção 2.5.4, foi possível verificar que o método de dois passos obtém um modelo de perturbação com a variância do erro mínima. A partir desses dois fatos, o algoritmo EMPEM calcula um modelo de perturbação com variância de erro mínima, e utiliza esse modelo para realizar a filtragem dos dados de entrada e saída e assim obter um modelo da planta. Com base nessas premissas, o algoritmo EMPEM é composto pelos seguintes passos:

1. A partitr dos dados de entrada e saída da planta, fixa-se o modelo de perturbação $H_{0}(q)=1$ e é realizada a dentificação de um modelo FIR de alta ordem;

2. A partir do modelo de processo obtido, calcula-se o modelo de perturbação $H_{o p t}(q)$, que minimize o erro de variância;

3. Com o modelo de perturbação $H_{o p t}(q)$, calcula-se as entradas e saídas filtradas $u_{f}(t)=L\left(q^{-1}\right) u(t)$ e $y_{f}(t)=L\left(q^{-1}\right) y(t)$, onde o filtro $L\left(q^{-1}\right)$ é dado por (2-18);

4. O modelo da planta $G(q)$ é obtido identificando-se um modelo com estrutura "output error";

Um ponto relevante desse algoritmo, apresentado em (POTTS; ROMANO; GARCIA, 2012) ${ }^{1}$, é que é adicionada uma restrição de estabilidade para o modelo de perturbação, garantindo assim que os pólos do modelo de perturbação estejam no interior do circulo de raio unitário.

\subsubsection{Método PLS-PH}

Outra estratégia de abordagem para a identificação MRI consiste em reduzir o fenômeno de multicolinearidade existente nos regressores utilizados para a 
estimação do modelo. Tal fenômeno é analisado em detalhe na seção 2.6 e o algoritmo PLS-PH, a base dessa dissertação, é apresentado no capítulo 3

Ao longo deste trabalho, todas as avaliações do método PLS-PH utilizarão o método MPEM como referência, pois segundo (HUANG; WANG, 1999) apresenta bom desempenho para a identificação de sistemas em malha fechada. A razão para nenhum dos demais métodos ter sido escolhida é:

- O método LRPI, por ser o primeiro algoritmo MRI, é demasiadamente simples, não sendo esperados assim resultados satisfatórios quando comparados aos outros métodos MRI;

- O objetivo final da identificação é a obtenção do modelo do processo para controladores MPC. Assim, os métodos multi-modelos e MRI dois passos não produzem modelos satisfatórios para os fins desejados (para a aplicação em MPC, é importante que o modelo seja único, e o modelo do processo do MRI de dois passos possui estrutura FIR, que é demasiadamente simples);

- O método EMPEM é um método consideravelmente recente, de maneira que por foi pouco avaliado. Preferiu-se não utilizá-lo como método de referência para avaliar o algoritmo PLS-PH.

\subsection{Regressão Multivariável, Multicolinearidade e PLS}

Segundo (HAYTER, 2007), um modelo de regressão linear

$$
y_{i}=\beta_{0}+\beta_{1} x_{i}+\epsilon_{i}
$$

ajusta por uma reta os pares de dados $\left(y_{1}, x_{1}\right), \ldots,\left(y_{n}, x_{n}\right)$. Os termos de erro $\epsilon_{1}, \ldots, \epsilon_{\mathrm{n}}$ são observações independentes de uma distribuição de probabilidades normal $\mathrm{N}\left(0, \sigma^{2}\right)$. Neste problema, devem ser estimados os parâmetros $\beta_{0}, \beta_{1}$ e a variância do erro $\sigma^{2}$. 
Uma generalização desse problema, também apresentada em (HAYTER, 2007), consiste nos problemas de Regressão Linear Múltipla ou Regressão Linear Multivariável. Neste caso, ao invés de dispor de pares, o conjunto de dados é formado por $n$-uplas $\left(y_{1}, x_{11}, \ldots, x_{1 k}\right), \ldots,\left(y_{n}, x_{n 1}, \ldots, x_{n k}\right)$ que podem ser ajustadas pelo hiperplano:

$$
y_{i}=\beta_{0}+\beta_{1} x_{i 1}+\ldots+\beta_{k} x_{i k}+\epsilon_{i}
$$

Tanto para o caso SISO quanto para o caso multivariável, as funções geradas são afins. Tal fenômeno ocorre quando os dados utilizados não são centrados, isto é, possuem média diferente de 0 . Assim, ao utilizar variáveis centradas, tem-se $\beta_{0}=0$. Seja:

$$
\boldsymbol{\theta}=\left(\beta_{1}, \ldots, \beta_{k}\right)^{T}
$$

o vetor de parâmetros. Assim, este problema para variáveis centradas pode ser descrito matricialmente na forma:

$$
\boldsymbol{y}=\boldsymbol{X \theta}+\epsilon
$$

em que

$$
\begin{aligned}
& \boldsymbol{y}=\left(y_{1}, \ldots, y_{n}\right)^{T} \quad \text { é o vetor de saídas; } \\
& \boldsymbol{\epsilon}=\left(\epsilon_{1}, \ldots, \epsilon_{n}\right)^{T} \quad \text { é o vetor de perturbações; } \\
& \boldsymbol{X}=\left[\begin{array}{ccc}
x_{11} & \ldots & x_{1 k} \\
\vdots & \ddots & \vdots \\
x_{n 1} & \ldots & x_{n k}
\end{array}\right] \quad \text { é a matriz de regressores. }
\end{aligned}
$$

Assumindo a hipótese que $\epsilon$ seja de média nula, pode-se escrever:

$$
\boldsymbol{X}^{T} \boldsymbol{y}=\boldsymbol{X}^{T} \boldsymbol{X} \boldsymbol{\theta}
$$

Caso, as colunas da matriz $\boldsymbol{X}$ sejam linearmente independentes, o vetor de parâmetros pode ser escrito: 


$$
\boldsymbol{\theta}=\left(\boldsymbol{X}^{T} \boldsymbol{X}\right)^{-1} \boldsymbol{X}^{T} \boldsymbol{y}
$$

A equação (2-24), que é a solução do problema dos mínimos quadrados, é utilizada para a determinação da solução analítica do problema de Identificação de sistemas quando são escolhidas estruturas FIR ou ARX. Para a obtenção de tais soluções analíticas, é necessário que o vetor de saídas, a matriz de regressores e o vetor de parâmetros estejam na forma:

$$
\begin{gathered}
{\left[\begin{array}{c}
y(N) \\
\vdots \\
y(\tau)
\end{array}\right]=\left[\begin{array}{cccccc}
y(N-1) & \cdots & y\left(N-n_{A}\right) & u\left(N-n_{k}\right) & \cdots & u\left(N-n_{k}-n_{B}+1\right) \\
\vdots & \ddots & \vdots & \vdots & \ddots & \vdots \\
y(\tau-1) & \cdots & y\left(\tau-n_{A}\right) & u\left(\tau-n_{k}\right) & \cdots & u\left(\tau-n_{k}-n_{B}+1\right)
\end{array}\right] \cdot\left[\begin{array}{c}
-a_{1} \\
\vdots \\
-n_{n_{A}} \\
b_{1} \\
\vdots \\
b_{n_{B}}
\end{array}\right]} \\
\tau=\max \left(n_{A}, n_{B}+n_{k}\right) \\
A\left(q^{-1}\right)=1+a_{1} \cdot q^{-1}+\cdots+a_{n_{A}} q^{-n_{A}} \\
B\left(q^{-1}\right)=b_{1} \cdot q^{-n_{k}}+\cdots+b_{n_{B}} q^{-n_{k}-n_{B}+1}
\end{gathered}
$$

A utilização de métodos de regressão linear multivariados introduz um fenômeno conhecido como multicolinearidade, já mencionado. Segundo (HAYTER, 2007), esse fenômeno ocorre quando existe elevada correlação entre um conjunto de vetores regressores. Um exemplo didático (e trivial) desta situação pode ser observado na Figura 2.2, que retrata a tentativa de se estabelecer um modelo linear para a temperatura TT-001 (no instante atual) a partir das medições (também no instante atual) das vazões FT-001, FT-002 e FT-003. 


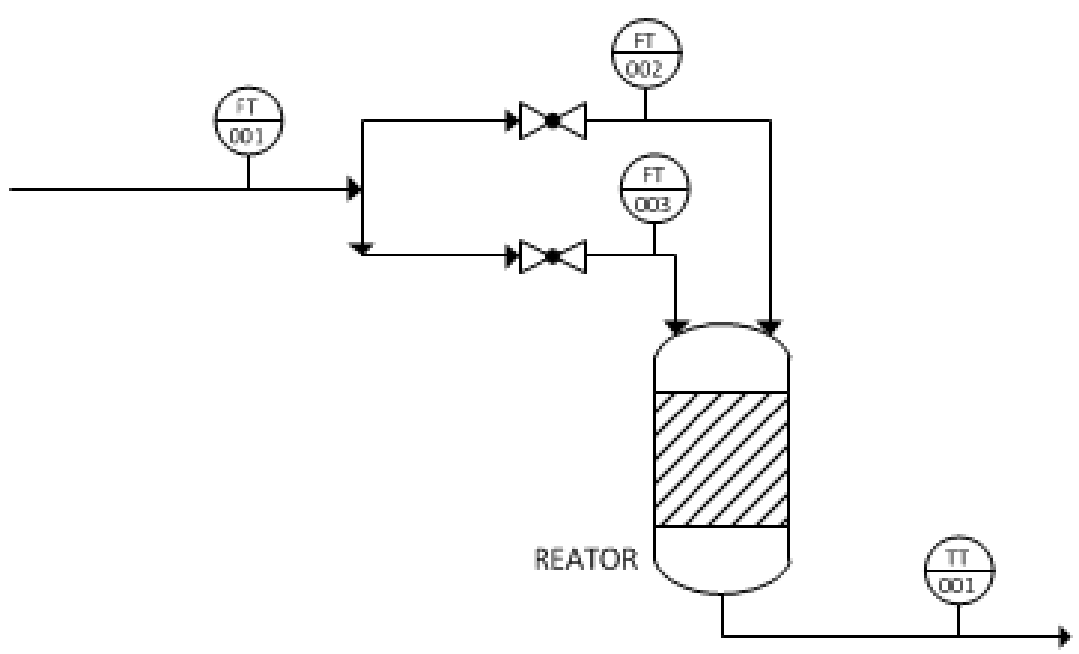

Figura 2.2 - Exemplo de multicolinearidade. (Autor)

Neste exemplo, a matriz de regressores é dada por:

$$
\boldsymbol{X}=\left[\begin{array}{ccc}
F_{1}(t+N) & F_{2}(t+N) & F_{3}(t+N) \\
\vdots & \vdots & \vdots \\
F_{1}(t) & F_{2}(t) & F_{3}(t)
\end{array}\right]
$$

em que $F_{i}(t)$ é a leitura do transmissor FT-00i, e $N+1$ é o número de amostras utilizadas para realizar a regressão.

Pela estrutura do problema, pode-se notar que as colunas dessa matriz são fortemente correlacionadas, pois, se não houvessem erros de medição

$$
F_{1}(t)=F_{2}(t)+F_{3}(t)
$$

Ora, pode-se notar a partir de (2-30) que as colunas da matriz de regressores são (praticamente) linearmente dependentes, criando problemas numéricos para o cálculo do vetor de parâmetros.

Este exemplo apresenta uma correlação evidente entre as variáveis. Em uma situação prática, esta escolha de variáveis dificilmente seria realizada. Entretanto, em situações usuais, tais correlações não são evidentes, ou não podem ser evitadas. 
Diversas maneiras de medir a multicolinearidade de um conjunto de regressores são apresentadas em (STEWART, 1987), entre elas a decomposição em valores singulares. Caso o fenômeno de multicolinearidade esteja presente na matriz de regressores, é possível identificar que pelo menos um dos valores singulares de tal matriz será próximo de zero. Entretanto, não é aconselhável utilizar os valores singulares diretamente, dado que as variáveis não estão necessariamente escaladas. Deste modo, para corrigir tal situação, utiliza-se o número de condicionamento da matriz, que é dado por:

$$
K(\boldsymbol{X})=\frac{\sigma_{\min }(\boldsymbol{X})}{\sigma_{\max }(\boldsymbol{X})}
$$

onde $\sigma_{\min }(\boldsymbol{X})$ e $\sigma_{\max }(\boldsymbol{X})$ são, respectivamente, os valores singulares mínimos e máximos da matriz de regressores.

Outros índices para identificação de multicolinearidade que serão utilizados nesse trabalho são os valores singulares normalizados. Para uma matriz com $n_{X}$ colunas, estes índices são calculados por:

$$
K_{i}(\boldsymbol{X})=\frac{\sigma_{i}(\boldsymbol{X})}{\sigma_{\max }(\boldsymbol{X})}, 1 \leq i \leq n_{X}
$$

Apesar de (STEWART, 1987) demonstrar que existem índices melhores para identificar a multicolinearidade em uma matriz, o número de condicionamento e os valores singulares normalizados podem ser utilizados, principalmente 0 segundo, como indicações da existência de multicolinearidade.

A multicolinearidade se apresenta como um grande problema para a determinação dos vetores de parâmetros do modelo por meio do método dos mínimos quadrados. Assim, nesse caso, é necessário utilizar um método de regressão mais robusto. KIERS e SMILDE (2007) apresentam grande quantidade de métodos estatísticos que lidam com dados em que existe a multicolinearidade. Dentre estes métodos, encontra-se o método dos mínimos quadrados parciais (Partial Least Squares, PLS), que é analisado a seguir. 
A base do método PLS consiste em realizar uma transformação nas variáveis, de modo a escolher exclusivamente aquelas que possuam informação significativa. Assim, ao invés de utilizar a matriz de regressores e o vetor de saídas nas formas em que são fornecidos, é realizada uma transformação afim tal que a nova matriz de regressores apresente as colunas ordenadas segundo a quantidade de inovação que elas possuem. As colunas colineares não possuem quantidade significativa de informação relevante. Deste modo, a não utilização das colunas colineares não implica em uma perda significativa de informação. O algoritmo PLS gera a redução máxima da covariância de $\boldsymbol{X}^{T} \boldsymbol{Y}$ (HÖSKULDSON, 1988), sendo possível, portanto, obter um pequeno número de coeficientes capazes de fornecer informação suficiente sobre o sistema. Uma descrição acerca do desenvolvimento do algoritmo pode ser encontrada em (MARTENS, 2001).

Desta maneira, o algoritmo PLS busca reescrever a matriz de regressão e o vetor de saída como (LAURI et al., 2010):

$$
\begin{aligned}
& \boldsymbol{X}=\boldsymbol{T} \boldsymbol{P}^{T}+\boldsymbol{E}_{\boldsymbol{X}} \\
& \boldsymbol{Y}=\boldsymbol{U} \boldsymbol{L}^{T}+\boldsymbol{E}_{\boldsymbol{Y}}
\end{aligned}
$$

em que:

$\begin{array}{cl}\boldsymbol{T} & \text { Matriz de scores de } X \\ \boldsymbol{P} & \text { Matriz de loadings de } X \\ \boldsymbol{E}_{\boldsymbol{X}} & \text { Matriz de resíduos de } X \\ \boldsymbol{U} & \text { Matriz de scores de } Y \\ \boldsymbol{L} & \text { Matriz de loadings de } Y \\ \boldsymbol{E}_{Y} & \text { Matriz de resíduos de } Y\end{array}$

As matrizes de score podem ser interpretadas como a representação dos regressores em outra base, contendo, portanto, os dados analisados. As matrizes de loadings, podem ser interpretadas como as matrizes responsáveis pela mudança de base dos dados. É importante ter em mente que essa 
interpretação é uma mera aproximação, pois os dois espaços podem possuir dimensões diferentes. Assim, a matriz de score $\boldsymbol{T}$ é uma aproximação da matriz $\boldsymbol{X}$, assim como a matriz $\boldsymbol{U}$ é uma aproximação da matriz $\boldsymbol{Y}$. Para o caso específico de $\boldsymbol{T}$, esta matriz possui $n_{p c} \leq n_{X}$ colunas, em que $n_{p c}$ é o número de componentes principais, definido externamente. O número de componentes principais é o número de regressores que é utilizado para obter o vetor de parâmetros.

Com base nessas matrizes de score, é possível realizar a regressão linear como:

$$
U=T b
$$

onde $\boldsymbol{b}$ é o vetor de parâmetros obtido a partir das matrizes de score.

Um algoritmo para o cálculo da regressão PLS é o algoritmo NIPALS, descrito em (HÖSKULDSON, 1988). Este algoritmo apresenta uma particularidade, pois além das matrizes apresentadas em (2-33) e (2-34), é realizado o cálculo da matriz $\boldsymbol{S}$, que substitui a matriz $\boldsymbol{P}$ para que a matriz $\boldsymbol{T}$ possua colunas ortogonais. Assim, o vetor de parâmetros é obtido como (LAURI et al., 2010):

$$
\boldsymbol{\theta}=\boldsymbol{S}\left(\boldsymbol{P}^{T} \boldsymbol{S}\right)^{-1} \boldsymbol{b} \boldsymbol{L}^{T}
$$

O algoritmo NIPALS, da maneira que é descrito em (HÖSKULDSON, 1988), é apresentado a seguir:

1. Início: $\boldsymbol{u}$ recebe a primeira coluna de $\boldsymbol{Y}$

2. $\boldsymbol{w}=\boldsymbol{X}^{T} \boldsymbol{u} /\left(\boldsymbol{u}^{T} \boldsymbol{u}\right)$

3. $\boldsymbol{w}=\boldsymbol{w} /\|\boldsymbol{w}\|$

4. $t=X w$

5. $c=\boldsymbol{Y}^{T} \boldsymbol{t} /\left(\boldsymbol{t}^{T} \boldsymbol{t}\right)$

6. $c=c /\|c\|$

7. $u=Y c /\left(c^{T} c\right)$

8. Caso $\left\|\mathbf{u}_{\mathbf{i}}-\mathbf{u}_{\mathbf{i}-\mathbf{1}}\right\| \leq$ tolerância, vá para 9 . Caso contrário, vá para 2 .

9. $\boldsymbol{p}=\boldsymbol{X}^{T} \boldsymbol{t} /\left(\boldsymbol{t}^{T} \boldsymbol{t}\right)$

10. $\boldsymbol{l}=\boldsymbol{Y}^{T} \boldsymbol{u} /\left(\boldsymbol{u}^{T} \boldsymbol{u}\right)$

11. $\boldsymbol{b}=\boldsymbol{u}^{T} \boldsymbol{t} /\left(\boldsymbol{t}^{T} \boldsymbol{t}\right)$ 
12. $X=X-\boldsymbol{t p}^{T}$

13. $Y=Y-b t c^{T}$

14. Caso ( $\|X\|=0$, ou outro critério de parada), pare. Caso contrário, vá para 1.

$\mathrm{Na}$ implementação do algoritmo realizada no presente texto, é adicionado um critério de parada, tal que o número máximo de iterações deste algoritmo seja igual ao número de componentes principais definido.

É possível notar que esse algoritmo é composto por duas tarefas principais:

1. Obter o projetor ortogonal das colunas da matriz $\boldsymbol{X}$, no subespaço gerado pelas colunas da matriz $Y$, e encontrar o projetor inverso, isto é, aquele que dada uma projeção em $\boldsymbol{Y}$, restauraria o vetor original em $\boldsymbol{X}$. No algoritmo, esta tarefa é realizada entre as linhas 2 e 7.

2. Ao encontrar estes projetores, é possível encontrar a duas direções correspondentes em nos espaços gerados pelas colunas de $\boldsymbol{Y}$ e $\boldsymbol{X}$. Uma vez que essas direções tenham sido encontradas, vão sendo extraídas das matrizes originais de maneira reduzir a informação na matriz de regressores. No algoritmo esta tarefa é realizada entre as linhas 9 e 13.

Uma aplicação direta do algoritmo PLS para a identificação de sistemas com elevado número de variáveis pode ser encontrada em (SONG et al., 2002). 


\section{ALGORITMO PLS-PH}

O objetivo deste capítulo é apresentar o algoritmo PLS-PH desenvolvido em (LAURI et al., 2010). A organização do presente capítulo é a seguinte: na seção 3.1 o algoritmo PLS-PH é descrito. Uma justificativa para a utilização deste algoritmo na identificação de sistemas em malha fechada é apresentada na seção 3.2 .

\subsection{Análise do Algoritmo}

O algoritmo PLS-PH foi proposto em (LAURI et al., 2010) como um método MRI para a identificação de sistemas com variáveis correlacionadas. Este algoritmo consiste basicamente em uma busca linear executada de maneira a encontrar o valor mínimo da função custo $J_{L R P I}(2-13)$. A base desse algoritmo consiste em reduzir a colinearidade contida na matriz de regressores, a partir do uso do algoritmo PLS.

Para iniciar o algoritmo, é necessário fornecer o número de componentes principais $n_{p c}$ e um valor inicial para o vetor de parâmetros $\boldsymbol{\theta}_{\mathbf{0}}$. (LAURI et al., 2010) propõem a seguinte estratégia: para a obtenção destes dois valores, é utilizada a regressão PLS (seção 2.6) variando o valor $n_{p c}$ entre 1 e o número total de colunas da matriz de regressores. Durante a execução do algoritmo, a última linha da matriz de regressores é descartada, para ser utilizada na validação. Esta abordagem é conhecida como LOOCV (Leave One Out Cross Validation, validação cruzada por descarte de um elemento), sendo apresentada em (TROPSHA; GRAMATICA; GOMBAR, 2003). Embora seja possível executar a validação com uma quantidade maior de informação, optou-se por analisar o algoritmo tal qual apresentado por (LAURI et al., 2010). Para cada um dos valores de $n_{p c}$ calcula-se o quadrado do erro de predição 
um passo a frente para o ponto de validação. $O n_{p c}$ escolhido é o último que causa uma variação significativa no erro de predição. A partir do valor escolhido de $n_{p c}$, executa-se o algoritmo PLS para obter uma estimativa inicial de $\boldsymbol{\theta}_{0}$.

Outra estratégia para a obtenção de $n_{p c}$, adotada no presente trabalho, consiste em analisar os valores singulares normalizados da matriz de regressores e definir $n_{p c}$ como o maior número de componentes em que não seja observada uma queda significativa nos valores singulares normalizados, identificados a partir de inspeção visual, do gráfico dos componentes principais. Alternativamente, poderia ser analisada a razão entre valores singulares consecutivos e escolhida a máxima variação (e assim automatizar o processo de escolha). Com a definição do número de componentes, a estimativa inicial de $\theta_{0}$ é realizada de maneira análoga ao procedimento descrito no parágrafo anterior. Apesar de ser um procedimento que necessite da intervenção humana, permite que o fenômeno de multicolinearidade possa ser evitado.

A idéia básica por detrás do algoritmo PLS-PH consiste em escrever a função custo $J_{L R P I}$ e minimizá-la por meio de busca direta. O procedimento é descrito em detalhes a seguir.

A partir do valor de $\boldsymbol{\theta}_{0}$, o vetor de parâmetros é obtido a partir da equação:

$$
\boldsymbol{\theta}_{k+1}=\boldsymbol{\theta}_{k}+\alpha_{k} \boldsymbol{p}_{k}
$$

em que $\boldsymbol{p}_{k}$ é a direção de atualização dos parâmetros e $\alpha_{k}$ é a intensidade da atualização. Estes parâmetros são obtidos iterativamente por meio do procedimento descrito a seguir.

Inicialmente, a matriz de regressores expandidos é obtida por meio das equações:

$$
\boldsymbol{X}=\left[\begin{array}{c}
\boldsymbol{X}_{1} \\
\vdots \\
\boldsymbol{X}_{N}
\end{array}\right]
$$




$$
\boldsymbol{X}_{j}=\left[\begin{array}{c}
\boldsymbol{x}_{j}(n+j \mid n) \\
\vdots \\
\boldsymbol{x}_{j}\left(\max \left(n_{a}, n_{b}\right)+j \mid \max \left(n_{a}, n_{b}\right)\right)
\end{array}\right]
$$

$$
\begin{gathered}
\boldsymbol{x}_{j}(k+j \mid k)=\left[u\left(k+j-n_{k}-2\right) \ldots u\left(k+j-1-n_{b}-n_{k}\right)\right. \\
\left.\bar{y}(k+j-2 \mid k) \ldots \bar{y}\left(k+j-1-n_{a} \mid k\right)\right]
\end{gathered}
$$

A principal diferença da regressão linear tradicional e do algoritmo PLS-PH encontra-se na equação (3-5). Segundo esta equação, em um dado instante $k$, caso seja necessária uma medida de um instante $l>k$, esta deve ser substituída pela sua predição. Porém, como o vetor de parâmetros $\boldsymbol{\theta}$ é desconhecido, é introduzida uma incógnita na matriz de regressores, fazendo com que o problema de otimização torne-se não-linear.

Na sequência, o algoritmo PLS é executado utilizando a matriz expandida de regressores (3-2). Tal execução gera um vetor de parâmetros, $\boldsymbol{\theta}_{P L S}$, a partir do qual é possível obter a direção de atualização por meio da equação:

$$
\boldsymbol{p}_{\boldsymbol{k}}=\boldsymbol{\theta}_{P L S}-\boldsymbol{\theta}_{k}
$$

Finalmente, $\alpha_{k}$ é escolhido de modo a minimizar a função custo $J_{L R P I}$. Entretanto, tal função custo não é necessariamente convexa. Deste modo, não é possível garantir que o valor atingido será o mínimo global. Por este motivo, a função custo é aproximada por uma função quadrática, conforme (3-7).

$$
J_{L R P I}\left(\boldsymbol{\theta}_{k}+\alpha_{k} \cdot \boldsymbol{p}_{k}\right) \approx \delta_{1, k}+\delta_{2, k} \cdot \alpha_{k}+\delta_{3, k} \cdot \alpha_{k}^{2}
$$

A cada iteração do algoritmo, para determinar um novo conjunto de parâmetros $\delta_{1, k}, \delta_{2, k}, \delta_{3, k}$, fixa-se $\alpha_{k}$ respectivamente em 0, 0,5 e 1, (LAURI, et. al, 2010) e em seguida, resolve-se o correspondente sistema linear para a obtenção dos valores. Uma vez determinada a aproximação quadrática, o valor de $\alpha_{k}$ é determinado e consequentemente o novo valor de $\theta_{k}$. 
Este procedimento iterativo é executado enquanto a expressão (3-8) for válida:

$$
\left\|J_{L R P I}\left(\boldsymbol{\theta}_{k+1}\right)-J_{L R P I}\left(\boldsymbol{\theta}_{k}\right)\right\| \geq 10^{-4}
$$

(LAURI; et al.; 2010) utiliza uma tolerância igual a $10^{-3}$, porém no presente trabalho, optou-se por utilizar o parâmetro $10^{-4}$, que caracteriza-se por uma convergência mais lenta, porém uma maior precisão do algoritmo.

No presente trabalho, foi incorporada uma condição de parada adicional. Como o algoritmo consiste em uma busca linear pelo mínimo, a cada iteração a função custo é reduzida. Desta maneira, foi incluída a condição $J_{L R P I}\left(\boldsymbol{\theta}_{k}\right)>$ $J_{L R P I}\left(\boldsymbol{\theta}_{k+1}\right)$, que define o parâmetro procurado $\boldsymbol{\theta}_{k}$. Esta nova condição foi incluída por terem sido constatados tempos de convergência elevados.

Uma vez determinado o vetor de parâmetros $\boldsymbol{\theta}$, este pode ser rearranjado, de modo a obter um modelo com a estrutura ARX.

A razão da escolha de ARX para a estrutura identificada (embora seja considerada uma estrutura pobre por possuir um modelo de perturbação muito simples) decorre do fato que o algoritmo PLS-PH é fundamentado em uma variante do método dos mínimos quadrados, o algoritmo PLS. Em outras palavras, supõe-se que a estrutura seja dada pela equação (2-22),em que não é previsto um modelo independente de perturbação.

LAURI et al. (2010) propõem uma variante, em que, caso o modelo de perturbação seja conhecido, torna-se possível realizar uma filtragem dos dados de entrada e saída antes de realizar a identificação, de maneira análoga à proposta por (SHOOK; MOHTADI; SHAH, 1991), conforme subseção 2.5.1. Assim, pode-se notar que o objetivo do algoritmo PLS-PH consiste na obtenção de um modelo de processo que seja ótimo para a predição todos os $i=$ $1, \ldots, N_{2}$ passos à frente, para um dado modelo de perturbação.

Assim, em virtude da indisponibilidade de um modelo de perturbação a priori, é escolhida a estrutura ARX. Não existem, entretanto, restrições para que o método seja integrado a métodos para a identificação de modelos de perturbação. 


\subsection{Regressão linear em malha fechada}

Nesta seção, é apresentada uma breve discussão, desenvolvida ao longo desse mestrado, que pode servir de base para justificar a utilização do algoritmo PLS-PH para a identificação de sistemas em malha fechada.

Um questionamento pode ser levantado: a utilização do algoritmo PLS-PH é realmente capaz de promover alguma melhoria em relação a identificação de sistemas em malha fechada? Durante a apresentação do método dos mínimos quadrados, na equação (2-24) foi assumida a hipótese que a correlação entre o erro e a matriz de regressores não existia. Portanto, para a identificação de sistemas em malha fechada, tal formulação não pode ser utilizada, visto que essa premissa foi violada. Assim, para resolver esse problema, a equação (2-22) é reescrita como:

$$
\boldsymbol{y}=\boldsymbol{X}_{\epsilon} \boldsymbol{\theta}_{\epsilon}
$$

em que

$$
\boldsymbol{X}_{\epsilon}=\left[\begin{array}{cccc}
x_{11} & \ldots & x_{1 k} & \epsilon_{1} \\
\vdots & \ddots & \vdots & \vdots \\
x_{n 1} & \ldots & x_{n k} & \epsilon_{n}
\end{array}\right]
$$

e

$$
\boldsymbol{\theta}_{\epsilon}=\left(\beta_{1}, \ldots, \beta_{k}, 1\right)^{T}
$$

A partir de (3-9), supondo que as colunas de $X_{\epsilon}$ sejam linearmente independentes, é possível obter uma expressão "explícita" para o vetor de parâmetros:

$$
\boldsymbol{\theta}_{\epsilon}=\left(\boldsymbol{X}_{\epsilon}^{T} \boldsymbol{X}_{\epsilon}\right)^{-1} \boldsymbol{X}_{\epsilon}^{T} \boldsymbol{y}
$$

A expressão (3-12) foi referida como explícita (entre aspas), pois os valores do vetor de perturbações são desconhecidos a priori. Assim, a matriz de regressores possui um conjunto de incógnitas. Entretanto, pelo fato dos dados terem sido coletados em um experimento em malha fechada, sabe-se que este vetor de incógnitas é correlacionado com as demais entradas. Por esta razão a 
informação contida neste vetor também estará presente nas demais colunas da matriz de regressores. Isso implica que tal matriz será numericamente malcondicionada. Uma das maneiras para resolver esse problema consiste em utilizar métodos de regressão linear que sejam robustos a matrizes regressoras mal condicionadas como, por exemplo, os mínimos quadrados parciais, substituindo $X_{\epsilon}$ por $X$ e substituindo $\theta_{\epsilon}$ por $\theta$.

É importante notar que o raciocínio apresentado nessa seção não consiste em uma prova matemática formal que garanta o funcionamento do algoritmo PLSPH para identificação de sistemas em malha fechada. São apresentados indícios de que este método poderia apresentar bons resultados. A comprovação do bom desempenho deste algoritmo para identificação em malha fechada, por meio de simulações, é objeto do próximo capítulo. 


\section{IDENTIFICAÇÃO DE SISTEMAS SISO}

Após a apresentação do algoritmo PLS-PH no capítulo anterior, a avaliação de seu desempenho é realizada neste capítulo para a identificação de sistemas SISO. Para tal, foi escolhido um modelo fenomenológico não-linear de um trocador de calor casco-tubo, apresentado em detalhes em (GARCIA, 2005).

Uma síntese dos resultados apresentados nesse capítulo pode ser encontrada em (QUACHIO; GARCIA, 2011b).

\subsection{Descrição do processo}

Considere o P\&ID do trocador de calor apresentado na Figura 4.1.

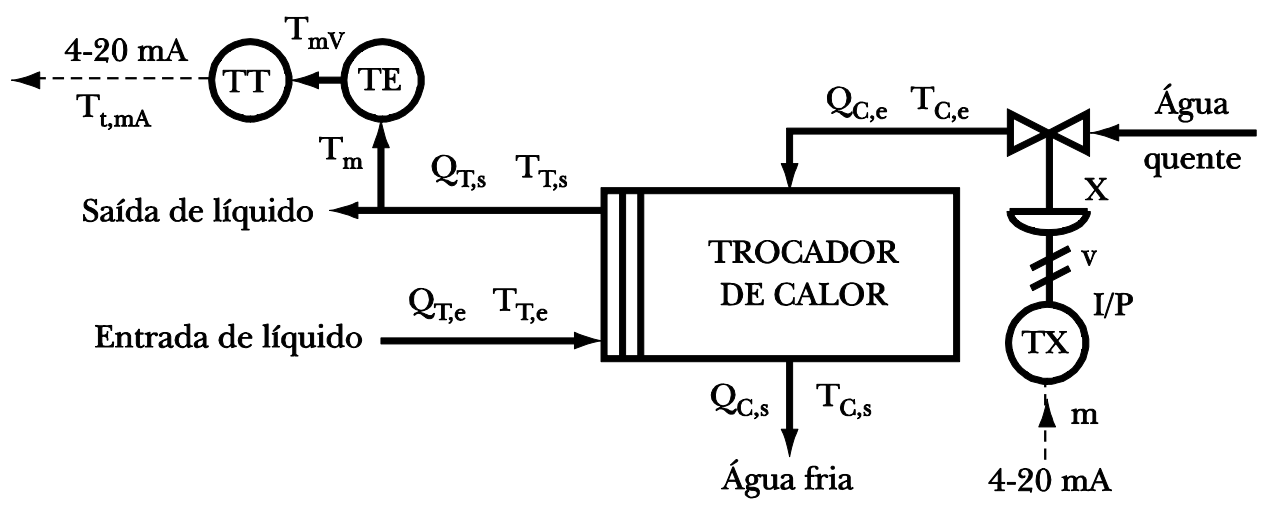

Figura 4.1 - P\&ID do trocador de calor casco-tubo - Fonte: (GARCIA, 2005).

Este trocador é composto por um casco com características tais que pode ser considerado um sistema adiabático. O casco está interligado a uma linha que fornece água a temperatura constante de $90^{\circ} \mathrm{C}$, utilizada para aquecer o fluido que circula nos tubos. Este trocador é composto por um feixe de 20 tubos de cobre de 1,20m, por onde circula uma vazão de água constante de $6.10^{-4} \mathrm{~m}^{3} / \mathrm{h}$ em contra-corrente. A temperatura de água na entrada dos tubos é ambiente, 
sendo modelada como um ruído branco com média igual a $20^{\circ} \mathrm{C}$ e desvio padrão igual a $0,2^{\circ} \mathrm{C}$. Uma nova amostra dessa perturbação é sorteada a cada passo de integração.

Para realizar o monitoramento e posterior controle da temperatura de saída da água nos tubos, dispõe-se de um termopar, em conjunto com um transmissor de temperatura nesta linha, à distância de $15 \mathrm{~m}$ do trocador. Esta distância introduz um atraso de transporte no sistema, referente ao tempo necessário para que o fluido se desloque da saída do trocador até o elemento sensor. $O$ comportamento do transmissor é modelado como um sistema de primeira ordem.

O atuador desse sistema, utilizado para poder controlar a temperatura da água na saída dos tubos, consiste em uma válvula globo com característica igualporcentagem instalada na linha de alimentação de água do casco do trocador. Para modular a abertura desta válvula é utilizado um conversor $\mathrm{I} / \mathrm{P}$, modelado com uma dinâmica de de primeira ordem.

Neste sistema, o transmissor de temperatura e o conversor I/P se comunicam utilizando sinais 4-20 mACC. A malha de controle é fechada utilizando um controlador PI analógico que foi sintonizado utilizando o método das oscilações contínuas de Ziegler-Nichols.

Para a realização dos experimentos é injetado no valor de referência um sinal PRBS, oscilando a temperatura desejada entre $39,2^{\circ} \mathrm{C}$ e $40,8^{\circ} \mathrm{C}$. A vazão de água fria e a temperatura de água quente foram consideradas constantes. Como os dados são coletados com o sistema operando em malha fechada, optou-se por realizar uma identificação direta, onde o sinal de entrada é associado ao sinal de controle enviado para o transmissor I/P e o sinal de saída é dado pela leitura do transmissor de temperatura. 


\subsection{Identificação utilizando o algoritmo PLS-PH}

Utilizando o modelo do trocador apresentado na seção anterior, é realizada a identificação do sistema utilizando o algoritmo PLS-PH conforme descrito na seção 3.1. Em todos os ensaios descritos nessa seção, foram utilizadas amostras com 2000 pontos de entrada e saída para a identificação e amostras distintas, também com 2000 pontos, para a validação. Todos os conjuntos de dados foram coletados com um período de amostragem de 1s, por ser um valor aproximadamente igual a $5 \%$ da constante de tempo mais lenta do sistema. Um exemplo de conjunto de dados do set point, saída do controlador $(m)$ e variável controlada $\left(T_{t, m a}\right)$, é apresentado na Figura 4.2.
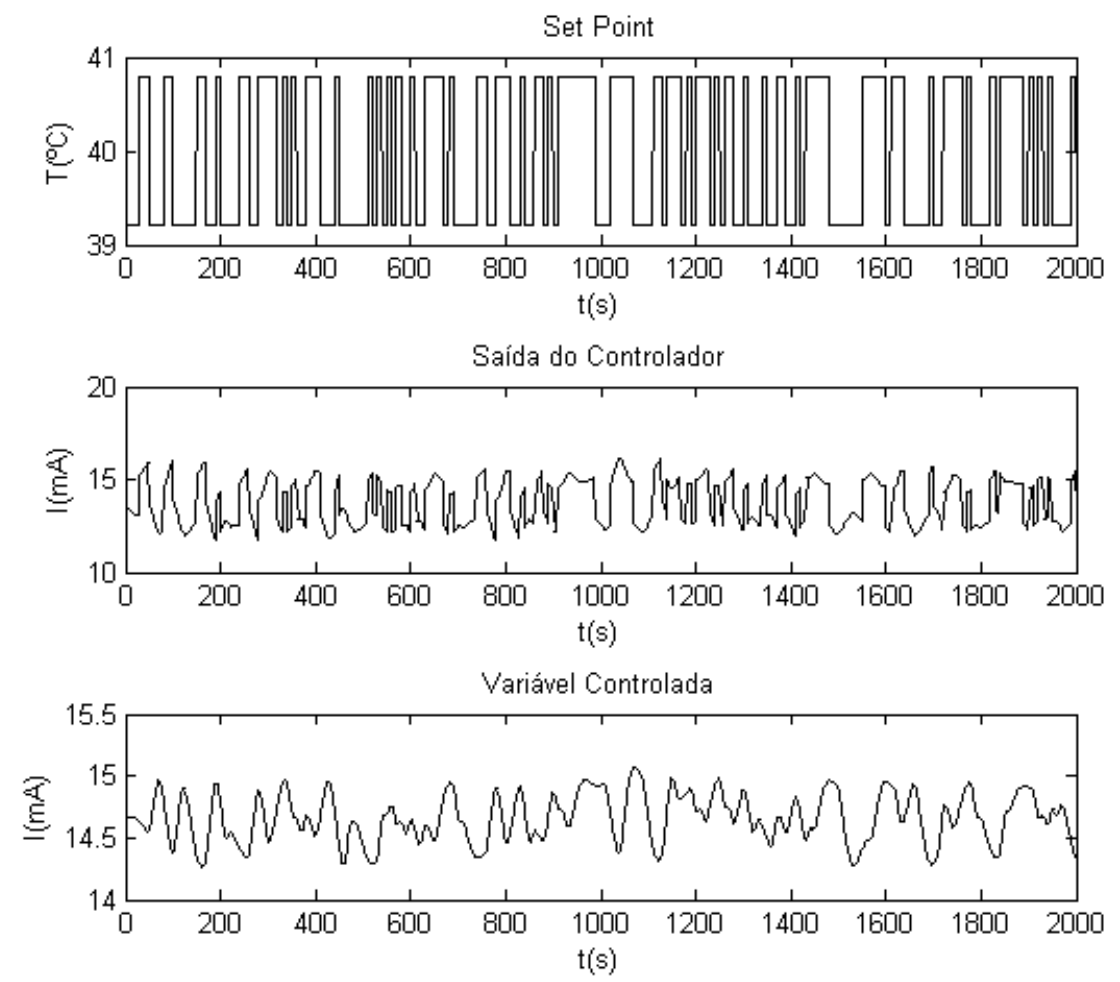

Figura 4.2- Conjunto de dados. (Autor)

Foram realizados os testes descritos a seguir. 


\subsubsection{Estimação de tempo morto}

Para realizar a estimação do tempo morto, foi utilizada a rotina delayest do Matlab. Essa rotina estima o valor de tempo morto capaz de melhor identificar o processo utilizando um modelo com estrutura ARX (LJUNG, 2011). Essa rotina foi escolhida pelo fato de métodos de validação usualmente utilizados para estimativa de tempo morto, como cálculo de correlação cruzada entre os sinais de entrada e saída, não apresentarem bons resultados para dados coletados em malha fechada. O resultado obtido pela rotina delayest foi um atraso de 17s. De acordo com o modelo do trocador, o tempo morto do sistema é de 15s. Em virtude dessa diferença, será realizada a análise da influência do tempo morto na identificação deste sistema.

\subsubsection{Identificação do fenômeno de multicolinearidade}

Ao longo dos capítulos 2 e 3, foi dito que a identificação de sistemas em malha fechada poderia propiciar a ocorrência do fenômeno de multicolinearidade, sendo, portanto, indicada a utilização do algoritmo PLS-PH. A verificação da presença ou não da colinearidade é o objetivo da presente análise.

Para realizar tal análise, em um primeiro momento, foi simulado um conjunto de dados similar ao observado na Figura 4.2. Em seguida, foi realizada uma simulação do sistema em malha aberta utilizando como dados de entrada a saída do controlador coletada no experimento em malha fechada. No experimento em malha aberta, atentou-se para que as perturbações aleatórias possuíssem sementes distintas daquelas utilizadas no experimento em malha fechada e que a variância da perturbação nos dois ensaios fosse a mesma de maneira a garantir que a relação sinal ruído dos dois experimentos fosse similar.

Pelo fato dos dados terem sido coletados em malha fechada, o sinal de perturbação utilizado no ensaio se encontra presente nos dados de entrada da planta. Por esta razão, a fim de se evitar que a correlação entre perturbação e 
entrada continue existindo, no ensaio em malha aberta, é realizada a alteração da semente geradora da sequência aleatória utilizada para o distúrbio, descorrelacionando assim os dois sinais.

Com base nos conjuntos de dados entrada-saída coletados nos dois experimentos, foram construídas as matrizes de regressores para ambos os conjuntos, de maneira que o modelo identificado por tal matriz fosse de grau 3. Os valores singulares normalizados das matrizes de regressores, e os respectivos números de condicionamento, são apresentados na Figura 4.3.

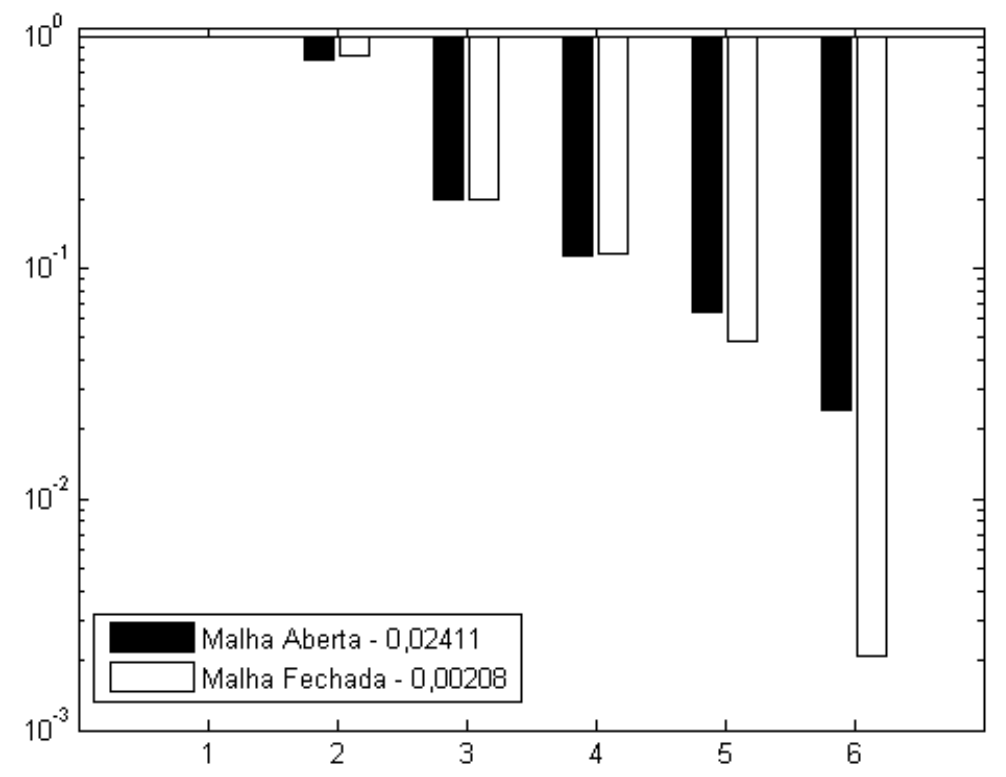

Figura 4.3 - Valores singulares normalizados das matrizes de regressores para dados coletados em malha aberta e em malha fechada. (Autor)

É possível observar que o sexto (e, consequentemente, menor) valor singular normalizado para o experimento realizado em malha fechada é inferior ao observado para o experimento em malha aberta. Esta diferença pode ser explicada pela presença do fenômeno de multicolinearidade para o sistema operando em malha fechada, justificando assim a utilização do algoritmo PLSPH para a identificação de sistemas em malha fechada. É importante notar os valores singulares normalizados 2, 3 e 4 em malha aberta são ligeiramente menores que os valores encontrados para a malha fechada. Essa diferença decorre do fato da perturbação introduzida na simulação ser diferente, gerando 
assim, conjuntos de dados distintos. Deve-se ressaltar, entretanto, que essa diferença é muito inferior a diferença observada para o sexto valor singular, não sendo contrária a constatação do fenômeno de multicolinearidade em malha fechada.

A fim de verificar que o resultado apresentado acima não foi uma mera coincidência numérica, foi realizada a inversão das sementes utilizadas entre os experimentos. A semente utilizada para gerar a perturbação do experimento em malha aberta foi utilizada para a perturbação no experimento em malha fechada. Por outro lado a semente que havia gerado a perturbação do experimento em malha fechada foi utilizada para gerar o distúrbio em malha aberta. Com esses novos sinais de perturbação, o experimento foi repetido e o resultado é apresentado na Figura 4.4.

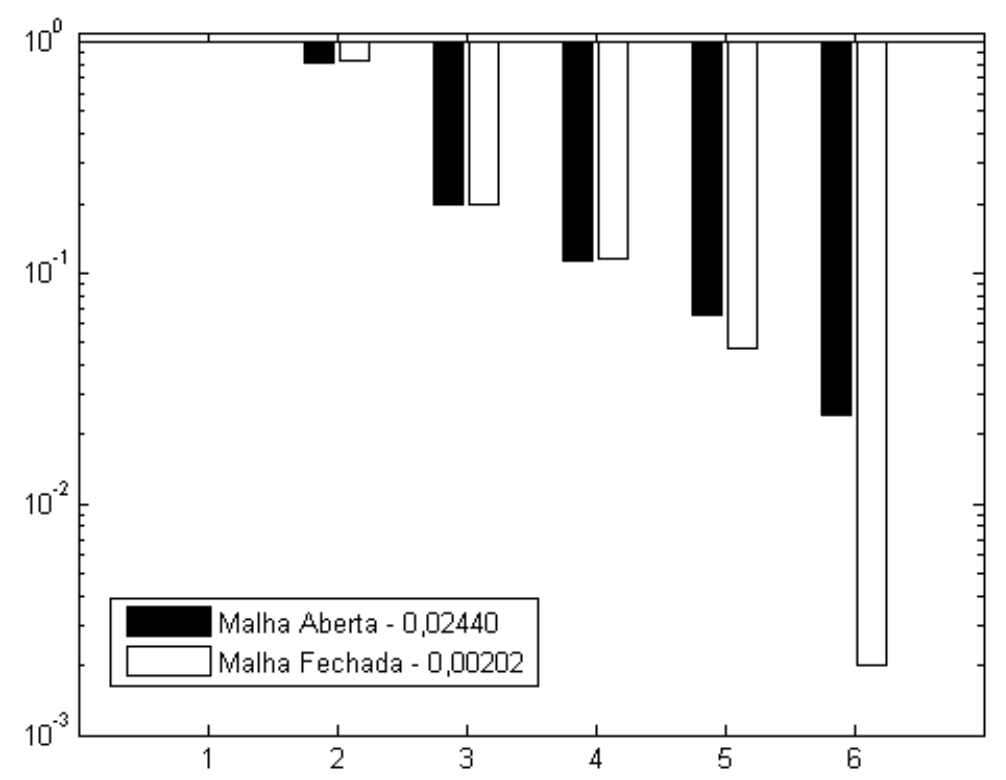

Figura 4.4 - Valores singulares normalizados das matrizes de regressores para dados coletados em malha aberta e em malha fechada. (Autor)

É possível observar que resultados similares foram encontrados, sendo possível verificar uma maior evidência do fenômeno de multicolinearidade para identificação em malha fechada. 


\subsubsection{Comparação entre PLS-PH e MPEM}

A presente análise consiste em uma comparação entre os modelos obtidos utilizando o algoritmo PLS-PH e os modelos obtidos utilizando o método MPEM para identificação direta em malha fechada com diferentes horizontes de predição. Para tal, foram geradas duas séries de dados similares às apresentadas na Figura 4.2. A primeira série foi utilizada para realizar a identificação do sistema, enquanto a segunda série foi utilizada na validação cruzada.

Além do modelo obtido pelo algoritmo PLS-PH, foi realizada a comparação com o modelo obtido pelo método MPEM, que possui estrutura Box-Jenkins. Os graus dos polinômios definidos para cada modelo são apresentados na Tabela 4.1 .

Tabela 4.1 - Graus dos polinômios utilizados para a identificação.

\begin{tabular}{|c|c|c|c|c|c|}
\hline Algoritmo/Estrutura & $A(q)$ & $B(q)$ & $C(q)$ & $D(q)$ & $F(q)$ \\
\hline PLS-PH & 3 & 3 & - & - & - \\
\hline MPEM & - & 3 & 3 & 3 & 3 \\
\hline
\end{tabular}

Para a seleção da ordem, considerou-se o trocador de calor, o transmissor de temperatura e o atuador da válvula como sistemas primeira ordem, totalizando assim terceira ordem para a planta. Além disso, a fim evitar a explosão combinatória de parâmetros que seria gerada ao variar o grau de todos os polinômios, optou-se por fixar o mesmo grau para todos.. Ao considerar que a discretização da planta contínua seja realizada pela transformação bilinear, tem-se que a ordem do polinômio do numerador é igual a ordem do polinômio do denominador, o que justifica, ao menos para o modelo de processo, a escolha.

Para essas identificações, foram utilizados os valores de tempo morto iguais a 15 e a 17 segundos, conforme observado na subseção 4.2.1 e o número de componentes principais igual a 5, conforme pode ser extraído da Figura 4.3. 
Com os parâmetros dos modelos definidos, para cada horizonte de predição, variando entre 2 e 40, foram realizadas identificações utilizando o algoritmo PLS-PH e o algoritmo MPEM.

Para avaliar cada modelo, utilizou-se a série de dados de validação para realizar a validação cruzada com dados centrados e escalados, gerando diversas sequências de predição. Foram realizadas as seguintes análises:

- Cálculo do critério fit para a predição $k$-passos à frente, que é dado por (LJUNG,1999):

$$
f i t=100 \cdot\left(1-\frac{\|y-\hat{y}\|_{2}}{\|y-\operatorname{mean}(y)\|_{2}}\right)
$$

- Cálculo do valor da função-custo $J_{L R P I}$, dada pela equação (2-13)

Os resultados destas análises são apresentados nas figuras 4.4 a 4.7

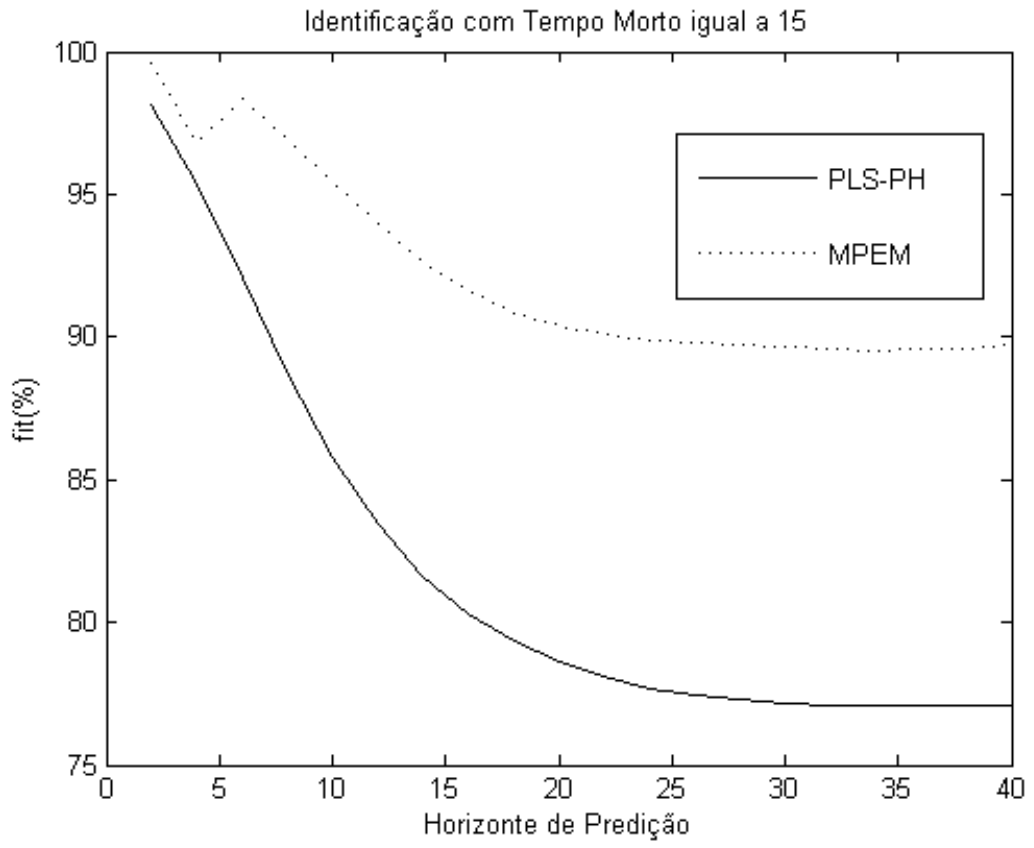

Figura 4.5 - Critério fit para diferentes modelos com tempo morto igual a 15 segundos. (Autor) 


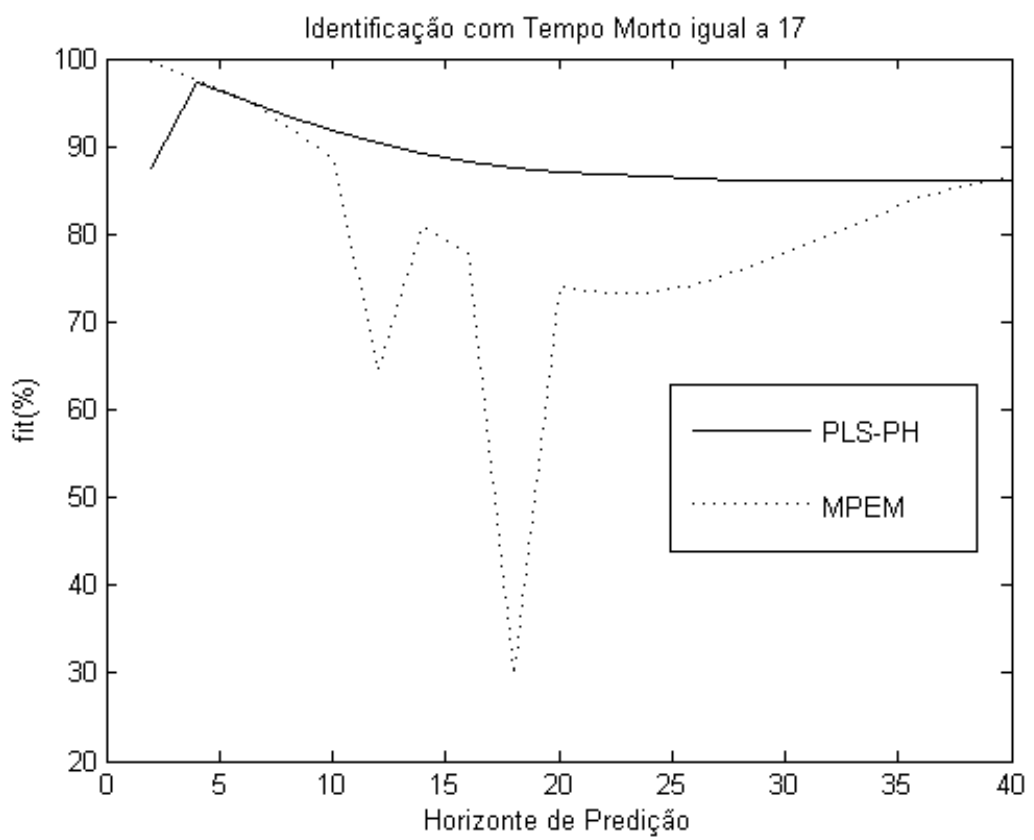

Figura 4.6 - Critério fit para diferentes modelos com tempo morto igual a 17 segundos. (Autor)

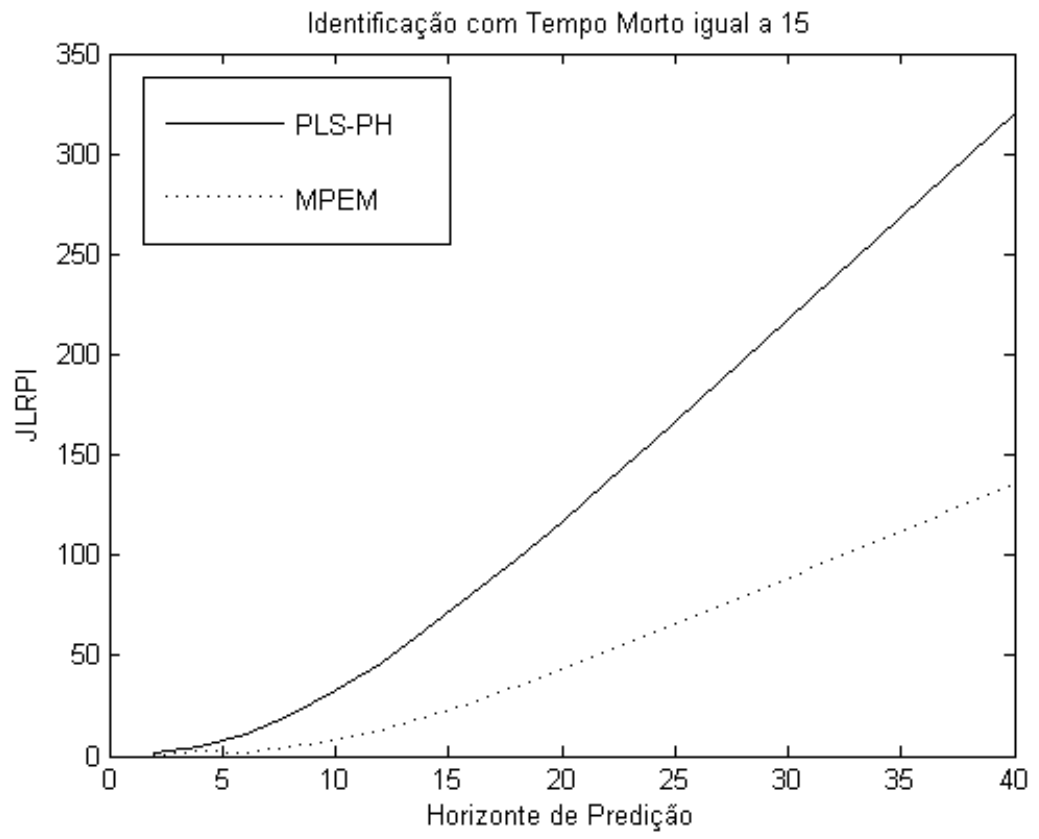

Figura 4.7 - Parâmetro $J_{L R P I}$ para diferentes modelos com tempo morto igual a 15 segundos. (Autor) 


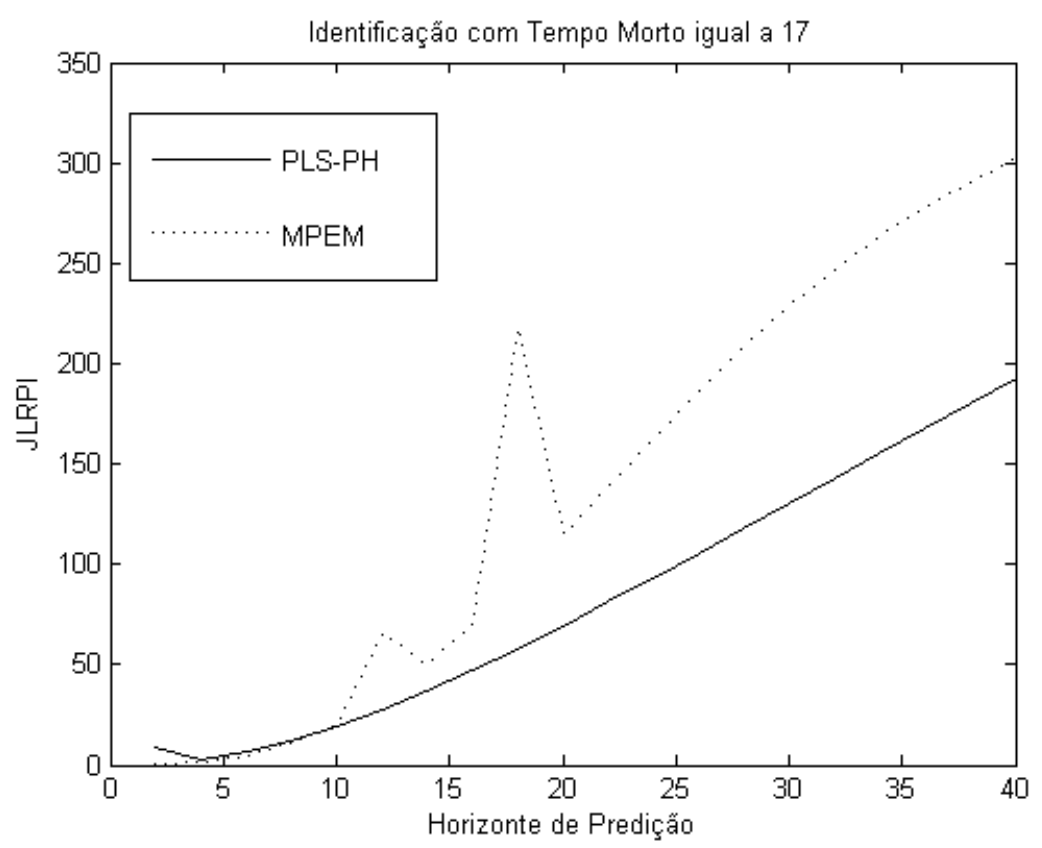

Figura 4.8 - Parâmetro JLRPI para diferentes modelos com tempo morto igual a 17 segundos. (Autor)

Analisando os resultados destes experimentos, é possível verificar, em relação as métricas determinadas pelos parâmetros fit e $J_{L R P I}$, que:

- Para horizontes de predição menores, o algoritmo PLS-PH apresenta um pior desempenho que o algoritmo MPEM. Uma possível explicação para isto é o fato do modelo PLS-PH possuir uma estrutura ARX, e portanto, um modelo de perturbação mais simples, enquanto o modelo obtido pelo MPEM possui o modelo de perturbação de uma estrutura Box-Jenkins.

- Com o aumento do horizonte de predição, é possível observar que o modelo MPEM, para a estimativa de tempo morto igual a 17 segundos, apresenta desempenho variável, enquanto os modelos identificados pelo algoritmo PLS-PH, apresentam um desempenho similar para diferentes horizontes de predição.

- Para o tempo morto igual a 15 segundos, os modelos identificados pelo algoritmo PLS-PH apresentaram desempenho inferior aos modelos gerados pelo algoritmo MPEM. 
- Analisando a figura 4.5, é possível verificar um aumento do critério fit entre os horizontes de predição 2 e 4 . Uma possível explicação é o fato do algoritmo PLS-PH ser baseado em um método de busca direta para a minimização de uma função não-convexa. Nessa situação, o algoritmo irá retornar o mínimo local da função custo, em relação ao ponto inicial escolhido, independente desse ser o mínimo global. Assim, tal fenômeno pode ter ocorrido em função do algoritmo ter encontrado um mínimo local que não seja global.

\subsubsection{Efeito do Erro de Estimação de Tempo Morto}

Na subseção 4.2.3, foi possível verificar que, com uma estimativa de tempo morto diferente do valor real, os modelos gerados pelo PLS-PH apresentaram parâmetros fit superiores àqueles verificados para os modelos identificados utilizando o algoritmo MPEM. Com base nessa constatação, decidiu-se verificar o impacto do erro de estimação do tempo morto em relação aos parâmetros fit.

Para realizar tal avaliação, utilizando as séries de dados empregadas nos experimentos da subseção 4.2.3, decidiu-se identificar modelos de $3^{\mathrm{a}}$ ordem para horizonte de predição igual a 30 , utilizando os algoritmos PLS-PH e MPEM. Para o algoritmo PLS-PH, o número de componentes principais escolhido foi igual a 5. Para todos esses modelos foi realizada a validação cruzada e calculado o critério fit. $O$ resultado dessa análise pode ser observado na Figura 4.9. 


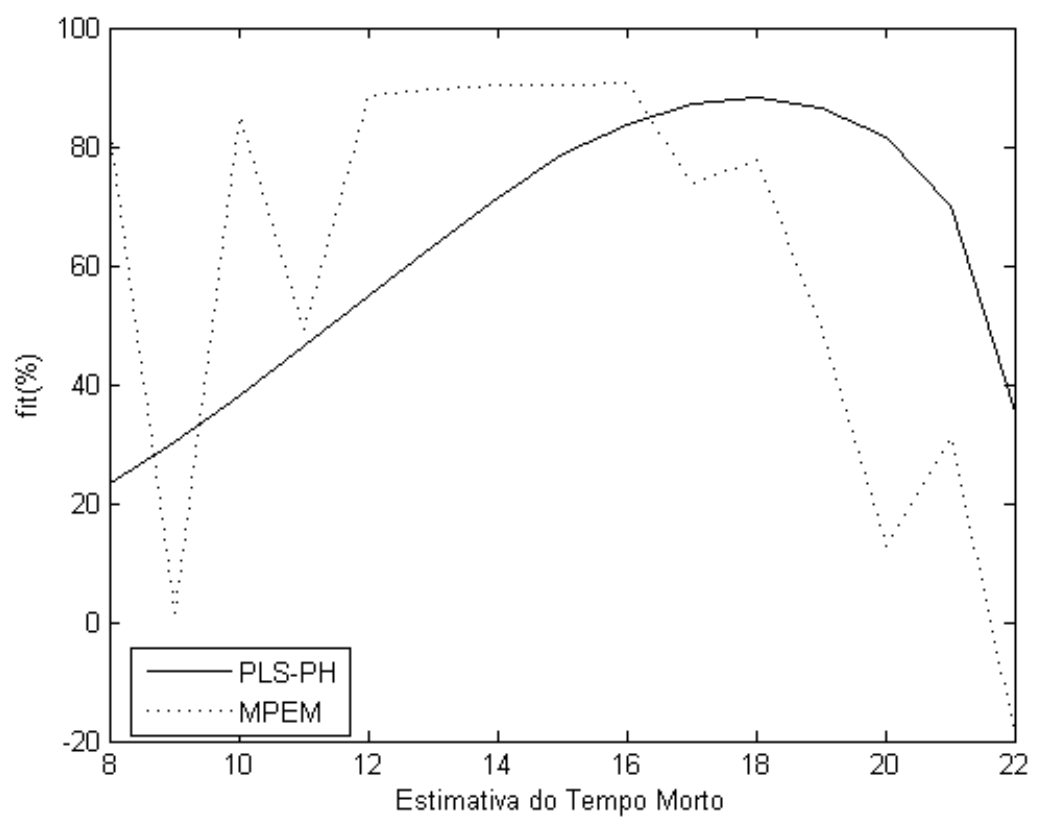

Figura 4.9 - Critério fit dos modelos identificados em função de diferentes estimativas de tempo morto. (Autor)

É possível verificar que os modelos MPEM são mais suscetíveis a erros na estimação do tempo morto que o algoritmo PLS-PH, apresentando uma elevada variabilidade em função de diferentes estimativas de tempo morto. Os modelos identificados pelo algoritmo PLS-PH, por sua vez, apresentam critério fit elevado para uma faixa de valores de tempo morto em torno de 17.

A partir dessa análise é possível verificar que os modelos identificados pelo algoritmo PLS-PH apresentaram maior robustez a erros na estimativa de tempo morto que os gerados pelo algoritmo MPEM.

\subsubsection{Análise de precisão da identificação}

A última análise realizada com base na planta do trocador de calor foi a identificação de modelos para diferentes conjuntos de dados entrada-saída da planta, com o objetivo de obter a média e a variância dos parâmetros, utilizando o método de Monte Carlo. 
Para este ensaio foram realizadas 80 simulações com o trocador de calor operando em malha fechada. Para cada ensaio, foi considerada uma nova semente para a perturbação e uma nova semente para o PRBS. Em sequência, foram identificados 80 modelos utilizando os algoritmos PLS-PH e MPEM. Os modelos identificados são de $3^{\mathrm{a}}$ ordem com tempo morto iguais a 15 s e $21 \mathrm{~s}$, horizonte de predição igual a 30 e o número de componentes principais igual a 5. A média e o desvio padrão para os parâmetros calculados são apresentados na Tabela 4.2. Foram escolhidos os valores 15 e 21 como estimativas e tempo morto pelo fato de 15 ser o valor real encontrado na planta e 21 ser o maior valor de tempo morto para qual o modelo identificado pelo algoritmo PLS-PH produz resultados satisfatórios, de acordo com a figura 4.8.

Tabela 4.2 - Média e desvio padrão do modelo PLS-PH.

\begin{tabular}{|c|c|c|c|c|c|c|c|c|}
\hline Método & T. Morto & & a1 (f1) & $10^{-1} \cdot \mathrm{a} 2(\mathrm{f} 2)$ & $10^{-1} . \mathrm{a} 3(\mathrm{f} 3)$ & $10^{-3} \cdot b 1$ & $10^{-3} \cdot \mathrm{b2}$ & $10^{-3} \cdot \mathrm{b} 3$ \\
\hline \multirow{6}{*}{ PLS-PH } & \multirow{3}{*}{21} & $\boldsymbol{\mu}$ & $-1,21$ & $-3,53$ & 5,79 & 23,7 & 1,62 & $-43,4$ \\
\hline & & $\sigma$ & 0,0074 & 0,015 & 0,073 & 0,83 & 0,21 & 0,61 \\
\hline & & $|\sigma / \mu|(\%)$ & 1 & 0 & 1 & 3 & 13 & 14 \\
\hline & \multirow{3}{*}{15} & $\mu$ & $-1,24$ & $-3,50$ & 6,01 & $-1,58$ & 2,71 & 18,2 \\
\hline & & $\sigma$ & 0,0024 & 0,011 & 0,019 & 0,38 & 0,13 & 0,69 \\
\hline & & $|\sigma / \mu|(\%)$ & 0 & 0 & 0 & 24 & 5 & 4 \\
\hline \multirow{6}{*}{ MPEM } & \multirow{3}{*}{21} & $\mu$ & $-1,54$ & 5,56 & 1,07 & 2,26 & 3,45 & 1,74 \\
\hline & & $\sigma$ & 0,0092 & 12,5 & 6,45 & 1,26 & 1,78 & 0,89 \\
\hline & & $|\sigma / \mu|(\%)$ & 60 & 225 & 602 & 56 & 51 & 51 \\
\hline & \multirow{3}{*}{15} & $\mu$ & $-0,81$ & 4,05 & $-5,65$ & 0,75 & 1,86 & 1,09 \\
\hline & & $\sigma$ & 1,48 & 14,8 & 4,07 & 1,17 & 2,29 & 1,24 \\
\hline & & $|\sigma / \mu|(\%)$ & 184 & 365 & 72 & 157 & 123 & 114 \\
\hline
\end{tabular}

O primeiro ponto que pode ser observado a partir da análise dos resultados é que os valores médios dos parâmetros são consideravelmente diferentes entre si, logo, é possível afirmar que cada algoritmo identificou modelos diferentes. Um segundo ponto a ser notado é que tanto o desvio padrão quanto o desvio padrão normalizado dos parâmetros encontrado pelo algoritmo PLS-PH foi inferior aqueles obtidos pelo método MPEM. 
A partir dessa análise é possível afirmar que o algoritmo PLS-PH apresentar uma menor variabilidade dos parâmetros estimados em relação ao algoritmo MPEM.

\subsection{Conclusão}

É possível constatar, portanto, por meio deste conjunto de ensaios para um sistema linear SISO (para o qual foram identificados modelos lineares com dados coletados em malha fechada) que o algoritmo PLS-PH foi capaz de:

- Identificar modelos que apresentaram um bom desempenho para a validação cruzada, apresentando um critério fit superior a $70 \%$ para 0 horizonte de predição que foi identificado.

- Os modelos identificados pelo algoritmo PLS-PH apresentaram considerável robustez a erros na estimativa do tempo morto.

- Estimar parâmetros com elevada precisão, apresentando para a grande maioria dos casos medida $|\sigma / \mu|$ inferior a $15 \%$.

É possível, portanto, afirmar que, para este ensaio, o algoritmo PLS-PH apresentou um desempenho satisfatório. 


\section{IDENTIFICAÇÃO DE SISTEMAS MIMO}

No capítulo 4, foram apresentados resultados satisfatórios para a identificação de modelos SISO. Entretanto, em aplicações industriais, o algoritmo MPC é usualmente utilizado para realizar o controle de sistemas com múltiplas entradas e múltiplas saídas. Por esta razão, no presente capítulo é apresentada a aplicação do algoritmo PLS-PH para realizar a identificação de um sistema MIMO e seu desempenho é avaliado aplicado a um controlador MPC.

\subsection{Coluna de Destilação Binária de Wood and Berry}

O modelo utilizado no presente capítulo para realizar identificações foi proposto em (WOOD; BERRY, 1973). Este modelo representa uma coluna de destilação binária, no qual é injetada uma carga com porcentagem mássica de 46,5\% de metanol e se tem por objetivo extrair, no topo, metanol com $96 \%$ de pureza. Nesse sistema, as variáveis controladas são as composições dos produtos de topo (deseja-se que a concentração de metanol esteja o mais próximo possível da concentração especificada) e de fundo (deseja-se que a concentração de metanol no produto de fundo seja a menor possível para que não haja desperdício de produto). As variáveis manipuladas são a vazão de refluxo do produto de topo e a vazão de vapor para o refervedor da coluna. A vazão de alimentação é utilizada como variável de perturbação. Um P\&ID da planta pode ser observado na Figura 5.1. 


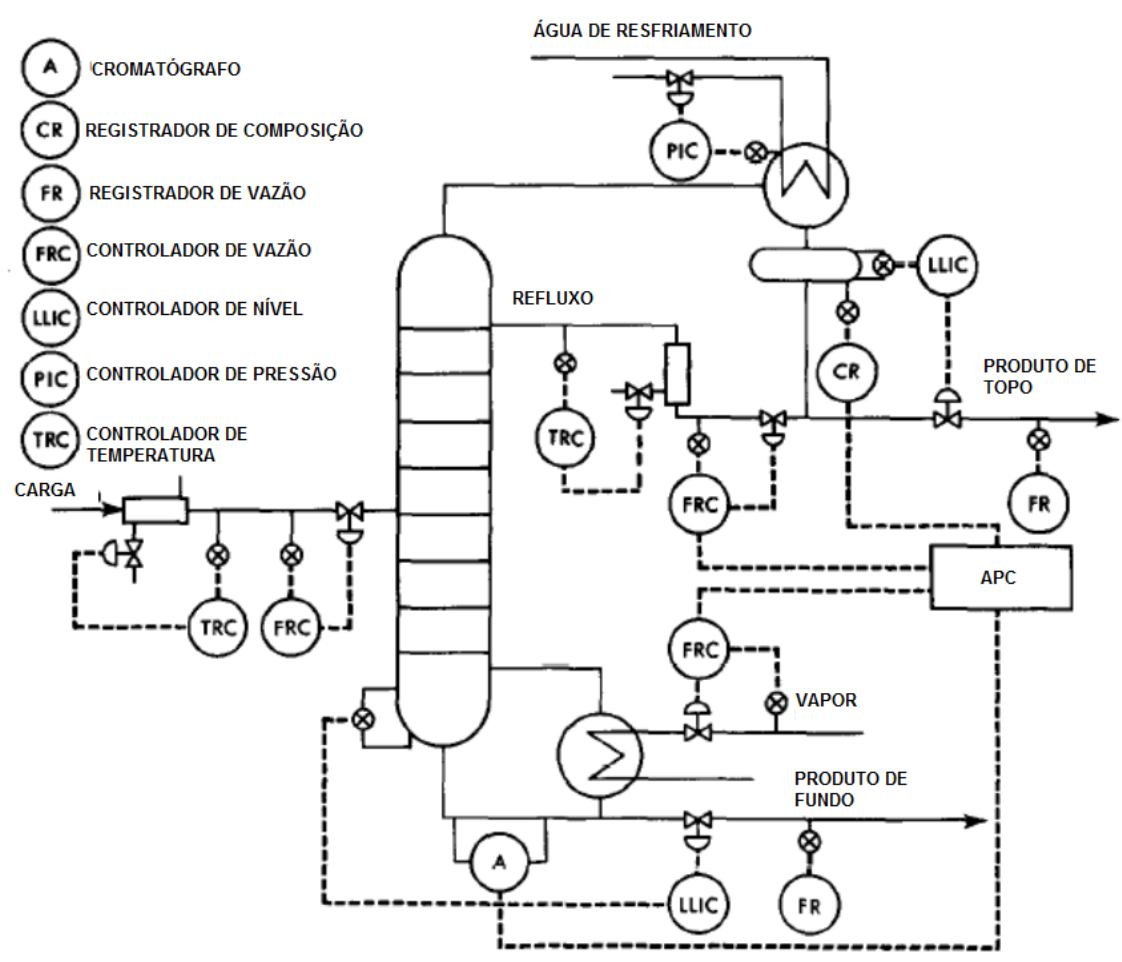

Figura 5.1 - P\&ID da Coluna de Destilação Binária de Wood and Berry.

Fonte (WOOD; BERRY, 1973) - adaptado

Apesar de existirem múltiplas malhas monovariáveis, como por exemplo, a malha de controle de nível do fundo da torre, a malha de vazão de vapor para o refervedor e a malha de controle de vazão de refluxo, no presente trabalho todas essas malhas serão consideradas como pertencentes ao controle regulatório, sendo portanto transparentes para a camada superior de controle.

O modelo é representado pela matriz de transferência:

$$
\left[\begin{array}{l}
X_{D}(s) \\
X_{B}(s)
\end{array}\right]=\left[\begin{array}{cc}
\frac{12,8 e^{-1 s}}{16,7 s+1} & \frac{-18,9 e^{-3 s}}{21,0 s+1} \\
\frac{6,6 e^{-7 s}}{10,9 s+1} & \frac{-19,4 e^{-3 s}}{14,4 s+1}
\end{array}\right]\left[\begin{array}{l}
R(s) \\
S(s)
\end{array}\right]+\left[\begin{array}{c}
\frac{3,8 e^{-8 s}}{14,9 s+1} \\
\frac{4,9 e^{-3 s}}{13,2 s+1}
\end{array}\right] F(s)
$$

em que:

$X_{D} \quad \%$ mássica de metanol na composição da corrente de topo;

$X_{B} \quad \%$ mássica de metanol na composição da corrente de fundo; 
$R(s) \quad$ Vazão de reciclo do produto de topo em lb/min;

$S(s) \quad$ Vazão de vapor do refervedor em lb/min;

$F(s) \quad$ Vazão da alimentação da coluna em lb/min.

Analisando o P\&ID da coluna de destilação, é possível identificar o bloco APC (Advanced Process Control). Neste bloco estão implementadas todas as estratégias de controle referentes ao controle de composição. Na aplicação avaliada, foram implementados dois controladores PID, Nos quais a vazão de refluxo foi utilizada para controlar a composição do produto de topo e a vazão de vapor foi utilizada para controlar a composição do produto de fundo. Foi implementado também um controlador de desacoplamento entre as malhas. Entretanto, a fim de criar condições mais severas de teste, ao longo de todo o ensaio, estes controladores estiveram desabilitados.

Em relação à sintonia dos controladores PID, foi escolhida uma que priorizou a diminuição da variabilidade da composição do produto de topo. A razão para tal escolha é que esta seria uma sintonia usualmente encontrada na indústria. A composição do produto de topo (metanol de alta pureza), provavelmente é a variável de qualidade mais importante para o processo produtivo. Devido ao elevado acoplamento das composições de topo e fundo, o controle fino da composição de topo faz com que o produto de fundo apresente maior variabilidade.

Por fim, foi implementado também um controlador MPC do tipo QDMC, cujo objetivo é definir os set-points ótimos dos controladores PID. Esse controlador foi configurado com um horizonte de predição igual a 30 e um horizonte de controle igual a 10, sendo configurado para execução a cada 20 minutos.

É importante ressaltar que apesar dessa configuração (duas camadas de controladores PID e um controlador MPC) é pouco usual em aplicações industriais. Geralmente o MPC atua diretamente na vazão de vapor do refervedor e na vazão de refluxo. Uma das vantagens dessa topologia consiste no fato dos controladores PID garantirem a estabilidade da planta e o acompanhamento dos set-points, fazendo com que o MPC se torne um otimizador que tem por objetivo garantir que as faixas de operação das 
variáveis controladas e manipuladas sejam respeitadas. Outra vantagem dessa topologia é que o sistema controlado pelo MPC possui ganho unitário, pois as entradas são os set-points, enquanto as saídas são as variáveis controladas. Isso permite que algoritmos que necessitem da normalização dos dados de entrada e saída, como é o caso do algoritmo PLS-PH, possam ser utilizados.

Ao longo do presente capítulo, a maior parte das análises é realizada com o controlador MPC desligado e o objetivo é a avaliação da capacidade do algoritmo realizar a identificação do modelo da planta. Na última análise será realizada a identificação do sistema planta + controladores PID, cujo modelo é utilizado para realizar a validação com o funcionamento do controlador MPC.

\subsection{Testes preliminares}

De maneira análoga ao caso SISO, antes de realizar a identificação é necessário determinar um conjunto de parâmetros como a ordem do modelo, o tempo morto e o número de componentes principais, que são parâmetros de entrada do algoritmo de identificação.

\subsubsection{Tempo morto}

Para realizar a correta estimação do tempo morto, o sistema foi colocado em malha aberta (os controladores PID foram desabilitados) e em ensaios distintos foram aplicados degraus nas variáveis manipuladas no instante de tempo 100 minutos. As respostas da planta são apresentadas nas figuras a seguir. 


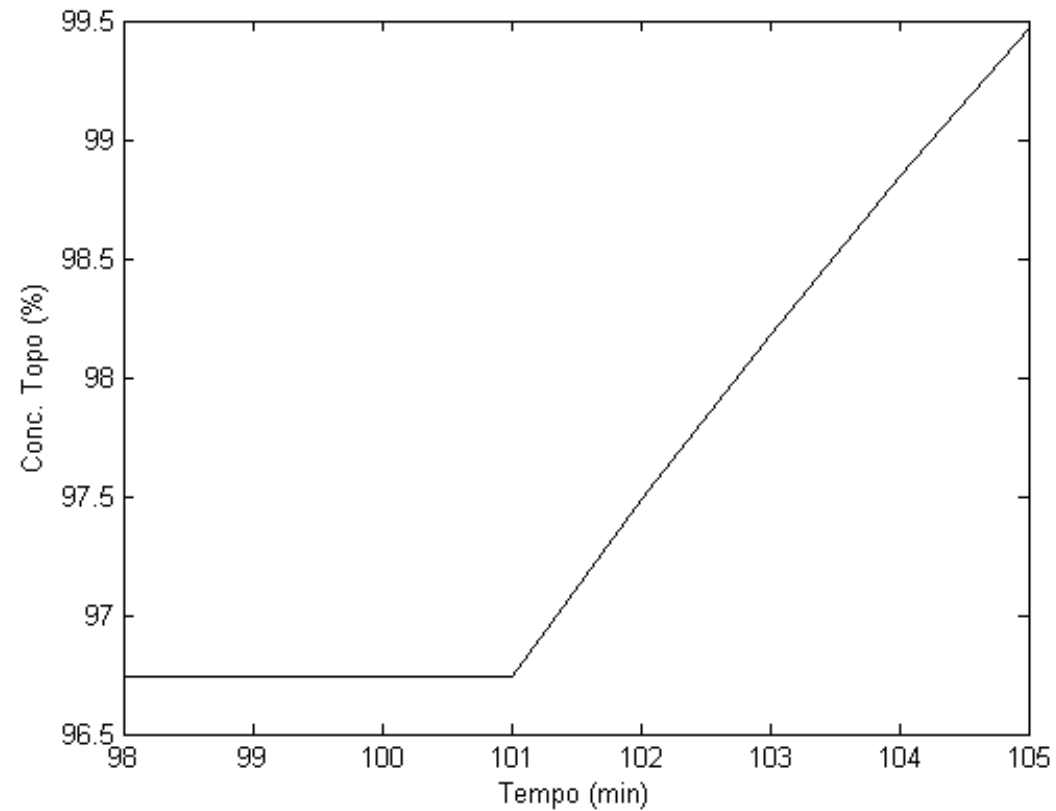

Figura 5.2 - Resposta da composição do produto de topo a degraus na vazão de refluxo. (Autor)

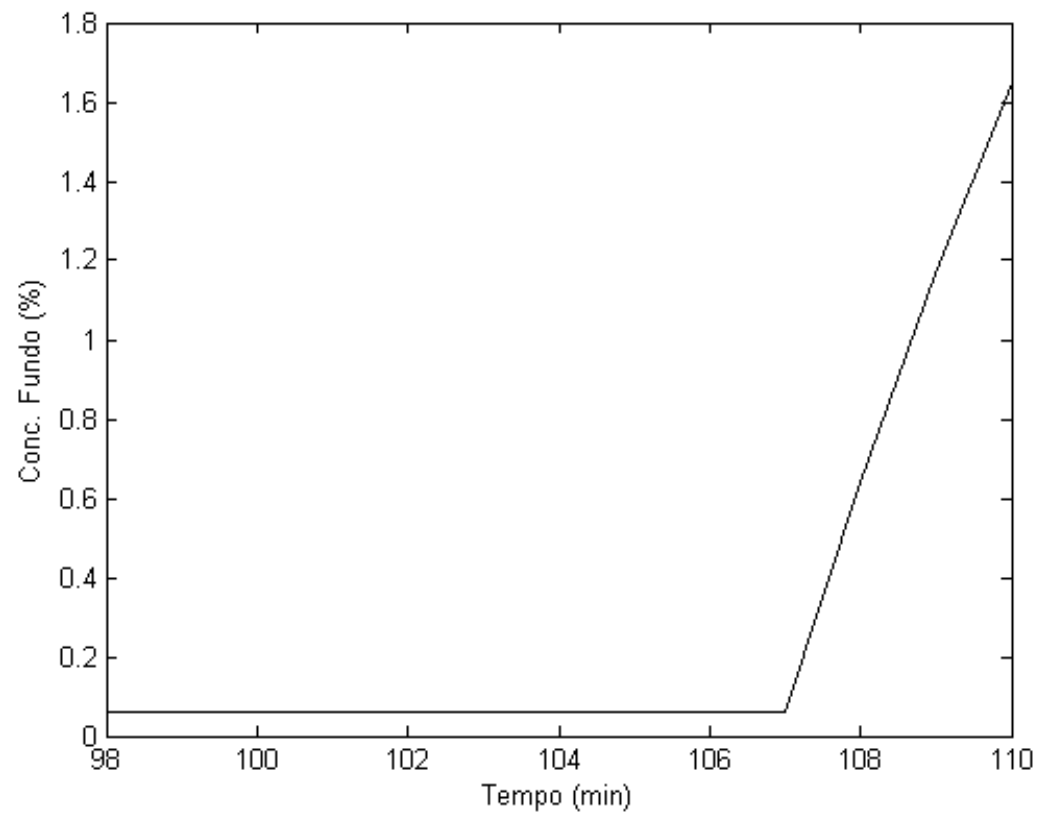

Figura 5.3 - Resposta da composição do produto de fundo a degrau na vazão de refluxo. (Autor) 


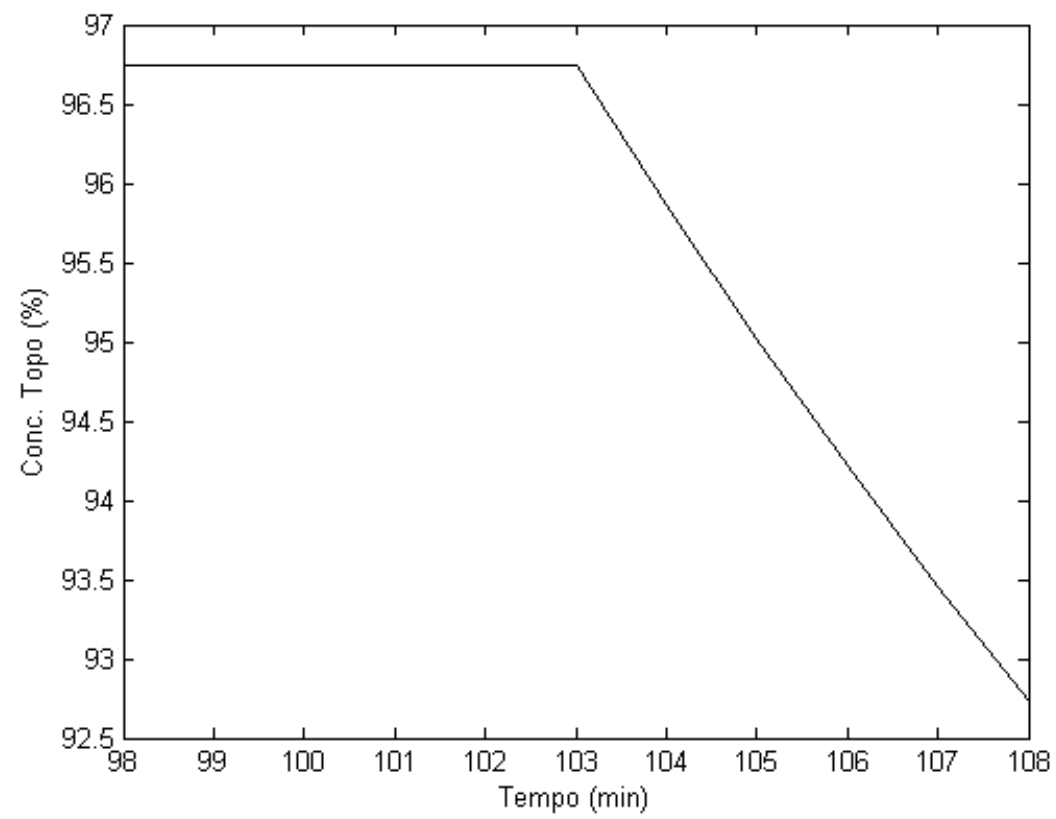

Figura 5.4- Resposta da composição do produto de topo a degrau na vazão de vapor. (Autor)

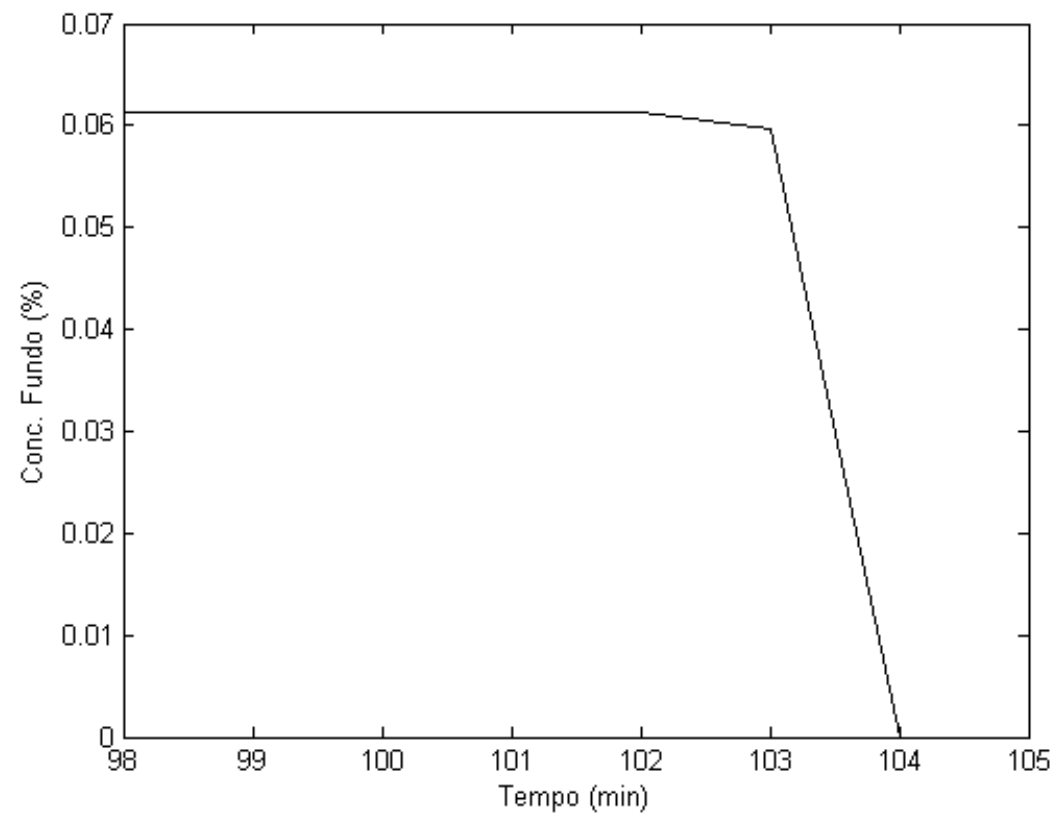

Figura 5.5- Resposta da composição do produto de fundo a degrau na vazão de vapor. (Autor)

A partir dessas figuras, é possível verificar que os tempos mortos que devem ser considerados neste ensaio são apresentadas na tabela 5.1. 
5.1 - Tempos Mortos utilizados na Identificação.

\begin{tabular}{|c|c|c|}
\hline & Vazão de Refluxo & Vazão de Vapor \\
\hline Composição de Topo & $1 \mathrm{~min}$ & $3 \mathrm{~min}$ \\
\hline Composição de Fundo & $7 \mathrm{~min}$ & $3 \mathrm{~min}$ \\
\hline
\end{tabular}

\subsubsection{Ordem do Modelo e Número de Componentes Principais}

Conforme pode ser observado pela equação ((5-1), o sistema é representado por modelos de primeira ordem. Entretanto, a fim de avaliar o impacto do sobredimensionamento da ordem do sistema, na identificação do algoritmo PLS-PH, foram identificados modelos de primeira ordem e também modelos de segunda ordem.

Assim, para determinar o número de componentes principais que devem ser utilizadas pelo algoritmo PLS-PH (com o intuito de identificar os modelos com as duas ordens selecionadas), foram injetados sinais PRBS nos set-points dos controladores PID e montadas as matrizes de regressores. Os valores singulares normalizados para os modelos são apresentados nas figuras a seguir. 


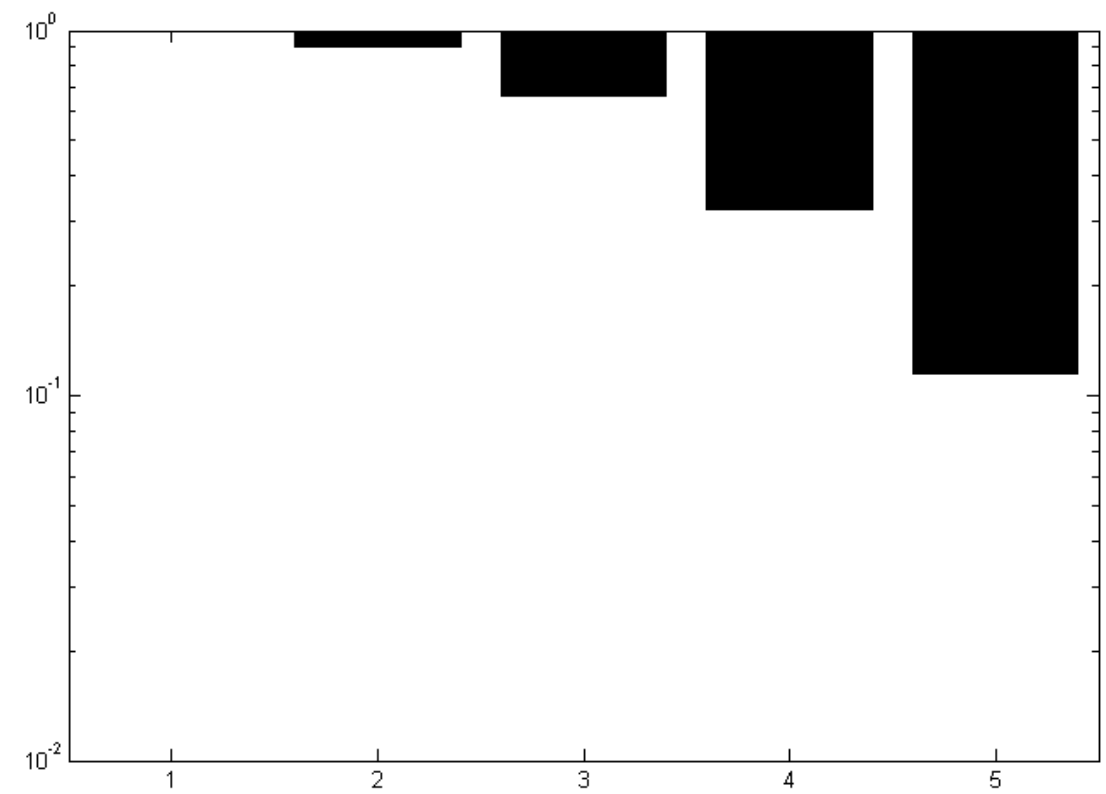

Figura 5.6 - Valores singulares para modelo de primeira ordem da composição de topo. (Autor)

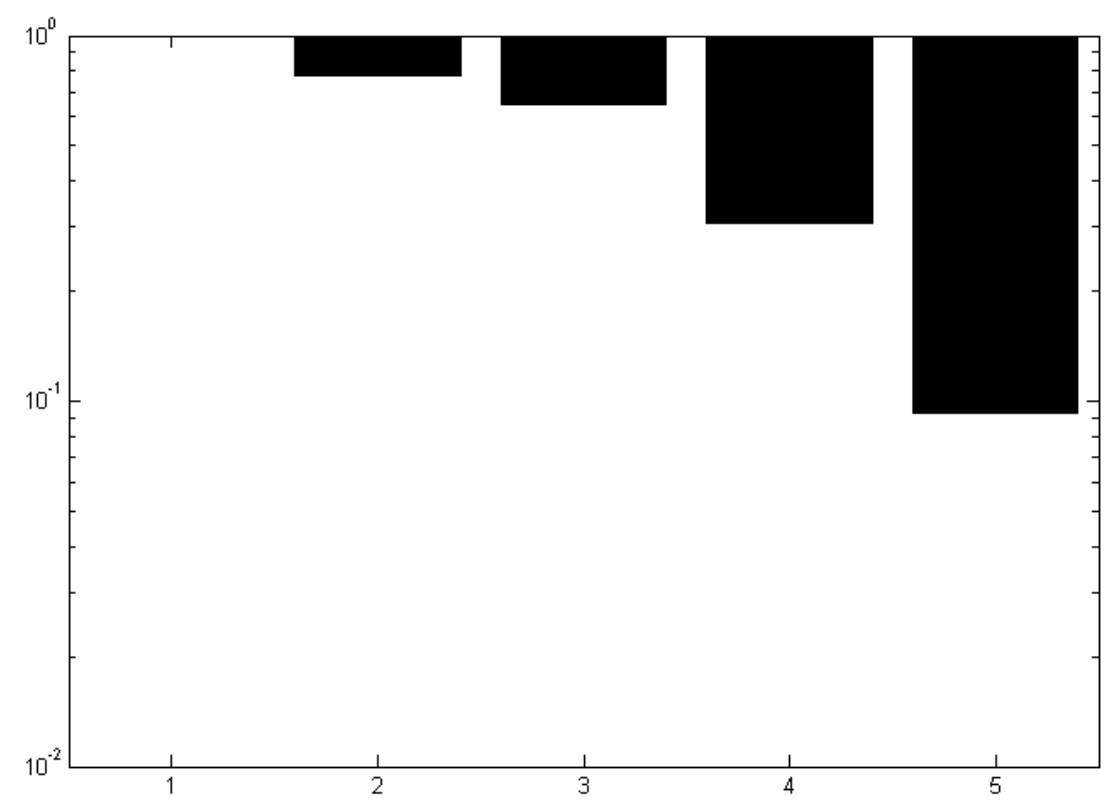

Figura 5.7 - Valores singulares para modelo de primeira ordem da composição de fundo. (Autor) 


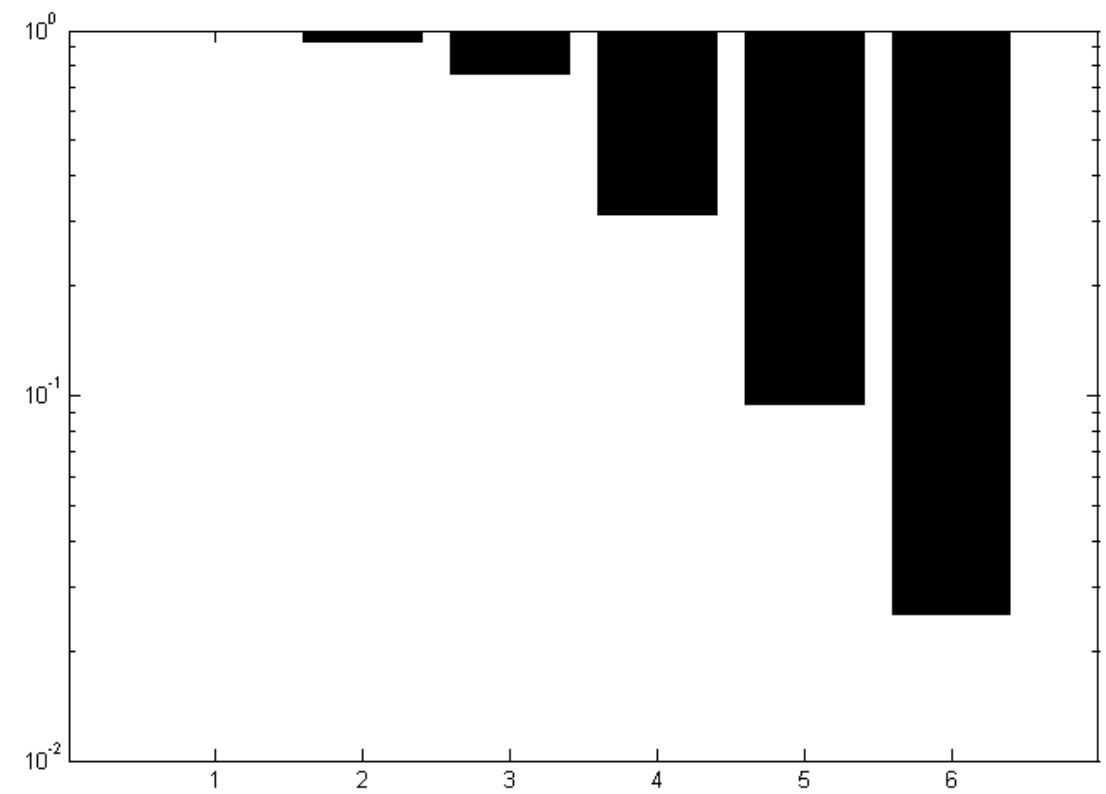

Figura 5.8- Valores singulares para modelo de segunda ordem da composição de topo. (Autor)

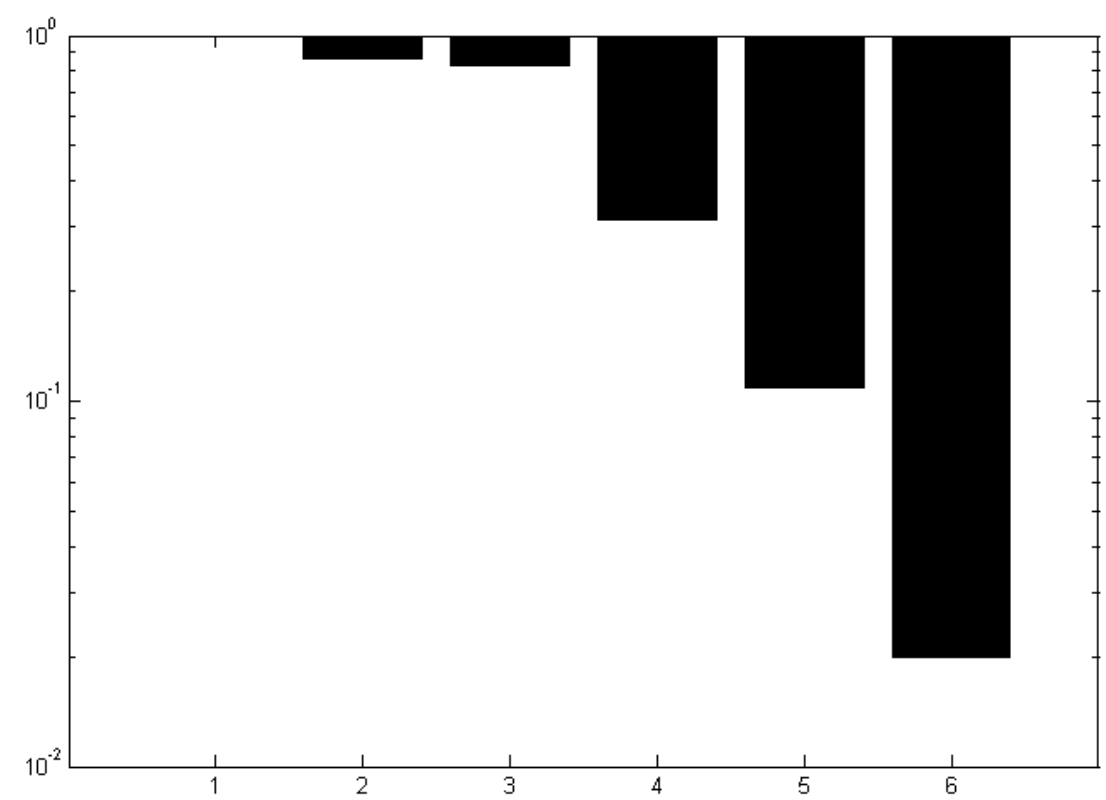

Figura 5.9 - Valores singulares para modelo de segunda ordem da composição de fundo. (Autor)

A partir destas figuras, pode-se afirmar que para os dois casos o número de componentes principais, que deve ser utilizado pelo algoritmo PLS-PH, 
indicado por uma grande diferença entre dois valores consecutivos, é igual a 3 para todos os 4 modelos a serem identificados.

\subsection{Dados Utilizados na Simulação}

A fim de validar o algoritmo PLS-PH para a identificação em malha fechada, os set-points foram estimulados com um sinal PRBS apresentado na Figura 5.10. Em seguida, as variáveis manipuladas e as variáveis controladas foram coletadas e apresentadas, respectivamente, na Figura 5.11 e na Figura 5.12.
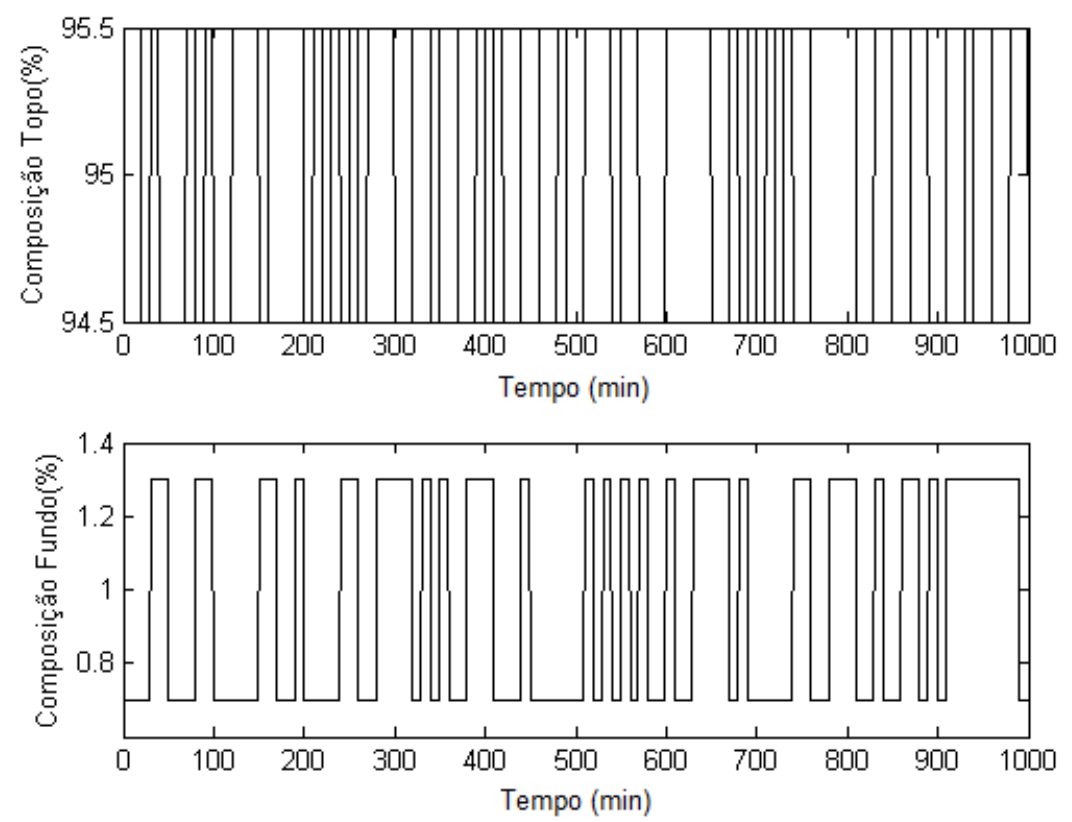

Figura 5.10 - Estimulo injetado no set-point da malha de controle. (Autor) 

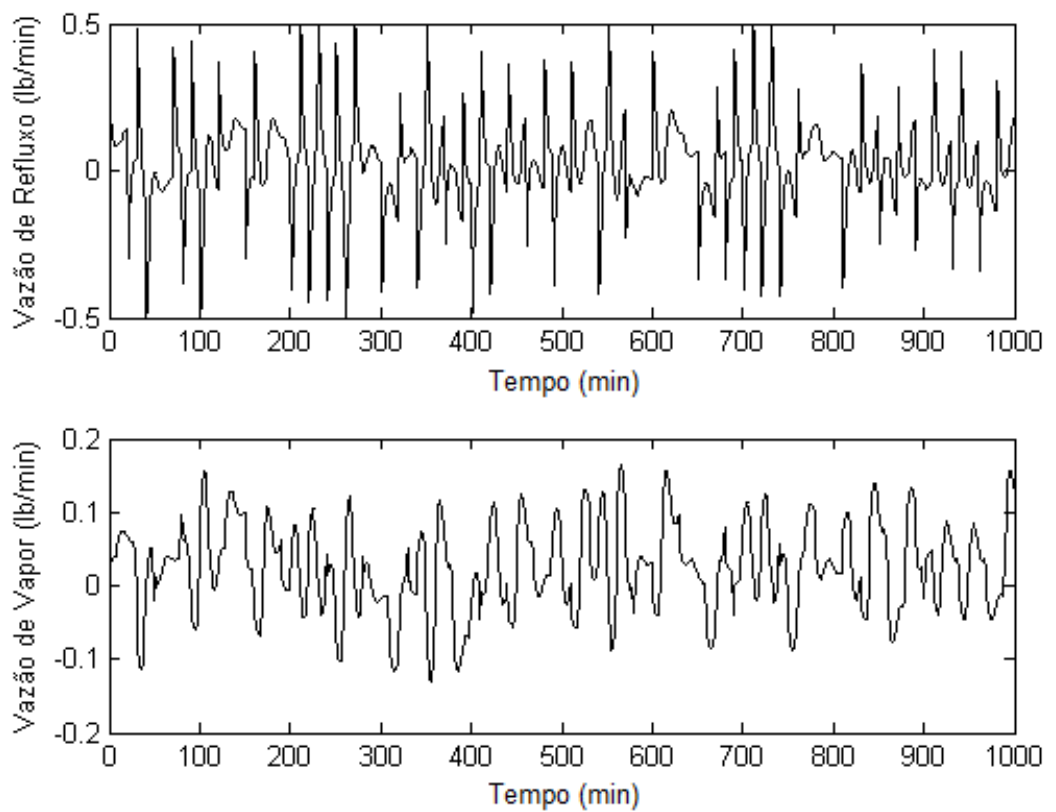

Figura 5.11 - Variáveis manipuladas (incrementais) coletadas na simulação. (Autor)
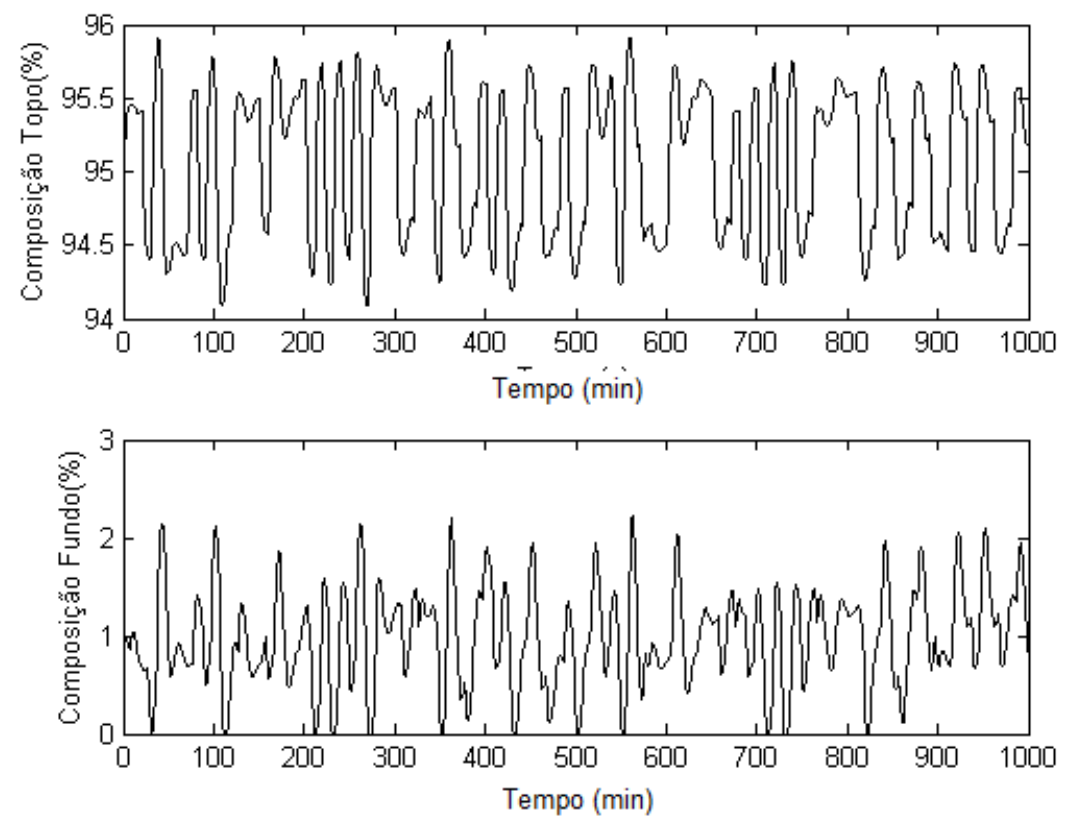

Figura 5.12 - Variáveis controladas obtidas na simulação. (Autor)

É importante atentar para o fato que, apesar de (WOOD; BERRY, 1973) explicar que a composição de fundo usualmente obtida é igual a $0,5 \%$, foi considerado durante as simulações que o valor estacionário fosse igual a $1 \%$. Essa alteração foi realizada para que ocorresse uma menor saturação da composição de fundo, que não pode ser negativa. Analogamente, a 
composição de topo foi fixada em 95\%. É importante salientar que, pelo fato do modelo ser linear, a alteração do set-point não altera a dinâmica do sistema.

Estes dados foram centrados e normalizados (isto é foi subtraída a sua média e foram divididos pelos seus respectivos desvios-padrão), e utilizados para as identificações apresentadas nas próximas seções.

\subsection{Identificação em malha fechada}

\subsubsection{Desempenho em função da ordem e do horizonte de predição}

Com os dados apresentados na seção anterior, que totalizam 1000 amostras, foi realizada a identificação múltiplos passos à frente de modelos da planta utilizando o algoritmo PLS-PH com diferentes horizontes de predição. Os modelos obtidos foram comparados com os gerados pelo método MPEM, utilizando os mesmos horizontes de predição. Em todas as identificações foi obtido um modelo MISO para cada saída, gerando assim um modelo para a composição de topo e outro para a composição de fundo da coluna. Foram identificados modelos de primeira e segunda ordens. A validação cruzada é realizada a utilizando um conjunto de dados, também com 1000 amostras, similar aos usados para identificação (isto é, dados coletados a partir da variação do set-point com um sinal PRBS), centrados e escalados. A partir dos dados de validação cruzada, são calculados o critério fit para o horizonte de predição igual ao utilizado para a identificação do modelo MPEM e também a somatória dos erros de predição para todos os passos de predição até o horizonte escolhido (parâmetro $J_{L R P I}$ ). Os resultados das validações são apresentados nas Figuras 5.13 a 5.20 . Na interpretação destas figuras é importante ter em mente que o quanto mais próximo o critério fit estiver de $100 \%$, melhores são as predições do modelo. Por outro lado, quanto menor o parâmetro $J_{L R P I}$, menor o erro de predição e, portanto, mais representativo o modelo. 


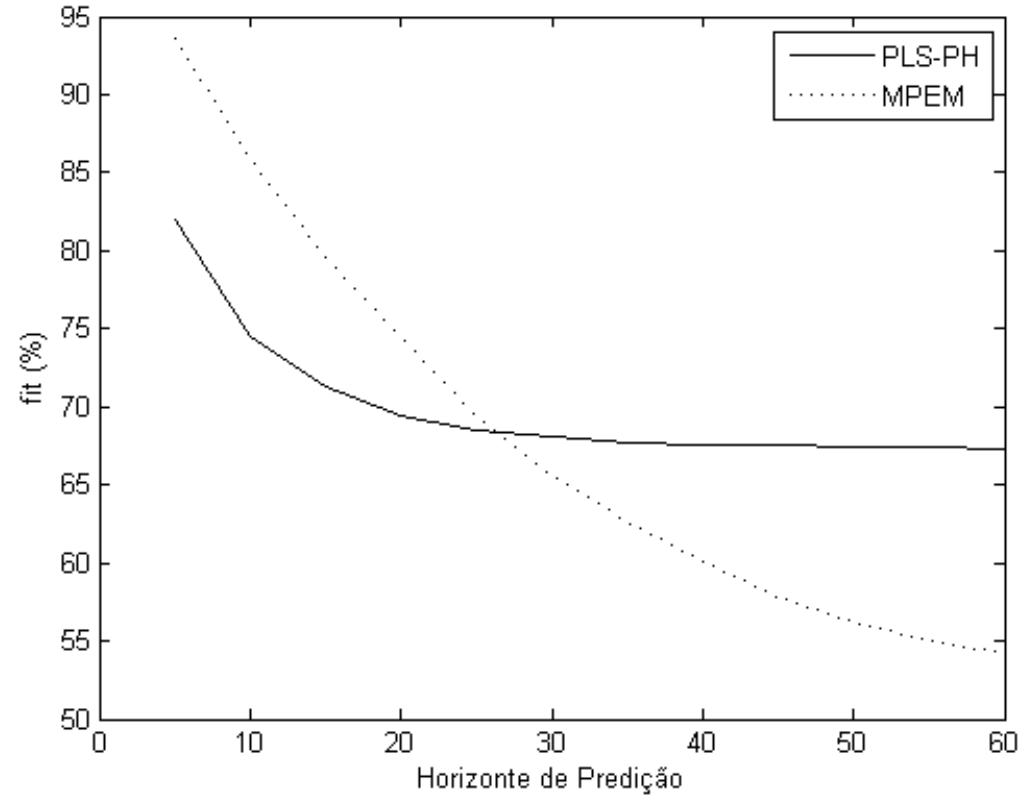

Figura 5.13 - Critério fit com diferentes horizontes de predição para modelos da composição de topo de primeira ordem. (Autor)

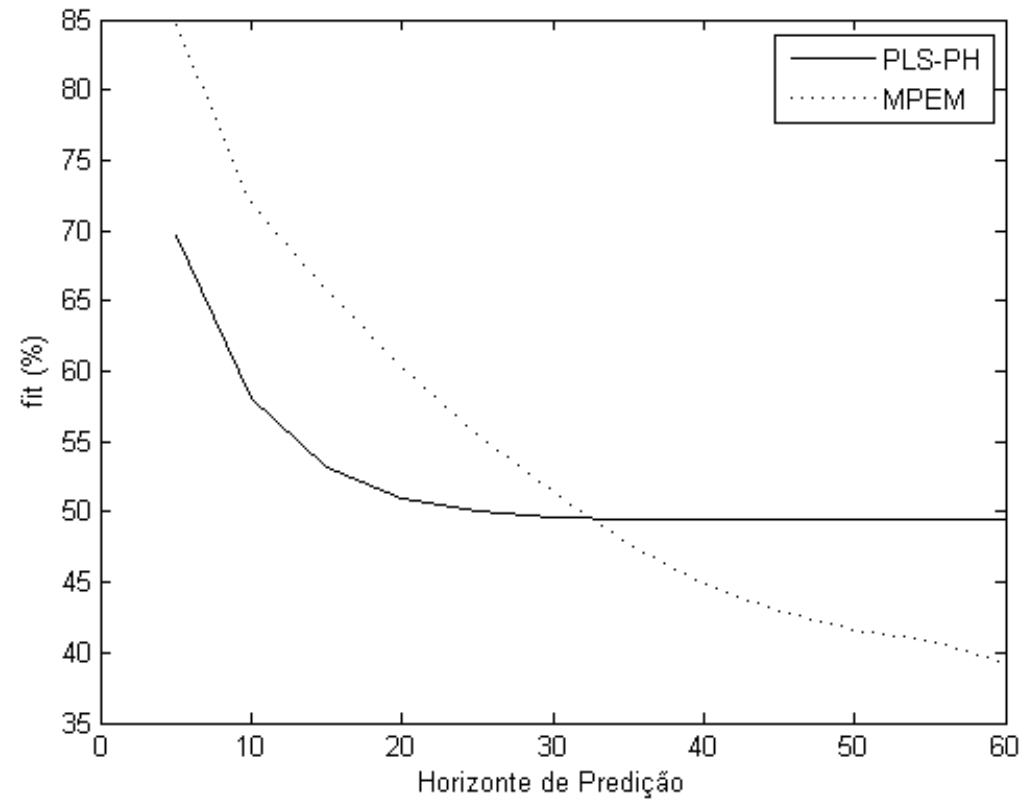

Figura 5.14 - Critério fit com diferentes horizontes de predição para modelos da composição de fundo de primeira ordem. (Autor) 


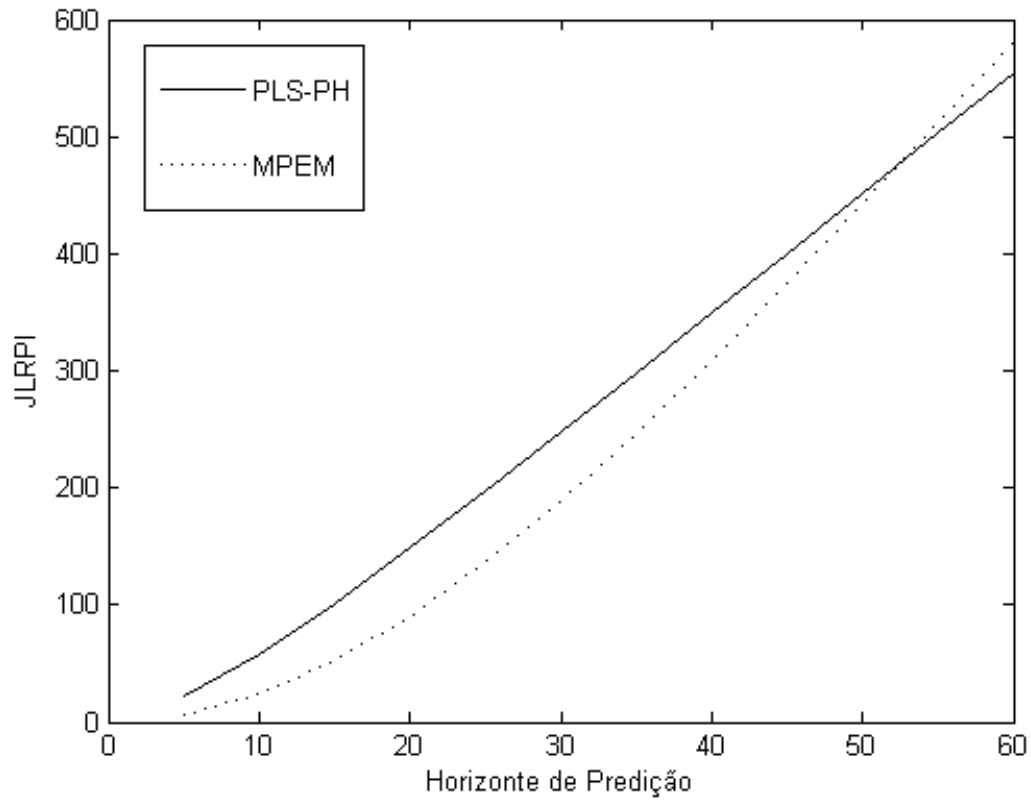

Figura 5.15 - Parâmetro $J_{L R P \mid}$ com diferentes horizontes de predição para modelos da composição de topo de primeira ordem. (Autor)

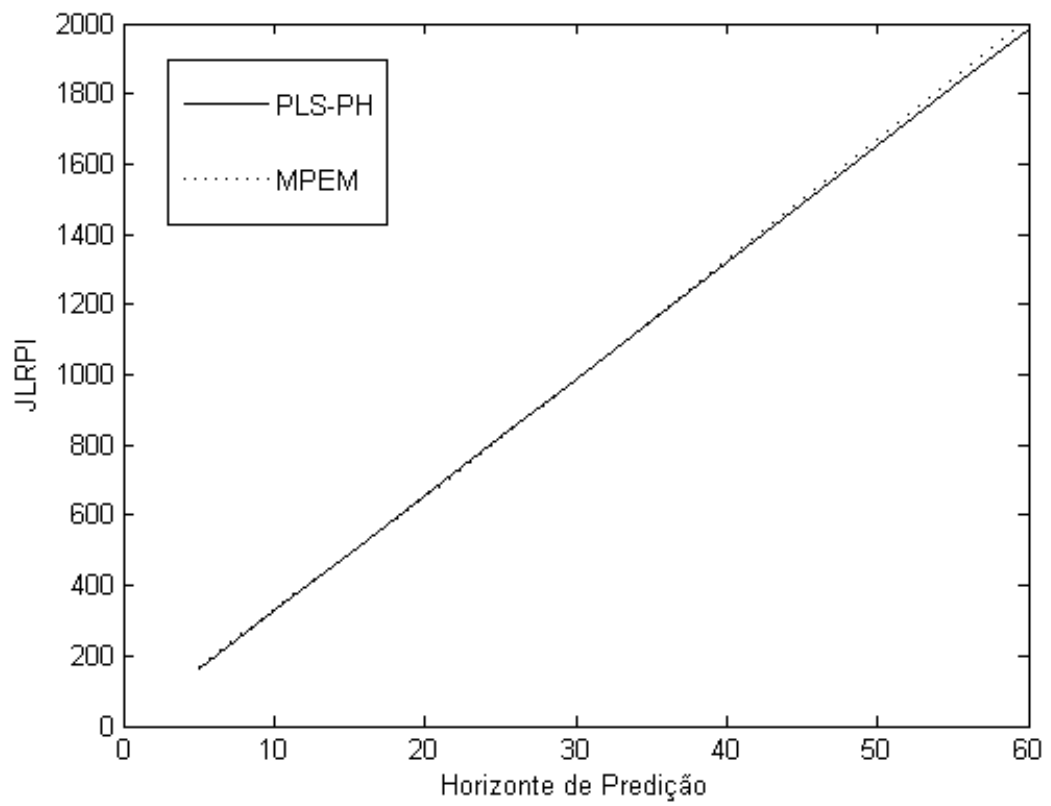

Figura 5.16 - Parâmetro $J_{L R P I}$ com diferentes horizontes de predição para modelos da composição de fundo de primeira ordem. (Autor) 


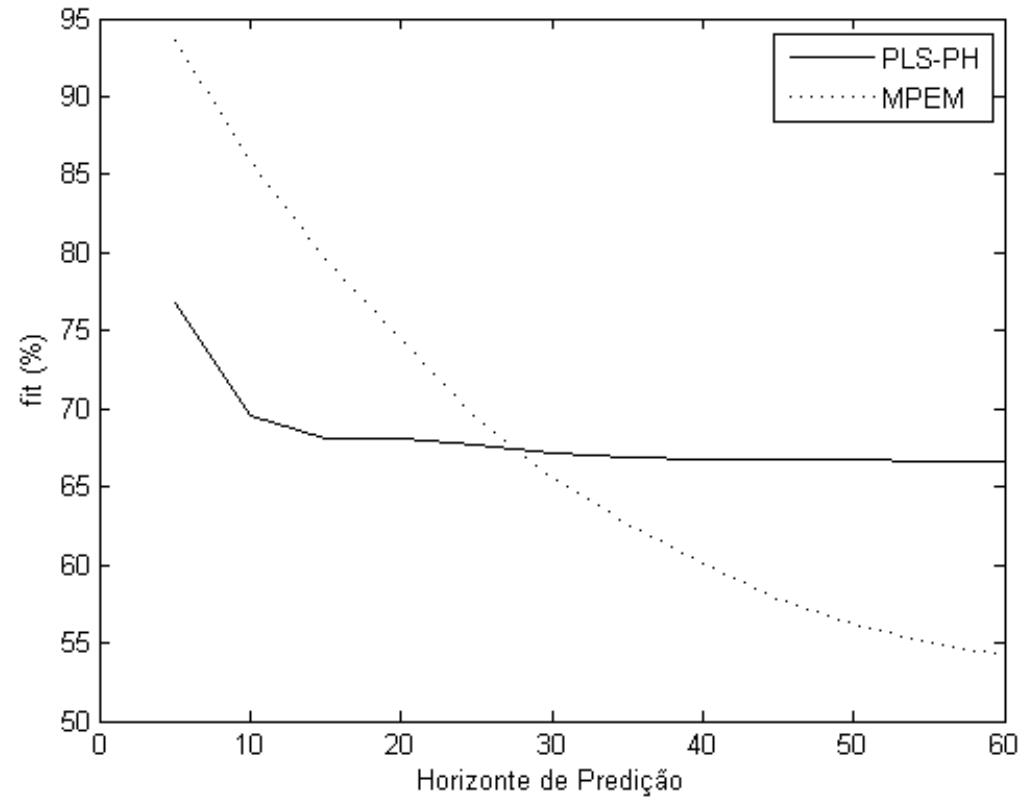

Figura 5.17 - Critério fit com diferentes horizontes de predição para modelos da composição de topo de segunda ordem. (Autor)

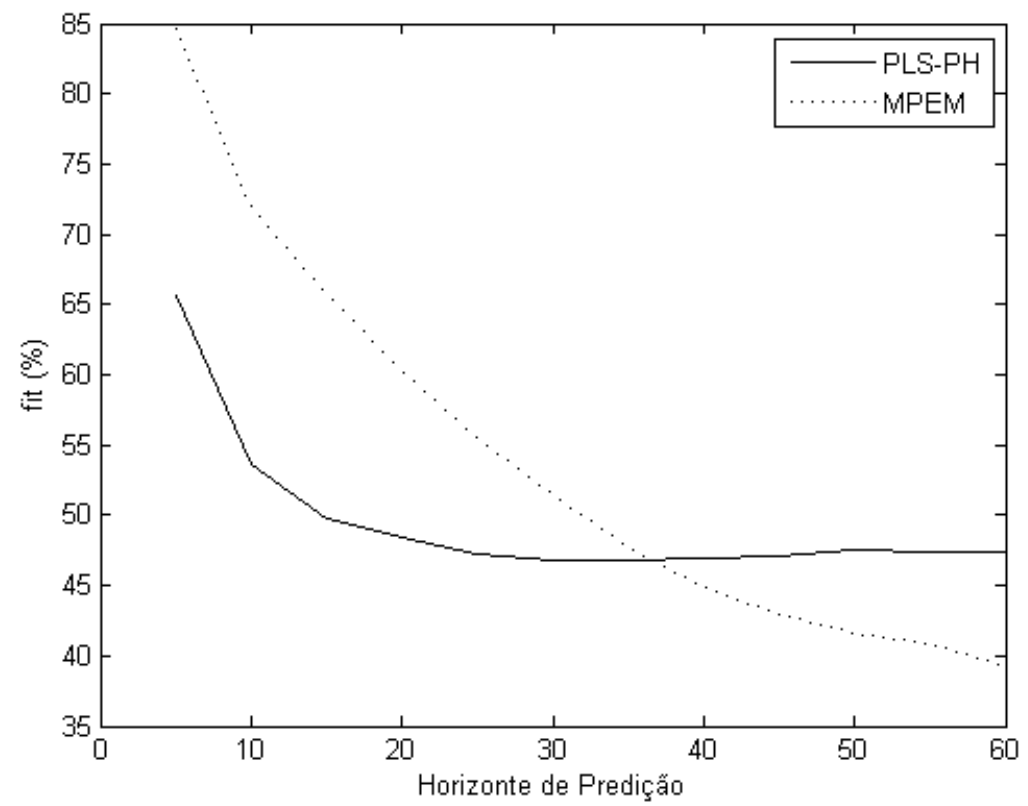

Figura 5.18 - Critério fit com diferentes horizontes de predição para modelos da composição de fundo de segunda ordem. (Autor) 


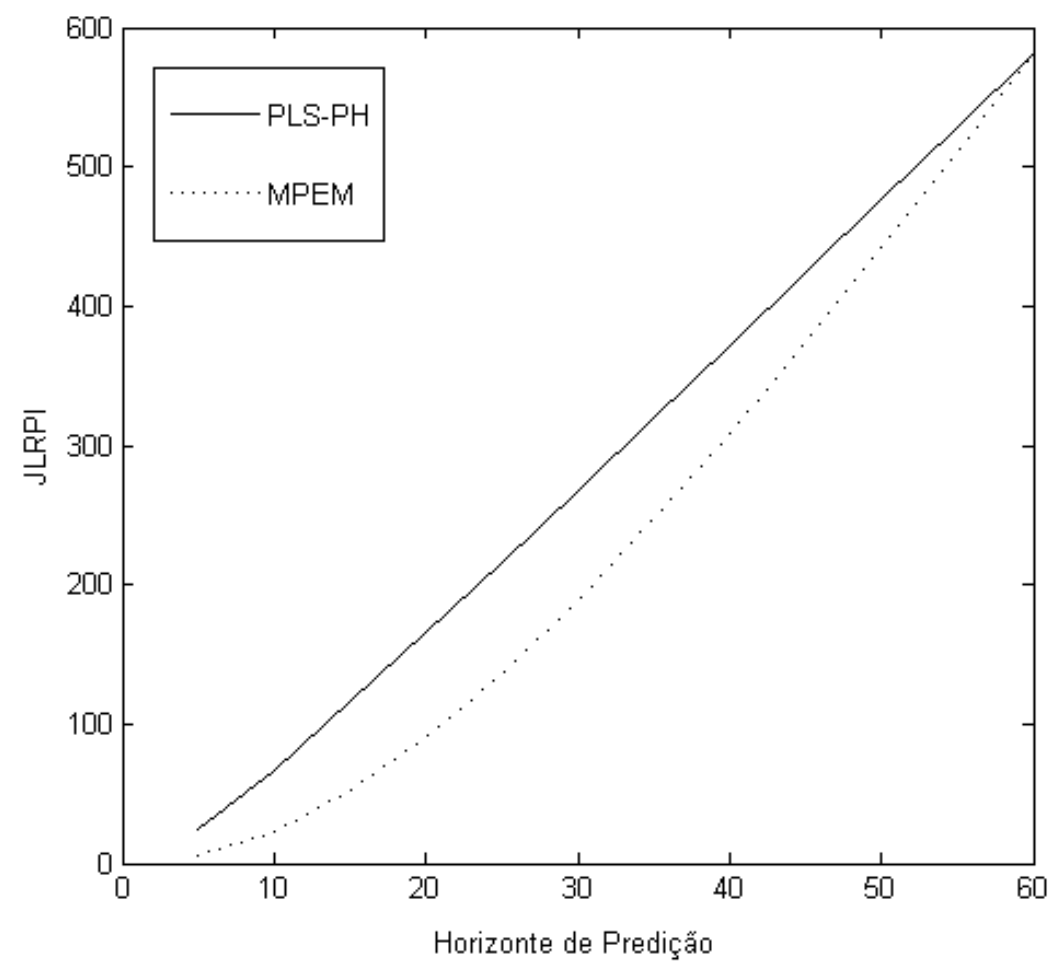

Figura 5.19 - Parâmetro $J_{L R P I}$ com diferentes horizontes de predição para modelos da composição de topo de segunda ordem. (Autor)

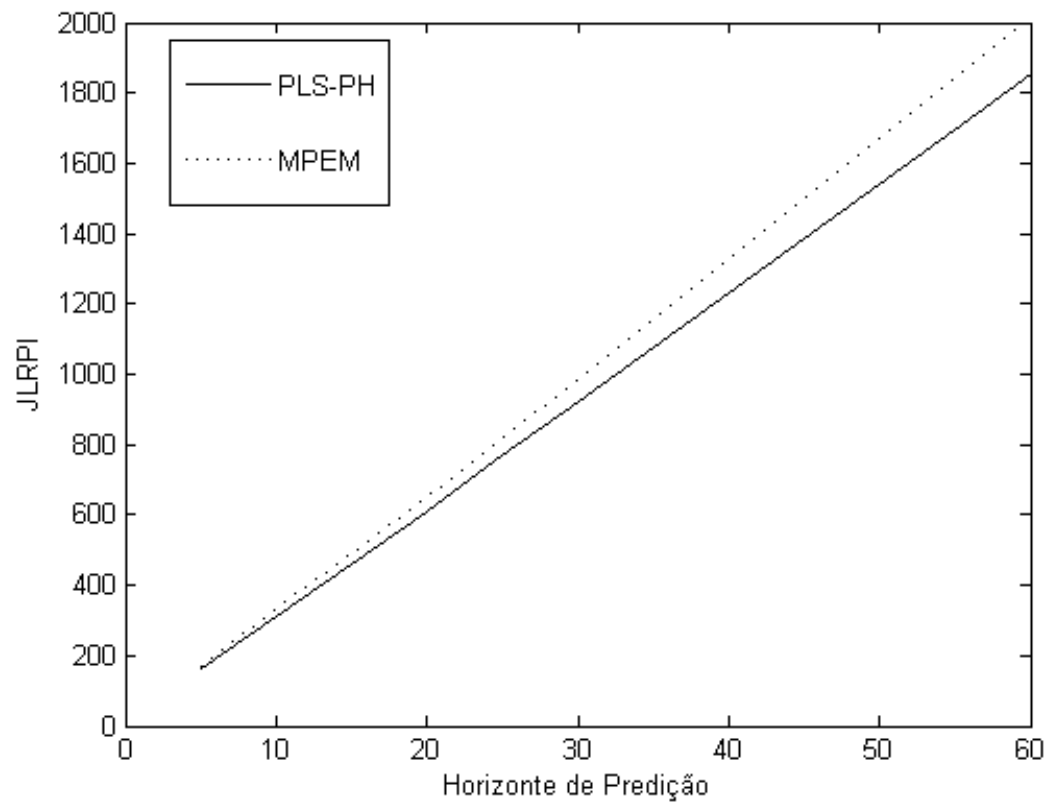

Figura 5.20 - Parâmetro $J_{L R P I}$ com diferentes horizontes de predição para modelos da composição de fundo de segunda ordem. (Autor)

A partir destas figuras, é possível verificar que: 
- Em todas as figuras é possível verificar que, para horizontes de predição maiores que 30 , os modelos obtidos pelo algoritmo PLS-PH apresentam melhor desempenho.

- Para todos os algoritmos, os modelos obtidos para a composição de topo foram melhores que os modelos para a composição de fundo. Isso provavelmente ocorreu pelo fato de durante aproximadamente $4 \%$ do tempo esta composição ser identicamente nula, o que implica que a saída estava saturada, deteriorando assim a qualidade dos dados e, consequentemente, dos modelos.

- Os modelos de primeira ordem gerados pelo algoritmo PLS-PH apresentaram desempenho ligeiramente superior ao dos modelos de segunda ordem, com exceção da figura 5.20.

\subsubsection{Efeito do erro da estimativa de tempo morto}

A fim de avaliar o efeito gerado por um erro na estimativa de tempo morto para um modelo de segunda ordem, com os horizontes de predição 30 e 60 , variouse a estimativa do tempo morto da função de transferência da composição do produto de fundo pela vazão de refluxo entre 2 e 12. A razão da seleção da composição de fundo, que na seção anterior apresentou modelos de pior qualidade, decorre exclusivamente do elevado tempo morto existente, permitindo assim utilizar um intervalo simétrico e amplo para a estimativa do tempo morto. Realizou-se então a validação cruzada dos modelos, calculando seus respectivos parâmetros fit, com os horizontes de predição utilizados para a identificação do modelo. Os resultados dessa análise são apresentados nas figuras a seguir. 


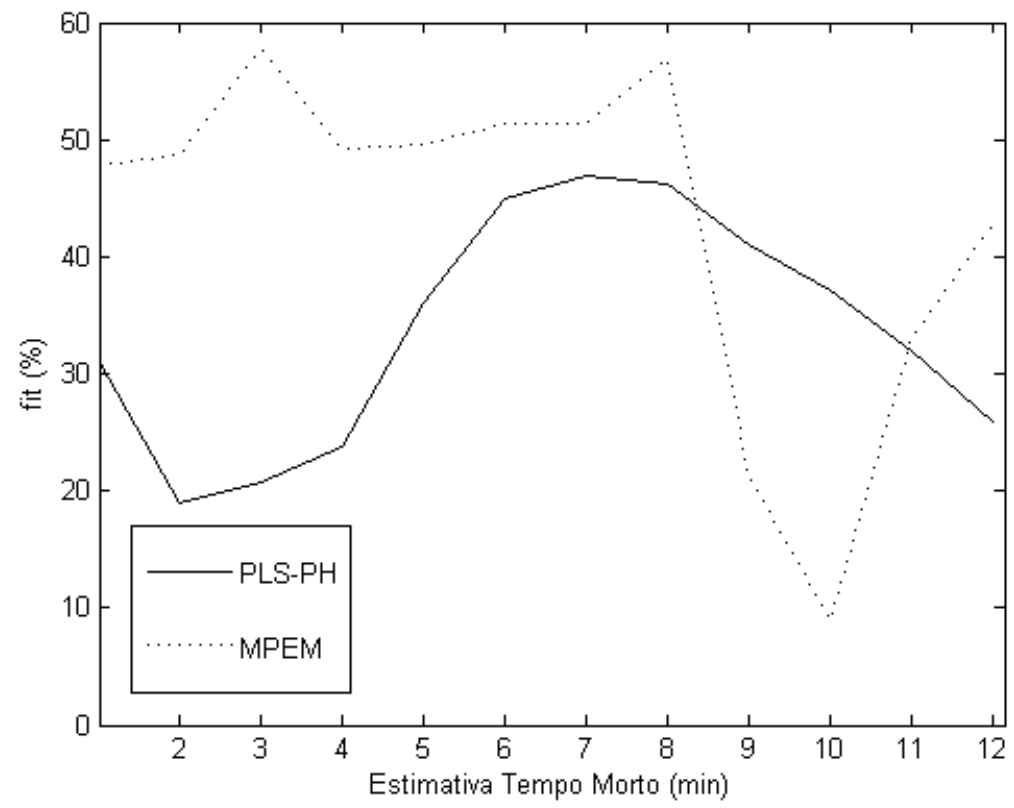

Figura 5.21 - Critério fit para modelo da composição de fundo em função de estimativa de tempo morto com horizonte de predição 30. (Autor)

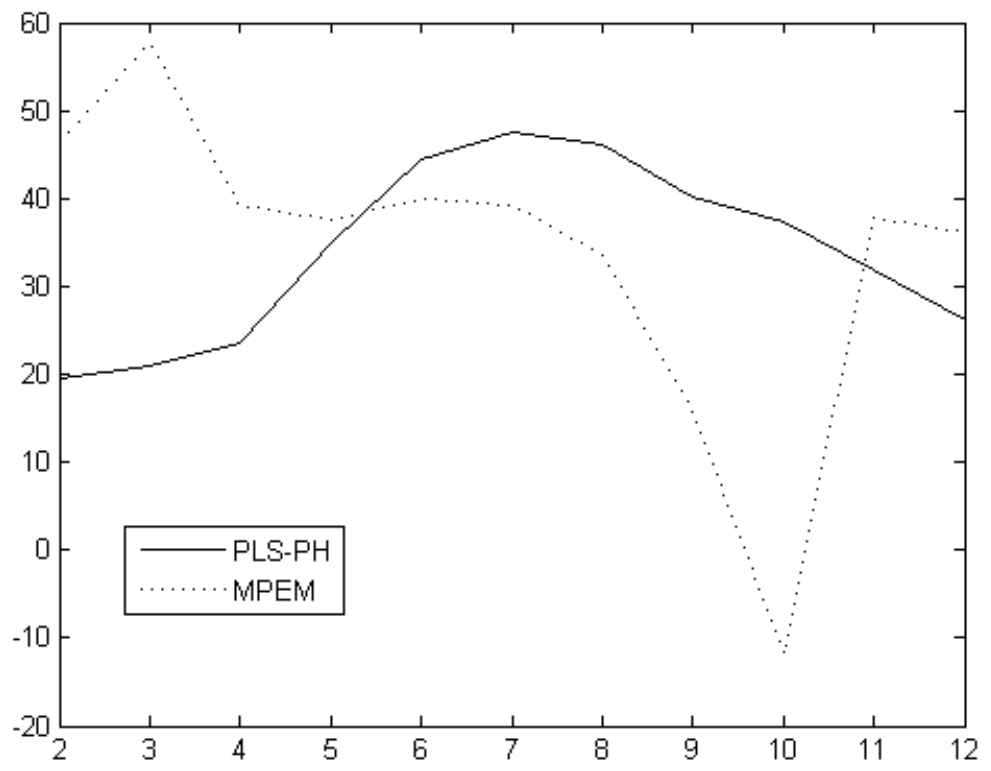

Figura 5.22 - Critério fit para modelo da composição de fundo em função de estimativa de tempo morto com horizonte de predição 60. (Autor)

Por meio dessas imagens, é possível realizar duas constatações: Primeira: para os dois horizontes de predição, o algoritmo PLS-PH apresenta certa 
robustez (apesar dos baixos valores de fit) a pequenos erros na estimativa de tempo morto, enquanto que para os modelos MPEM, pode-se observar certa variabilidade para os modelos identificados. Um segundo ponto importante a ser observado é que a robustez é maior quando o tempo morto é superestimado. Isso pode ser explicado pelo simples fato que quando o tempo morto é subestimado, as informações da entrada ainda não foram apresentadas na saída, não constando, portanto, na matriz de regressores.

\subsubsection{Análise de Precisão dos Algoritmos}

A fim de avaliar a precisão do algoritmo de identificação PLS-PH, foi realizada uma análise segundo o método de Monte Carlo. Foram gerados 100 conjuntos de dados de entrada e saída utilizando sementes aleatórias distintas. Para cada um desses conjuntos foi realizada a identificação múltiplos passos à frente de um modelo de segunda ordem, utilizando os algoritmos PLS-PH, e MPEM (modelos de processo). A partir dos modelos identificados foram calculados a média, o desvio padrão e a razão entre a média e o desvio padrão para cada um dos parâmetros. $O$ resultado dessa análise pode ser observado na Tabela 5.2

Tabela 5.2 - Análise de precisão pelo método de Monte Carlo.

\begin{tabular}{|c|c|c|c|c|c|c|c|c|}
\hline & & & a1 & a2 & b11 & b12 & b21 & b22 \\
\hline \multirow{6}{*}{ PLS-PH } & \multirow{3}{*}{ TOPO } & $\mu$ & $-0,105$ & $-0,107$ & $-0,111$ & $-0,112$ & $-0,103$ & $-0,102$ \\
\hline & & $\sigma$ & 0,273 & 0,271 & 0,274 & 0,274 & 0,275 & 0,271 \\
\hline & & $|\sigma / \mu|(\%)$ & 260 & 253 & 247 & 244 & 267 & 266 \\
\hline & \multirow{3}{*}{ FUNDO } & $\mu$ & $-0,127$ & $-0,126$ & $-0,122$ & $-0,132$ & $-0,122$ & $-0,122$ \\
\hline & & $\sigma$ & 0,244 & 0,239 & 0,256 & 0,258 & 0,246 & 0,236 \\
\hline & & $|\sigma / \mu|(\%)$ & 192 & 190 & 210 & 195 & 201 & 194 \\
\hline \multirow{6}{*}{ MPEM } & \multirow{3}{*}{ TOPO } & $\mu$ & $-0,134$ & $-0,135$ & $-0,133$ & $-0,134$ & $-0,135$ & $-0,135$ \\
\hline & & $\sigma$ & 0,478 & 0,479 & 0,472 & 0,477 & 0,483 & 0,503 \\
\hline & & $|\sigma / \mu|(\%)$ & 357 & 355 & 355 & 357 & 359 & 373 \\
\hline & \multirow{3}{*}{ FUNDO } & $\mu$ & $-0,142$ & $-0,149$ & $-0,166$ & $-0,146$ & $-0,146$ & $-0,145$ \\
\hline & & $\sigma$ & 0,675 & 0,863 & 0,947 & 0,787 & 0,717 & 0,833 \\
\hline & & $|\sigma / \mu|(\%)$ & 474 & 578 & 571 & 539 & 492 & 574 \\
\hline
\end{tabular}


A partir dessa tabela pode-se observar que:

- Os valores médios dos parâmetros dos modelos encontrados pelo algoritmo PLS-PH foram diferentes (até 30\%) dos valores encontrados pelo algoritmo MPEM;

- Os desvios padrão dos parâmetros obtidos pelo modelo PLS-PH para o modelo de composição de fundo são ligeiramente menores que aqueles obtidos para os modelos da composição de topo;

- O desvio padrão dos parâmetros dos modelos encontrados pelo algoritmo PLS-PH foram inferiores aos valores encontrados para os modelos do algoritmo MPEM;

- O desvio padrão normalizado, isto é, $\left|\frac{\sigma}{\mu}\right|$, encontrado para o algoritmo PLS-PH foi inferior ao valor obtido pelo algoritmo MPEM.

Com base nessas análises, é possível afirmar que o desempenho do algoritmo PLS-PH possui maior precisão que o método MPEM. Entretanto, nada se sabe sobre a qualidade dos modelos identificados. Para realizar uma avaliação da qualidade dos modelos, foi realizada a validação cruzada para um novo conjunto de dados e calculadas as médias e desvios padrão dos valores de fit com horizonte de predição 30 para os modelos utilizados no ensaio de Monte Carlo. Os resultados dessa análise são apresentados na Tabela 5.3

Tabela 5.3 - Análise de Monte Carlo sobre o parâmetro fit para uma predição 30 passos a frente.

\begin{tabular}{|c|c|c|c|c|}
\hline \multirow{2}{*}{} & \multicolumn{2}{|c|}{ TOPO } & \multicolumn{2}{c|}{ FUNDO } \\
\cline { 2 - 5 } & $\mu$ & $\sigma$ & $\mu$ & $\sigma$ \\
\hline PLS-PH & 53,20 & 2,21 & 26,91 & 3,28 \\
\hline MPEM & 46,38 & 5,88 & 38,06 & 3,53 \\
\hline
\end{tabular}

Ao avaliar os valores médios encontrados é possível observar que os valores médios encontrados são coerentes com aqueles vistos na Figura 5.18, eventualmente com a diferença da média ser inferior ao valor apresentado no gráfico. Por outro lado, avaliando os valores de desvio padrão, é possível constatar que o algoritmo PLS-PH apresenta para as predições da composição de topo menor valor de desvio padrão e valores de desvio padrão apenas 
ligeiramente menores para a composição de fundo. Desta maneira, é possível afirmar que o algoritmo PLS-PH fornece modelos com considerável precisão.

É importante verificar, entretanto que os valores de fit são baixos, principalmente para o modelo da composição de fundo. Uma possível causa é o fato dessa variável operar muito próximo do seu limite físico $(0 \%)$, e o fato da sintonia definida para as malhas ser tal que as respostas nesta variável são muito agressivas, favorecendo assim a presença de eventuais saturações.

\subsection{Identificação da Planta + Controlador PID}

Nesta seção é realizada a identificação do sistema coluna + controlador PID para utilização desse modelo em um controlador MPC. Para esta identificação foram utilizados os dados apresentados na seção 5.3, utilizando os valores de set-point como entradas e as variáveis controladas como saída.

Um primeiro ponto importante a ser avaliado antes de realizar a identificação é inspecionar a resposta do sistema identificado. Para realizar tal avaliação, foram realizadas duas simulações. Na primeira, foi aplicado um degrau com amplitude de $0,3 \%$ no set-point da composição do produto de topo no instante $t$ $=100$ minutos. Na segunda, foi aplicado um degrau com amplitude de 0,3\% no set-point da composição do produto de fundo no instante $t=100 \mathrm{~min}$. Os resultados são apresentados na Figura 5.23. 
(a)

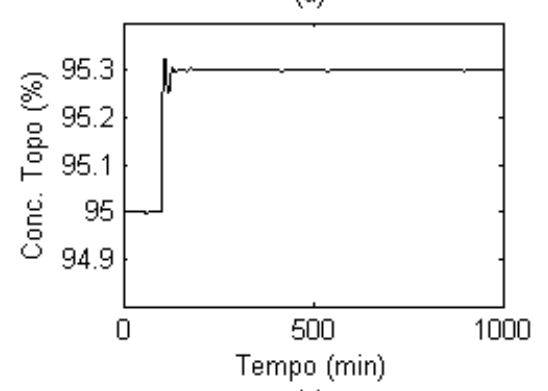

(c)

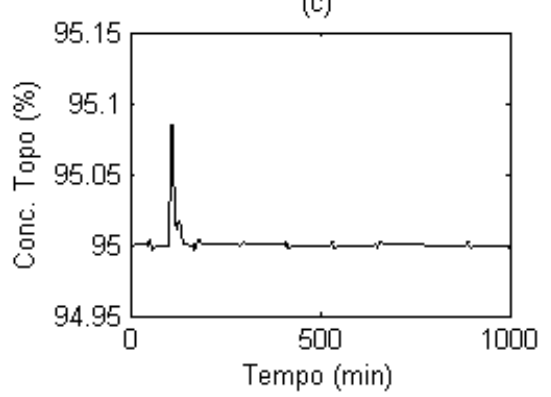

(b)

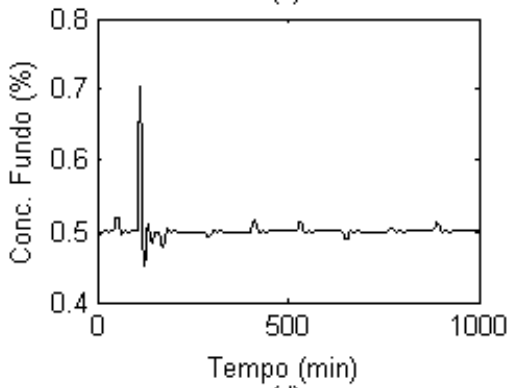

(d)

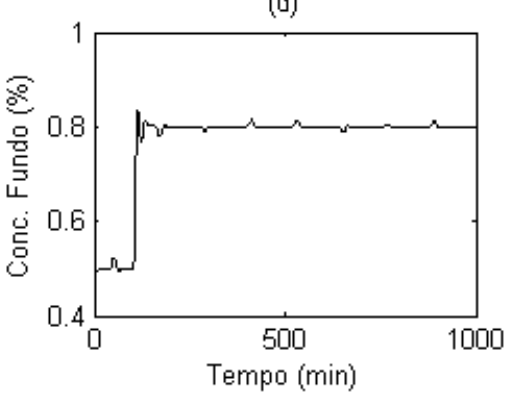

Figura 5.23 - (a,b) Respostas ao degrau no set-point da concentração de topo; (c,d) Resposta ao degrau no set-point da concentração de fundo. (Autor).

Analisando-se a Figura 5.23, é possível verificar que a matriz de ganhos para esse sistema é igual à matriz identidade. Tal comportamento mostra que os controladores PID geram um desacoplamento (em estado estacionário) das malhas. É importante observar o fato de que a existência de um zero na matriz de ganhos não necessariamente significa que não existe modelo.

Para avaliar o algoritmo PLS-PH foram identificados dois modelos para o sistema planta + controlador. No primeiro, chamado de modelo completo, foram considerados modelos de terceira ordem para todos os elementos da matriz de transferência. No segundo, chamado de modelo diagonal, foram identificadas exclusivamente as funções de transferência de terceira ordem para os elementos localizados na diagonal principal, considerando os demais modelos identicamente nulos. A escolha de terceira ordem dos modelos decorreu da escolha de um modelo de segunda ordem para a planta e de primeira ordem para os controladores PI. Para a realização da identificação, o horizonte de predição foi definido como 30 e o número de componentes principais foi igual a 3. 
Os modelos identificados foram utilizados no controlador MPC da planta, com o qual foram realizados dois ensaios. No primeiro, foi dado um degrau de $1 \%$ no set-point da concentração do produto de topo. No segundo, o set-point da concentração de fundo foi reduzido em $0,2 \%$. Nestes ensaios, foi incluída uma perturbação periódica decorrente da variação da carga da coluna. Estes dois cenários foram reproduzidos considerando os dois modelos identificados e também um modelo representado exclusivamente pela matriz de ganhos estacionários do sistema, que é a matriz identidade, como pode ser constatado pela figura 5.23. Os resultados dessas simulações são apresentados nas figuras 5.24 a 5.27 .
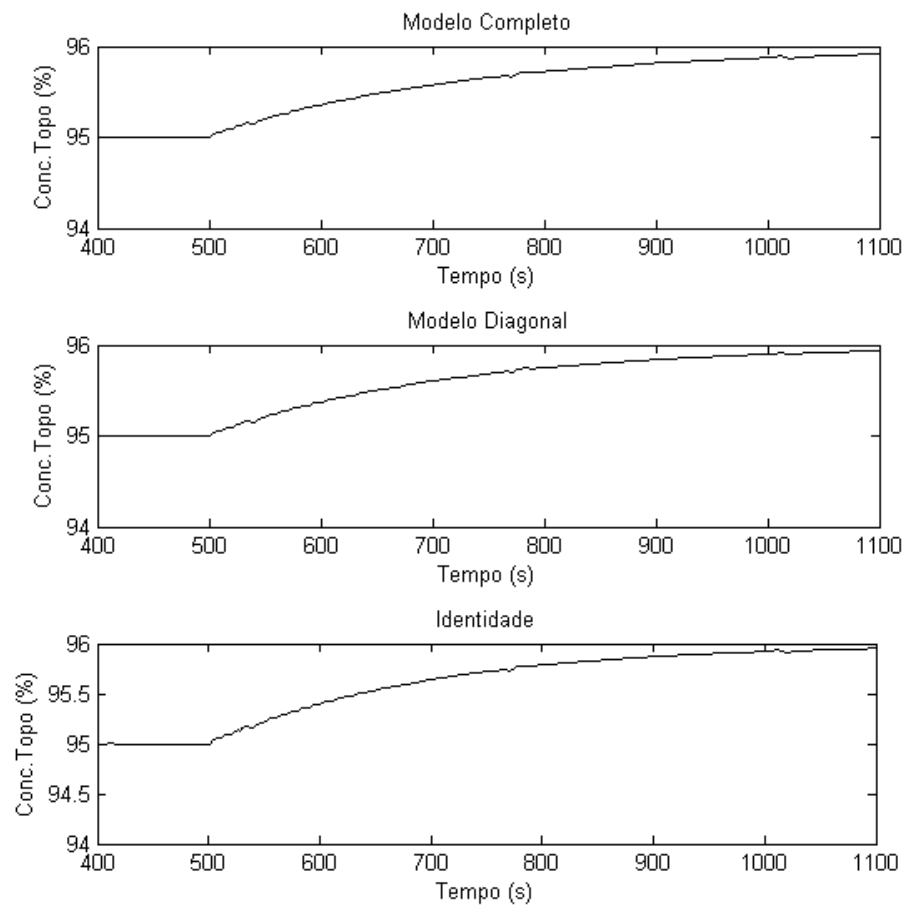

Figura 5.24 - Variação da composição de topo decorrente de alteração no set-point da composição de topo com o MPC ligado utilizando diferentes modelos. (Autor) 

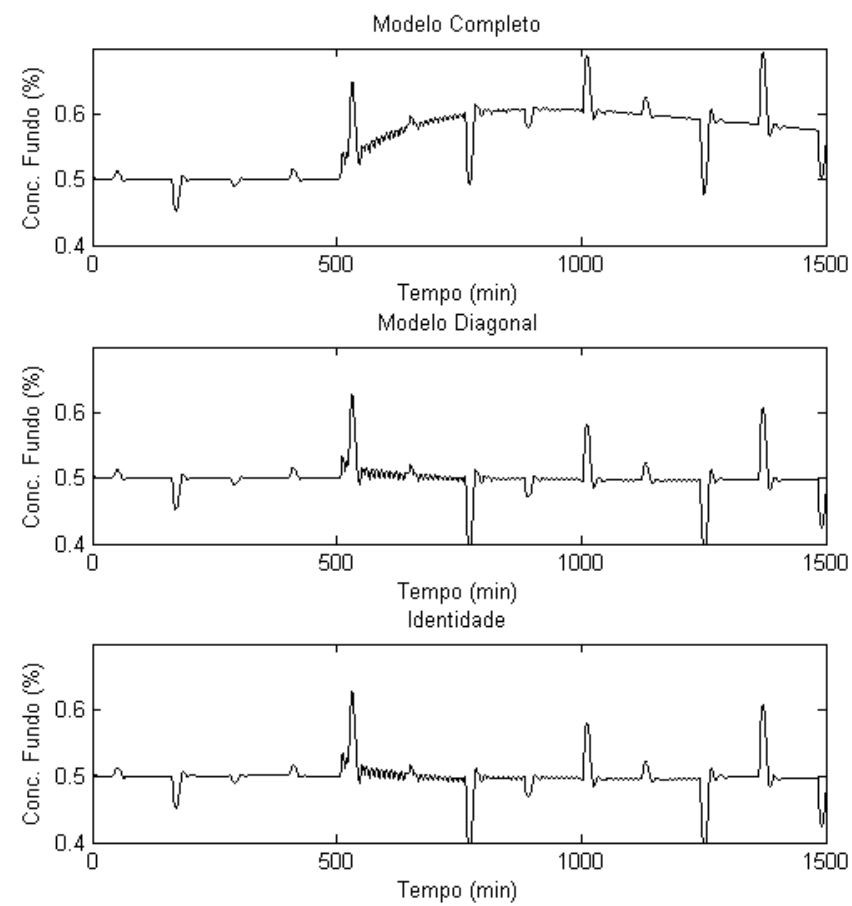

Figura 5.25 - Variação da composição de fundo decorrente de alteração no set-point da composição de topo com o MPC ligado utilizando diferentes modelos. (Autor)
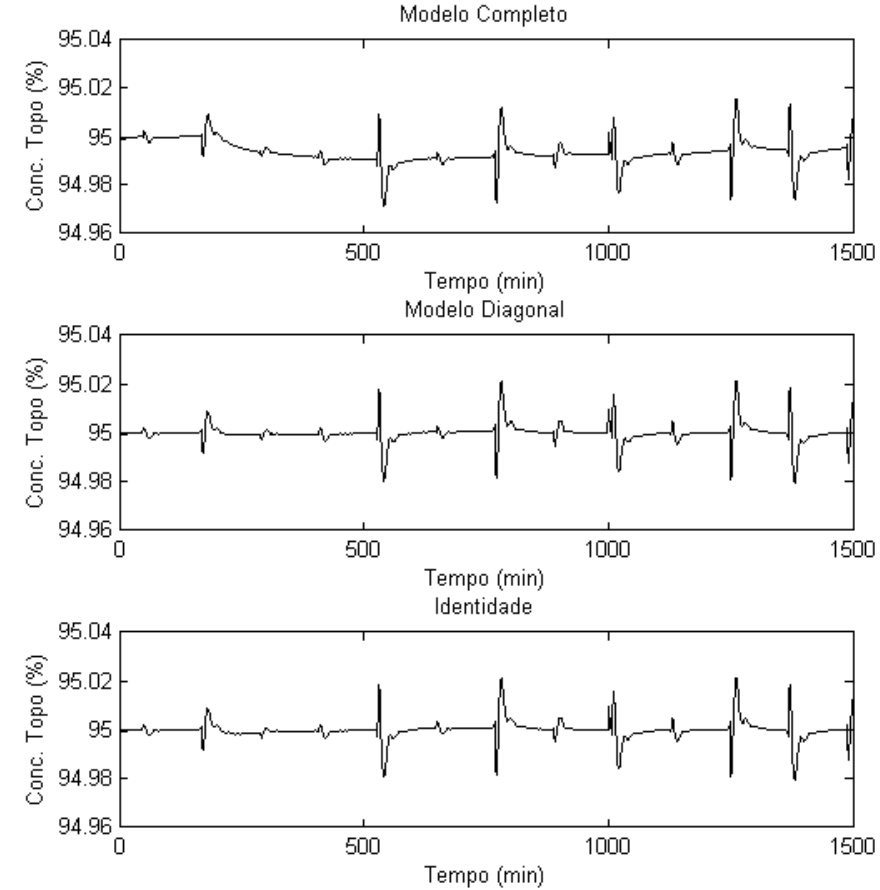

Figura 5.26 - Variação da composição de topo decorrente de alteração no set-point da composição de fundo com o MPC ligado utilizando diferentes modelos. (Autor) 

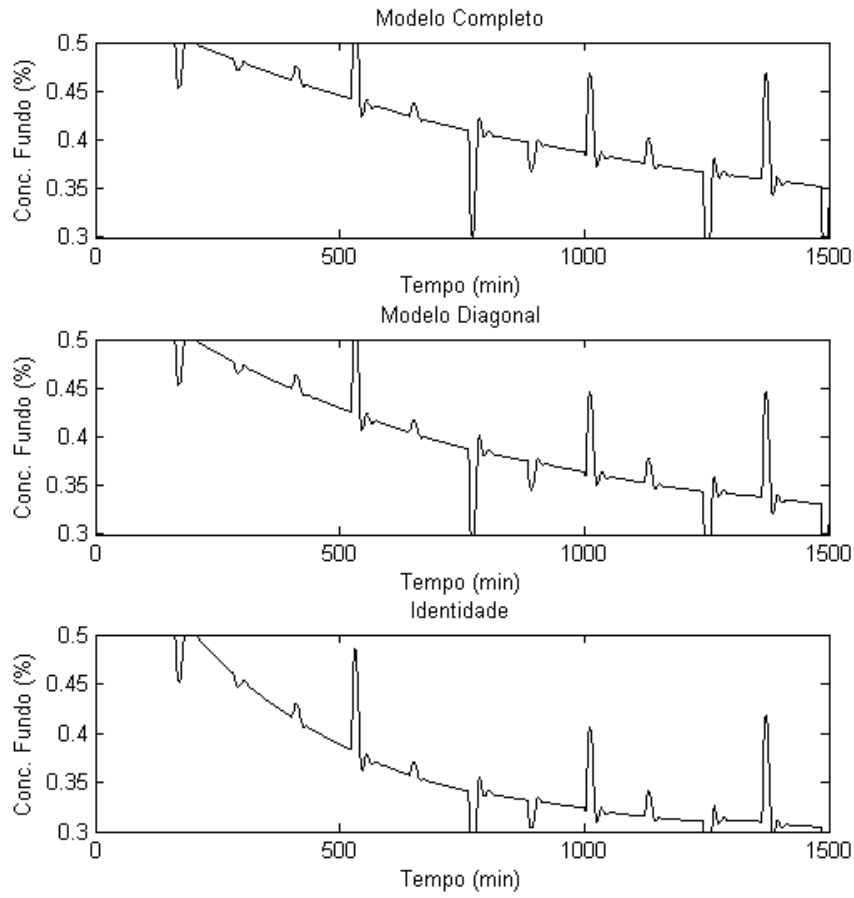

Figura 5.27 - Variação da composição de fundo decorrente de alteração no set-point da composição de fundo com o MPC ligado utilizando diferentes modelos. (Autor)

Em todos os casos, independente do modelo utilizado, é possível verificar que o modelo implementado no controlador MPC desempenhou um papel satisfatório, pelo fato dos modelos terem alterado o set-point do sistema, respeitando as restrições impostas, que são os requisitos mínimos do controlador. Entretanto, ao comparar o desempenho do controlador com os diferentes modelos, é possível perceber que o modelo onde a matriz de transferência era cheia apresentou uma resposta mais lenta para os dois cenários. Além disso, no primeiro cenário foi possível verificar um maior tempo para que a composição de fundo começasse a retornar ao seu set-point.

Ao analisar o desempenho do modelo diagonal, é possível verificar um desempenho similar ao modelo da matriz de ganhos para a variação do setpoint da composição de topo. Entretanto, no segundo cenário, esse modelo apresentou um desempenho inferior ao observado para o modelo da matriz de ganhos, que apresentou menor tempo de resposta. 
É importante notar que o modelo da matriz de ganhos, por não apresentar nenhuma dinâmica do sistema, deveria apresentar um desempenho inferior ao observado pelos modelos identificados pelo algoritmo PLS-PH. Portanto, a fim de avaliar o mau desempenho dos modelos identificados, foram aplicados degraus unitários, não-simultâneos, nos dois modelos. As respostas dos modelos são apresentadas nas figuras 5.28 e 5.29 .

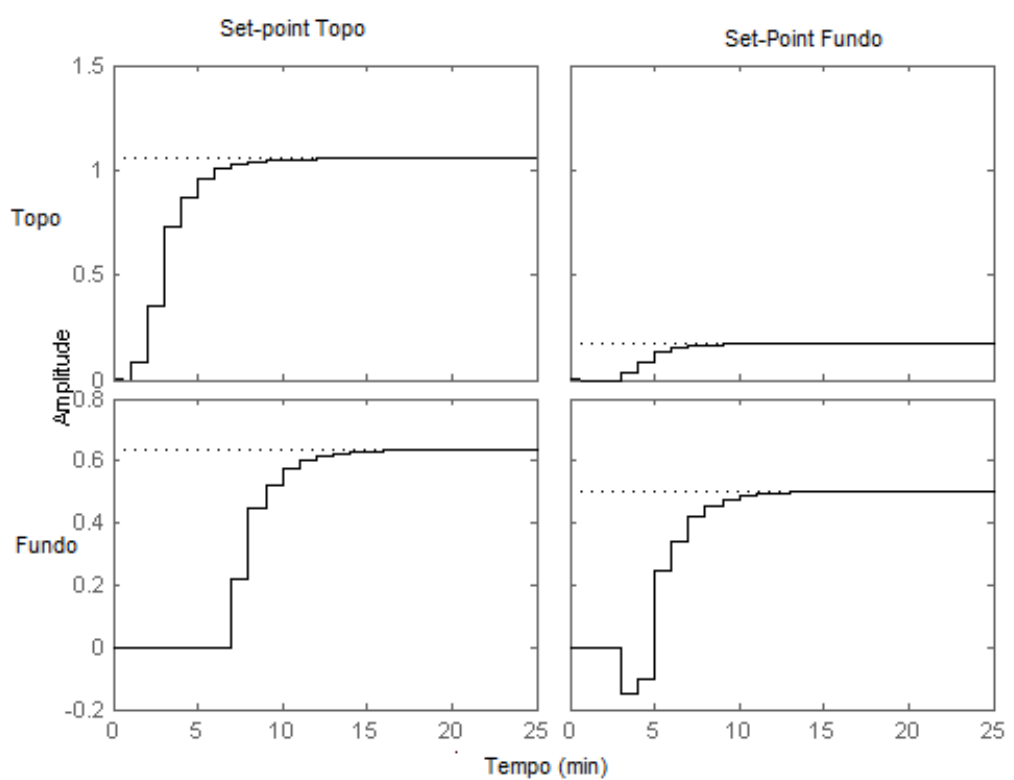

Figura 5.28 - Resposta ao degrau unitário para o modelo completo.(Autor) 


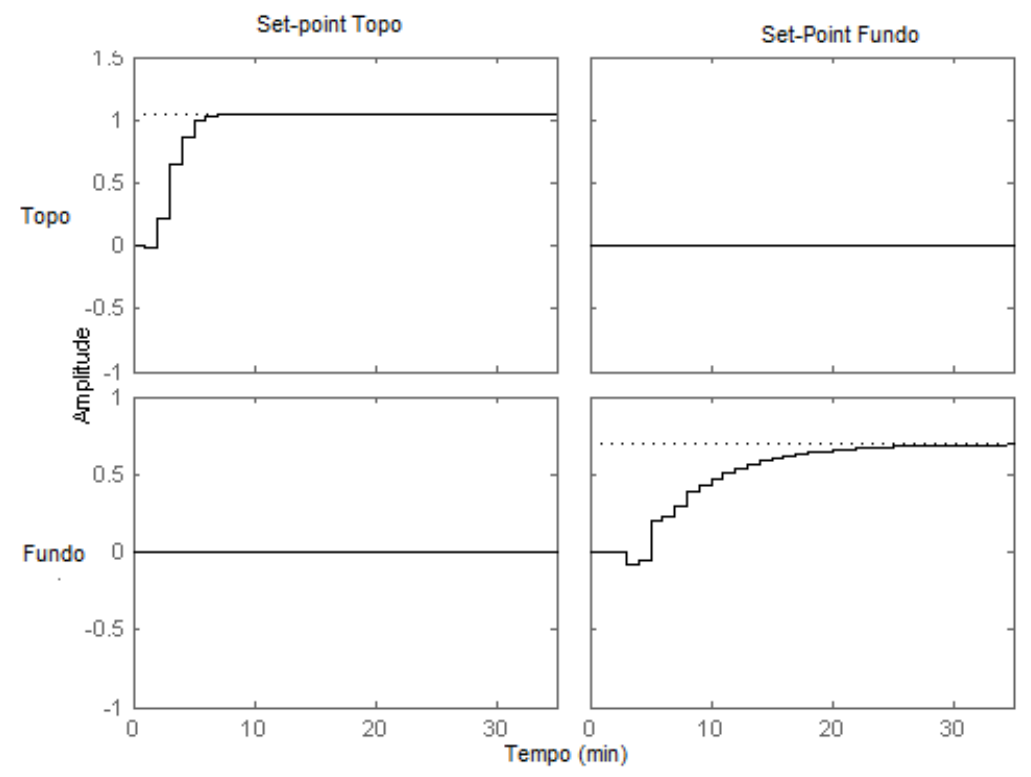

Figura 5.29 - Resposta ao degrau unitário para o modelo diagonal. (Autor)

A partir das respostas ao degrau, é possível constatar que os modelos foram incapazes de corretamente estimar os ganhos da planta. Uma razão para esse fenômeno é que, no algoritmo PLS-PH, os dados de entrada e saída devem ser centrados e escalados. Assim, todos os dados utilizados na identificação possuem média nula e desvio padrão igual a 1 . Como essa normalização é realizada independentemente em cada entrada e saída, as informações de ganho das variáveis são perdidas, não sendo, portanto, incluídas nos modelos. $\mathrm{Na}$ ausência de um modelo da na matriz de transferência, o algoritmo PLS-PH pode identificar um modelo com elevado ganho, em virtude da normalização dos dados. Assim, é importante informar ao algoritmo os zeros da matriz de transferência.

Outro ponto de atenção foi a identificação de modelos com resposta inversa para a resposta de fundo. O algoritmo PLS-PH executa uma busca sem restrições. Assim, da mesma maneira que o modelo encontrado apresentou resposta inversa, não existe nenhuma restrição no algoritmo impedindo a identificação de modelos instáveis. 


\subsection{Conclusão}

A partir dos resultados apresentados neste capítulo, é possível afirmar que:

- Para horizontes de predição mais elevados, o algoritmo PLS-PH apresentou um critério fit maior e um parâmetro $J_{L R P I}$ menor que aqueles dos modelos identificados utilizando o algoritmo MPEM;

- O algoritmo PLS-PH apresentou certa robustez para identificar modelos quando a estimativa do tempo morto era errada;

- O algoritmo PLS-PH apresentou menor desvio padrão na identificação dos modelos quando comparados com os modelos identificados pelo MPEM;

- O algoritmo PLS-PH, da maneira que foi proposto, é incapaz de realizar uma identificação correta dos ganhos do sistema. Assim, os modelos por ele identificados necessitam de uma correção de ganho antes de poderem ser aplicados a controladores MPC.

- Os modelos retornados pelo algoritmo PLS-PH podem apresentar resposta inversa, indicando que a otimização realizada pelo algoritmo não apresenta restrições.

Assim, existem indícios de que o algoritmo PLS-PH apresente desempenho superior aos algoritmos MPEM para a identificação da dinâmica de sistemas. Entretanto, para poder ser aplicado em controladores MPC, é necessária a implementação de uma correção de ganhos no modelo. 


\section{IDENTIFICAÇÃO DE SISTEMAS NARX POLINOMIAIS}

Diferente dos demais capítulos desta dissertação, em que o enfoque principal é a identificação de sistemas lineares, no presente capítulo é apresentada uma aplicação do algoritmo PLS-PH para a identificação de sistemas não-lineares com a estrutura NARX polinomial. São apresentadas algumas características dos principais algoritmos para a identificação de sistemas com esta estrutura. Em seguida, é realizada uma análise teórica relacionada à aplicação do algoritmo PLS-PH para a identificação de sistemas com esta estrutura. Por fim, é apresentado um estudo para a identificação de um forno elétrico.

A análise apresentada neste capítulo restringiu-se exclusivamente ao caso SISO. Uma versão resumida dos resultados deste capítulo foi apresentada em (QUACHIO; GARCIA, 2011a).

\subsection{Modelos NARX Polinomiais}

NARX (Nonlinear AutoRegressive with eXogenous input) é o nome dado à família de modelos que possuem a estrutura dada por:

$$
y(t)=F^{l}\left(y(t-1), \ldots, y\left(t-n_{a}\right), u\left(t-n_{k}\right), \ldots, u\left(t-n_{b}-n_{k}\right)\right)+e(t)
$$

em que $F^{l}: R^{n} \rightarrow R$ é uma função não-linear.

Ao analisar em maior detalhe esta estrutura, verifica-se um caráter muito genérico. De fato, tal estrutura só pode ser utilizada caso se possua algum conhecimento sobre o processo. Segundo (CHEN; BILINGS; LUO; 1989), qualquer modelo não-linear pode ser aproximado por uma função polinomial. 
Considerando esta aproximação, uma estrutura que passa a ter grande interesse são as estruturas do tipo NARX polinomiais, apresentada em (AGUIRRE, 2007), que possuem o formato dado por (6-2).

$$
y(t)=\sum_{j=1}^{l} \sum_{n_{a}=1}^{n} \sum_{n_{b}=1}^{m} \theta_{i, j, k} \prod_{a=0}^{j}\left(y\left(t-n_{a}\right)\right) \prod_{b=0}^{l-j}\left(u\left(t-n_{b}\right)\right)+e(t)
$$

Além de possuir uma estrutura mais específica que a definida em (6-1), é possível observar dois aspectos:

- Se $l=1$, então o modelo coincide com um modelo de estrutura ARX. Por esta razão, o parâmetro / é conhecido como grau de não-linearidade do modelo.

- Este modelo é estruturado como um somatório de termos com a forma dada por (6-3).

$$
\sum_{n_{b}=1}^{m} \theta_{i, j, k} \prod_{a=0}^{j}\left(y\left(t-n_{a}\right)\right) \prod_{b=0}^{l-j}\left(u\left(t-n_{b}\right)\right)
$$

Ora, sabendo que $\theta_{i, j, k}$ são os parâmetros do modelo, então é possível escrever a equação (6-2), na forma:

$$
y(t)=\boldsymbol{\theta} \cdot \boldsymbol{x}(t)+e(t),
$$

em que os elementos do vetor $\boldsymbol{x}(t)$, são expressos por:

$$
\prod_{a=0}^{j}\left(y\left(t-n_{a}\right)\right) \prod_{b=0}^{l-j}\left(u\left(t-n_{b}\right)\right)
$$

Assim, uma das grandes vantagens dos modelos NARX polinomiais consiste no fato que eles podem ser obtidos por meio da resolução de um problema de regressão linear. 


\subsection{Métodos de identificação para modelos NARX polinomiais}

Segundo (CHEN; BILLINGS; LUO, 1989), existem três categorias de algoritmos para realizar a identificação de sistemas com a estrutura NARX polinomial. Esses métodos são descritos nas subseções a seguir.

\subsubsection{Método dos mínimos quadrados}

Em razão da estrutura do problema recair em uma regressão linear, é possível a aplicação direta do método dos mínimos quadrados. Como analisado no capítulo 2, a resolução deste problema está relacionada com a inversão de uma matriz simétrica. A regressão pode ser numericamente resolvida aplicando diretamente o método da decomposição de Gauss ou a decomposição de Cholesky. CHEN; BILLINGS; LUO (1989) afirmam que a resolução de um problema NARX polinomial pode possuir elevada correlação entre os regressores. Também é afirmado que estes dois métodos são muito suscetíveis a erros de truncamento, podendo assim apresentar erros na determinação dos vetores.

\subsubsection{Métodos dos mínimos quadrados ortogonais}

Uma alternativa aos métodos propostos em 6.2.1 consiste em escolher um método de inversão matricial que seja menos sensível a erros de truncamento. Tal objetivo é atingido quando a matriz de regressores é reescrita utilizando uma base ortogonal. Deste modo, o problema de regressão na nova base pode ser reescrito como:

$$
\boldsymbol{y}=\boldsymbol{\Omega} \cdot \boldsymbol{g}+\boldsymbol{e}(\boldsymbol{t})
$$

em que: 
$\mathbf{\Omega} \quad$ Matriz de regressores na base ortogonal;

g Vetor de parâmetros de regressão na base ortogonal.

Alguns métodos para a resolução desse problema são o método de ortogonalização de Gram-Schimdt (GS), o método modificado de GramSchimdt (MGS) e o método de Golub-Householder (GH). O princípio de resolução desses métodos consiste em reescrever a matriz de regressores em uma base ortogonal. Os algoritmos de resolução são apresentados em detalhe em (AGUIRRE, 2007).

Uma comparação entre esses métodos, apresentada em (CHEN; BILLINGS; LUO, 1989) indica que o método GS, em virtude de problemas de truncamento, pode gerar decomposições não ortogonais. Ao comparar os métodos MGS e $\mathrm{GH}$, observa-se que ambos possuem um desempenho similar em precisão numérica e em complexidade algorítmica.

É importante ressaltar que, notadamente os métodos GS e MGS, por serem baseados em um conjunto de projeções ortogonais, possuem alguma similaridade com o algoritmo PLS apresentado no capítulo 2. É importante ressaltar que essa similaridade é meramente estrutural, visto que, enquanto os métodos dos mínimos quadrados ortogonais preocupam-se exclusivamente com a decomposição a partir da matriz de regressores, aplicando os resultados da decomposição ao vetor de saídas apenas a posteriori, o algoritmo PLS preocupa-se com a decomposição simultânea desses dois elementos.

\subsubsection{Métodos baseados em valores singulares}

Uma terceira categoria de métodos apresentada em (CHEN; BILLINGS; LUO, 1989) é a utilização da decomposição em valores singulares. Por meio destes métodos é possível resolver o problema de regressão realizando a decomposição:

$$
\boldsymbol{X}=\mathbf{T} \cdot \boldsymbol{\Sigma} . \boldsymbol{V}
$$


em que as matrizes $\mathbf{T}$ e $\boldsymbol{V}$ são ortogonais, e $\boldsymbol{\Sigma}$ é uma matriz diagonal contendo os valores singulares da matriz X. A partir de (6-7), é possível determinar a pseudo-inversa $\boldsymbol{X}^{+}$a partir da matriz de regressores.

$$
X^{+}=V^{T} \cdot \Sigma^{-1} \cdot T^{T}
$$

Utilizando a pseudo-inversa, o problema de regressão pode ser reescrito como:

$$
\boldsymbol{\theta}=\boldsymbol{X}^{+} \cdot \boldsymbol{y}
$$

\subsection{Métodos de redução da matriz de regressores}

Uma característica compartilhada pelos métodos discutidos é que todas as colunas da matriz de regressores são utilizadas para realizar a identificação. Quando os modelos possuem uma estrutura NARX polinomial, é possível observar uma explosão combinatória do número de colunas da matriz de regressores, em função do aumento da ordem de não-linearidade do sistema. Por exemplo, ao considerar um sistema SISO que considera as últimas 10 entradas e as últimas 10 saídas para identificar um sistema linear, o número de regressores será igual a 20. Para identificar um sistema com grau de nãolinearidade 3 utilizando as mesmas entradas e saídas, o número de regressores a ser utilizado será igual a 1771 (CHEN; BILLINGS; LUO, 1989). Assim, a fim de possibilitar a identificação de tais sistemas, são utilizados

métodos de seleção de regressores em combinação com os algoritmos de identificação descritos anteriormente. O método provavelmente mais utilizado, desenvolvido para ser utilizado em conjunto com os métodos de mínimos quadrados ortogonais, é a taxa de redução do erro (ERR, Error Reduction Ratio).

Esse método tem por base verificar a redução da variância do resíduo $\varepsilon(t)$, em virtude da inclusão de um novo parâmetro de regressão obtido pela representação em bases ortogonais (6-6). Segundo Aguirre (2007), o ERR para a inclusão do parâmetro de regressão $i$ pode ser calculado como: 


$$
[E R R]_{i}=\frac{g_{i}^{2} \mathbf{\Omega}_{i}^{T} \boldsymbol{\Omega}_{\boldsymbol{i}}}{\boldsymbol{y}^{T} \boldsymbol{y}}
$$

em que:

$[E R R]_{i} \quad$ Taxa de redução do erro gerado pela inclusão do parâmetro de regressão $i$;

$g_{i} \quad$ Parâmetro de regressão $i$;

$\boldsymbol{\Omega}_{\boldsymbol{i}} \quad$ Coluna da matriz de regressores referente ao parâmetro $i$.

Após a realização da regressão utilizando bases ortogonais, para cada parâmetro de regressão obtido é realizado o cálculo do ERR e em seguida são escolhidos os regressores que apresentem maior valor de ERR. A partir dessa seleção, ao invés de utilizar o modelo completo, são utilizados apenas os regressores escolhidos, solucionando assim o problema da explosão combinatória.

\subsection{Identificação não-linear com o algoritmo PLS-PH}

Conforme observado na equação (6-4), os modelos com estrutura NARX polinomiais podem ser escritos como um problema de regressão linear. Outro ponto relevante é o mau-condicionamento numérico da matriz de regressores, apresentado em (CHEN; BILLINGS; LUO, 1989). Ao combinar essas duas características, é possível destacar o algoritmo PLS-PH como um candidato para a resolução do problema de identificação. Para avaliar a capacidade do algoritmo PLS-PH em identificar modelos com a estrutura NARX polinomial, foi realizada a identificação do modelo de um forno elétrico, identificado em RODRIGUES, et al. (1996). Os dados para essa identificação foram disponibilizados em (AGUIRRE, 2011). O arquivo de dados é composto por 4 séries dados entrada e saída, denominadas F-0307, F-0407, F-0707 e F13072. 
Esse sistema possui uma entrada, a porcentagem da potência elétrica máxima de alimentação dos resistores de aquecimento do forno, e tem como saída a temperatura no interior do forno. Como a transmissão de calor no interior no forno é realizada principalmente por um processo de irradiação, que é um fenômeno majoritariamente não-linear, não se recomenda a utilização de um modelo linear para representá-lo.

Dentre os dados foram escolhidas duas séries de dados F-407, para a realização da identificação, e F-307 para a validação. Estas séries foram escolhidas por terem sido utilizadas em (RODRIGUES; et al., 1996), e são apresentadas nas figuras 6.1 e 6.2 .
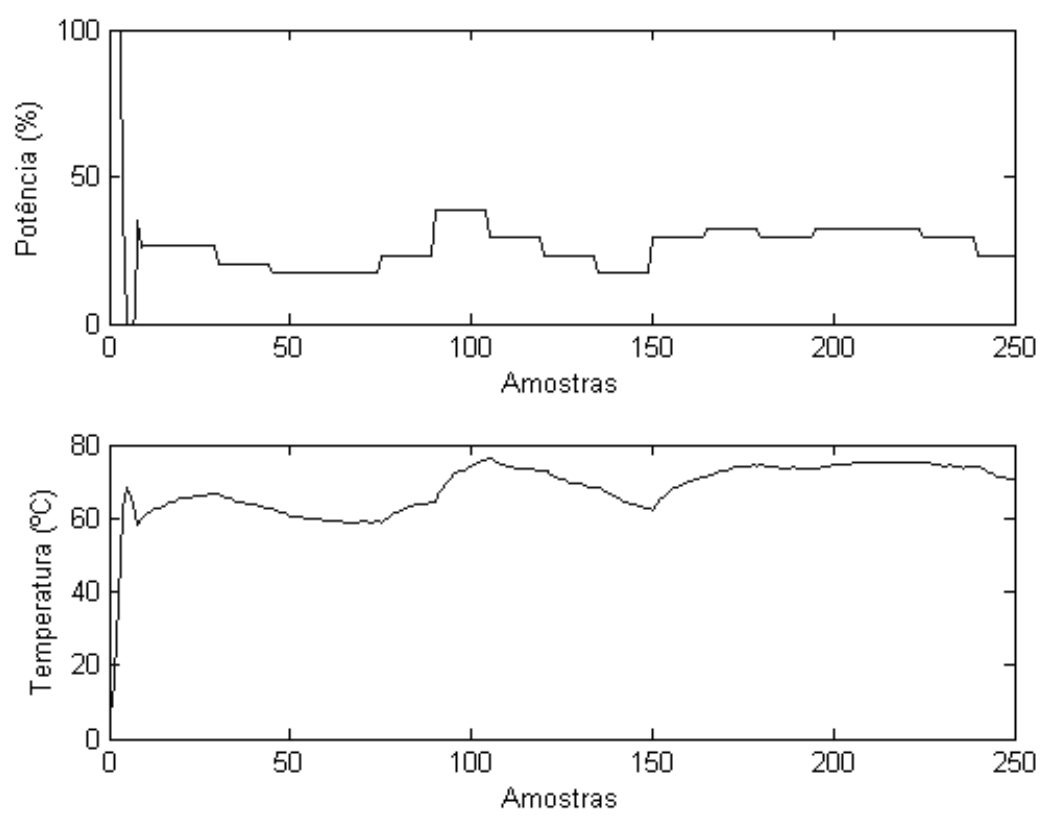

Figura 6.1 - Série de dados de identificação F-407. (Fonte: AGUIRRE (2011)) 

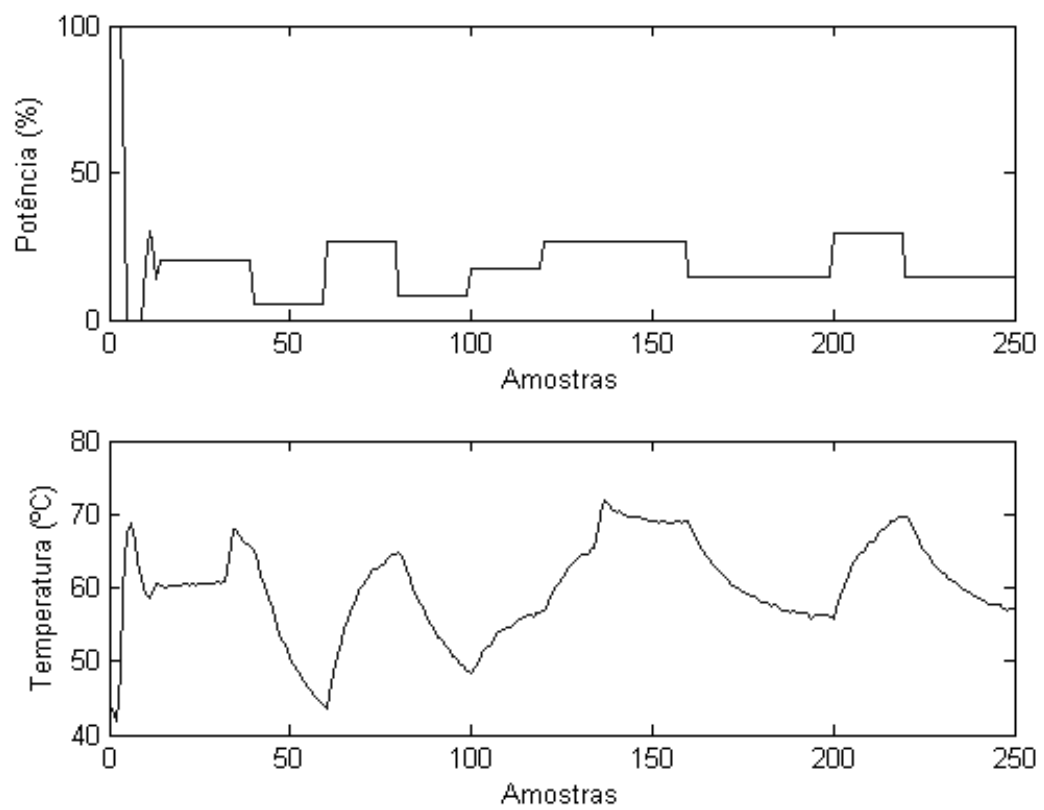

Figura 6.2 - Série de dados de validação F-307. (Fonte: AGUIRRE (2011))

A partir desses dados, foram escolhidos os seguintes parâmetros do modelo:

- Grau de não-linearidade: 2;

- Atraso máximo da entrada: 2;

- Atraso máximo da saída: 2.

Com tais parâmetros, a estrutura escolhida para o modelo totaliza 14 parâmetros. A escolha desses parâmetros foi realizada para que pudessem ser verificadas as características de dinâmica e não linearidade, sem que o número de parâmetros fosse muito elevado. O modelo escolhido possui a estrutura dada por (6-11):

$$
\begin{aligned}
y(t)=\sum_{i=1}^{2} a_{i} y(t-i)+\sum_{i=1}^{2} b_{i} u(t-i)+\sum_{i=1}^{2} \sum_{j=1}^{2} c_{i, j} y(t-i) y(t-j)+ \\
+\sum_{i=1}^{2} \sum_{j=1}^{2} d_{i, j} u(t-i) u(t-j)+\sum_{i=1}^{2} \sum_{j=1}^{2} f_{i, j} y(t-i) u(t-j)+ \\
+e(t)
\end{aligned}
$$


A partir da estrutura definida em (6-11) e dos dados do conjunto F-407 foi construída a matriz de regressores $\boldsymbol{X}$. Para realizar a identificação utilizando o algoritmo PLS-PH, é necessário determinar o número de componentes principais. Para tal, na Figura 6.3 são apresentados os valores principais normalizados da matriz de regressores.

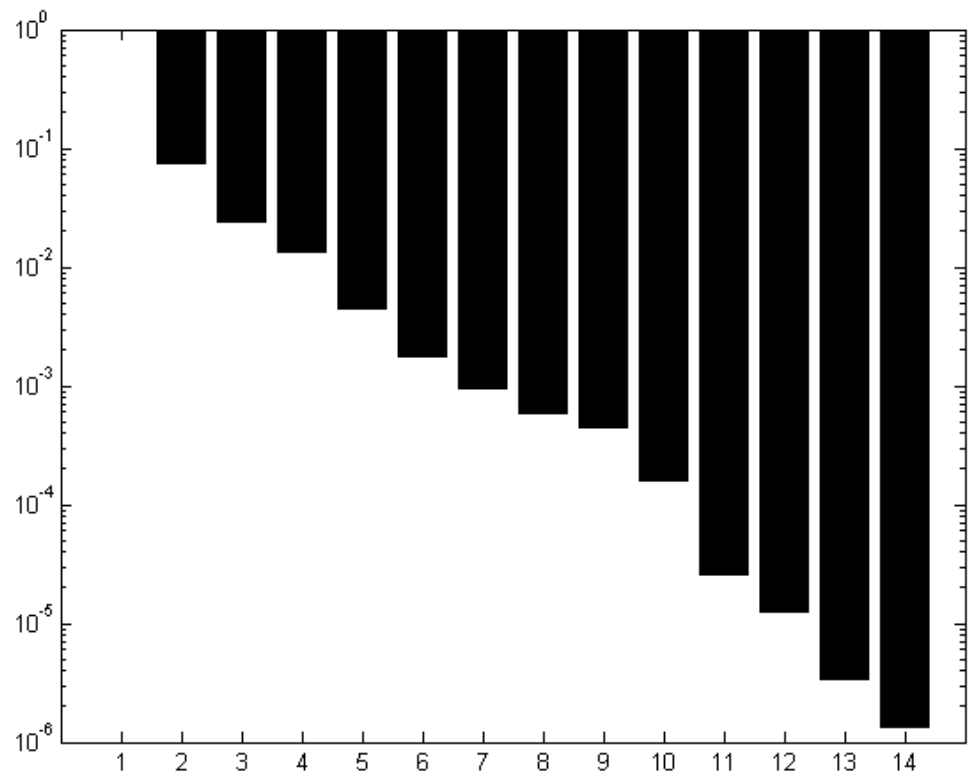

Figura 6.3 - Valores singulares normalizados da matriz de regressores. (Autor)

É possível notar, por inspeção visual, uma redução ligeiramente mais acentuada nos valores singulares superiores a 9. Por esta razão, o número de componentes principais escolhido para a execução do algoritmo PLS-PH foi igual a 9. É importante notar que, apesar do número de componentes principais escolhido ser inferior ao número de parâmetros da estrutura, o modelo identificado pelo algoritmo PLS-PH continua possuindo a estrutura pré-definida.

Com a estrutura e o número de componentes principais definidos, foi realizada a identificação para os horizontes de predição iguais a 1 e 12 passos. Os modelos identificados foram respectivamente: 


$$
\begin{array}{rl}
y(t)= & 0,4646 \cdot y(t-1)+0,4638 \cdot y(t-2)+0,1637 \cdot u(t-1) \\
& +0,168 \cdot u(t-2)+0,004374 \cdot y^{2}(t-1) \\
& -0,002079 \cdot y^{2}(t-2)-0,001762 \cdot y(t-1) \cdot y(t-2) \\
& +0,001343 \cdot u^{2}(t-1)+0,003363 \cdot u^{2}(t-2) \\
& -0,004747 \cdot u(t-1) \cdot u(t-2) \\
& -1,015 \cdot 10^{-5} \cdot y(t-1) \cdot u(t-1) \\
& -3,097 \cdot 10^{-4} \cdot y(t-2) \cdot u(t-1) \\
& -0,003393 \cdot y(t-1) u(t-2) \\
& +2,372 \cdot 10^{-4} \cdot y(t-2) \cdot u(t-2)+e(t) \\
& \\
& +0,5897 \cdot u(t-2)+0,003241 \cdot y^{2}(t-1) \\
& +0,007908 \cdot y^{2}(t-2)-0,00891 \cdot y(t-1) \cdot y(t-2) \\
& +0,002203 \cdot u^{2}(t-1)-0,009465 \cdot u^{2}(t-2) \\
& +0,0079 \cdot u(t-1) \cdot u(t-2)-0,00948 \cdot y(t-1) \cdot u(t-1) \\
& -0,02258 \cdot y(t-2) \cdot u(t-1)+0,006094 \cdot y(t-1) u(t-2) \\
& -0,001973 \cdot y(t-2) \cdot u(t-2)+e(t) \\
0,4776 & y(t-1)+0,436 \cdot y(t-2)+0,5968 \cdot u(t-1) \\
&
\end{array}
$$

Para poder analisar os modelos obtidos, foram escolhidos dois modelos de referência apresentados em (RODRIGUES, et. al, 1996). Segundo esse trabalho, os melhores modelos obtidos a partir de uma série de experimentos são descritos pelas equações (6-14) e (6-15). Estes modelos são denominados Referência 1 e Referência 2, respectivamente.

$$
\begin{aligned}
& y(t)=0,44551 \cdot y(t-1)+0,57773 \cdot y(t-2)-0,63628 \cdot u(t-2) \\
&+ 0,486 \cdot u(t-1)-1,1458 \cdot 10^{-6} \cdot y^{2}(t-1) \cdot u(t-1) \\
&-9,9776 \cdot 10^{-5} \cdot y^{2}(t-2) \cdot u(t-3) \\
&-2,02710 \cdot 10^{-5} \cdot y^{3}(t-3)+7,8831 \cdot 10^{-3} \cdot y(t-2) \cdot u(t-2) \\
&-7,4386 \cdot 10^{-6} \cdot y^{2}(t-3) \cdot u(t-3)+e(t)
\end{aligned}
$$




$$
\begin{array}{rl}
y(t)=-0,96 & 659 \cdot y(t-1)+1,813 \cdot y(t-2)-0,01888 \cdot u(t-2) \\
& +0,7482 \cdot u(t-1)-5,6553 \cdot 10^{-5} \cdot y^{2}(t-1) \cdot u(t-1) \\
& -7,4452 \cdot 10^{-5} \cdot u^{3}(t-1)-1,1534 \cdot 10^{-4} \cdot y^{3}(t-2) \\
& +1,1699 \cdot 10^{-4} \cdot y^{3}(t-1)+e(t)
\end{array}
$$

É interessante notar que os modelos utilizados como referência possuem um grau de não-linearidade maior e consideram até três atrasos dos dados de entrada e saída, sendo esperado que eles possuam maior capacidade de representar as não-linearidades.

Com o objetivo de avaliar o desempenho dos modelos identificados foram realizadas as predições 1 e 12 passos à frente utilizando o modelo obtido pelo algoritmo PLS-PH, com o respectivo horizonte de predição, e os dois modelos de referência. Os resultados são apresentados nas figuras 6.4 e 6.5.

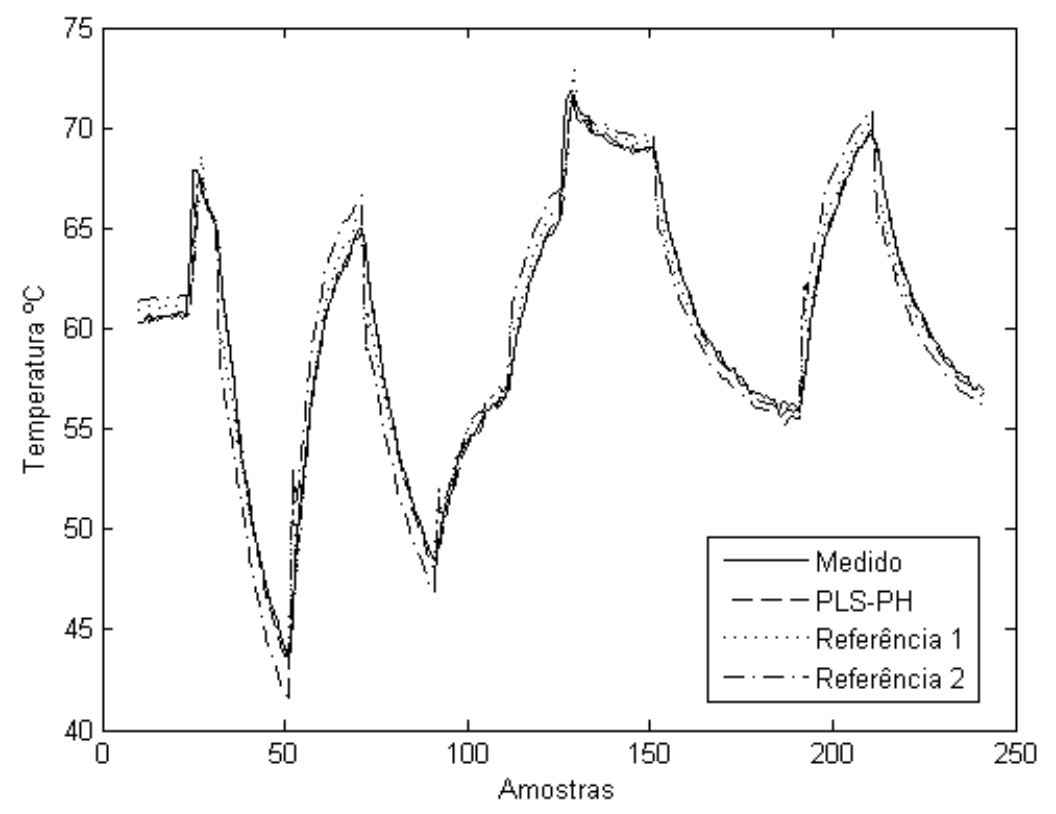

Figura 6.4 - Comparação entre os diferentes modelos para a predição 1 passo à frente. (Autor) 


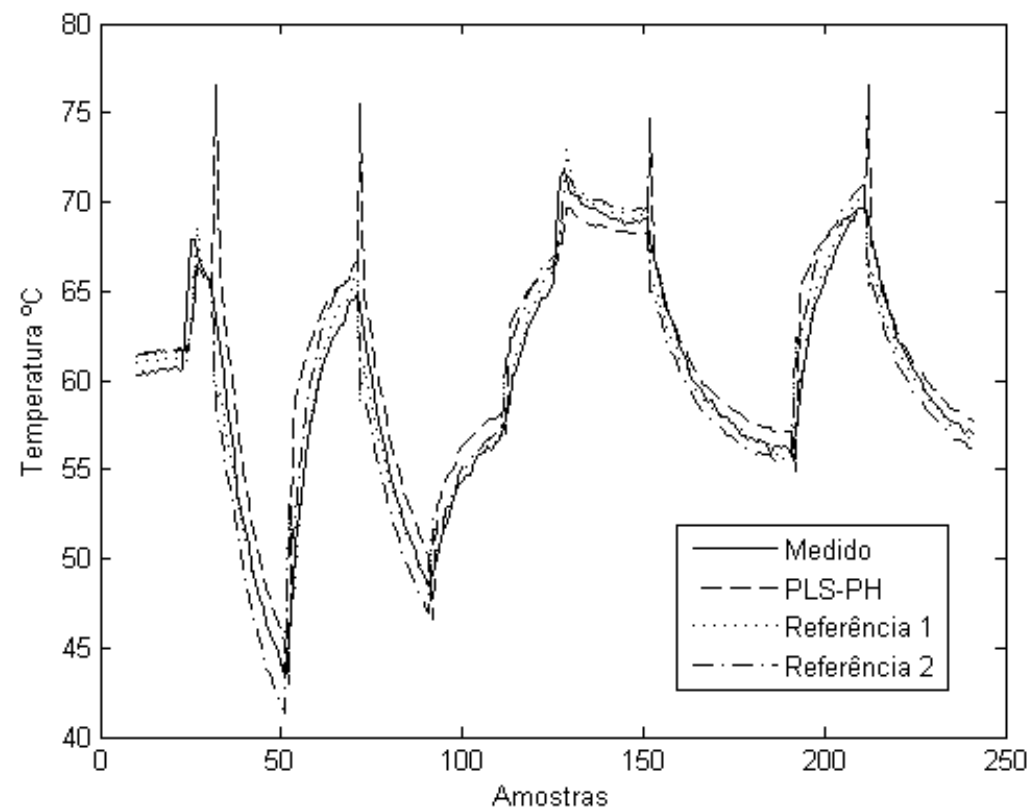

Figura 6.5 - Comparação entre os diferentes modelos para a predição 12 passos à frente. (Autor)

É possível verificar que para a predição 1 passo à frente, o modelo identificado pelo algoritmo PLS-PH apresentou um desempenho superior aos modelos de referência, pelo fato da curva de predições ficar mais próxima aos valores experimentais que os demais modelos. Entretanto, ao analisar o modelo PLS$\mathrm{PH}$ para a predição 12 passos à frente, é possível verificar respostas inversas de grande intensidade, principalmente quando estas decorrem de variações negativas no sinal de entrada. A fim de avaliar mais cuidadosamente esse comportamento, o modelo obtido pelo algoritmo PLS-PH para horizonte de predição igual a 12 foi excitado por uma onda quadrada. $\mathrm{O}$ resultado deste estímulo é apresentado na figura 6.6. 


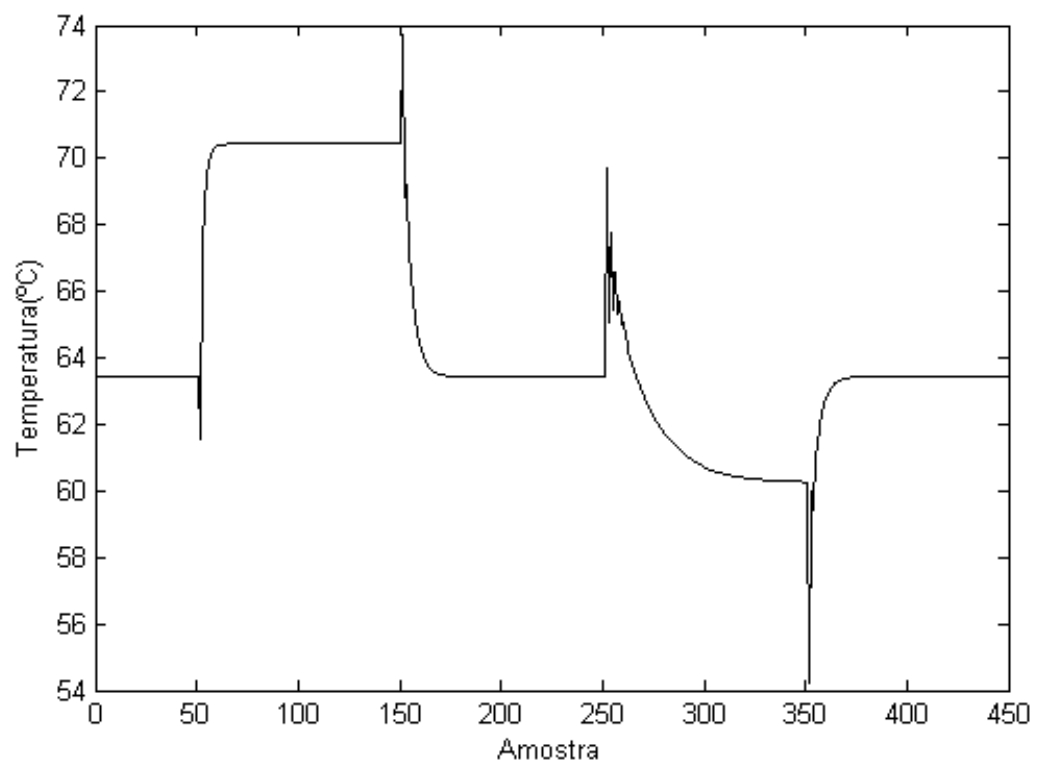

Figura 6.6 - Excitação do modelo PLS-PH obtido para horizonte de predição 12 por uma onda quadrada. (Autor)

Por meio da figura 6.6 é possível notar uma variação tanto na intensidade quanto na duração da resposta inversa, em função do diferente estado no qual o sistema se encontra. Um dos motivos para tal comportamento é o fato da identificação ter sido realizada sem a inclusão de restrições para os modelos identificados, de maneira que o modelo identificado pode ser instável ou apresentar características indesejáveis, como a presença de respostas inversas quando elas não existem.

Por fim, para avaliar o desempenho do algoritmo PLS-PH para diferentes horizontes de predição, utilizando o conjunto de dados F-407, é realizada a identificação de modelos múltiplos passos à frente para horizontes de predição variando entre 1 e 12 . Em seguida é calculada a função custo $J_{L R P I}$ para cada um dos horizontes de predição, utilizando o conjunto de dados F-307. De maneira análoga, para cada horizonte de predição, também são calculados os valores da função custo para os modelos de referência. $O$ resultado dessa análise é apresentado na figura 6.7. 


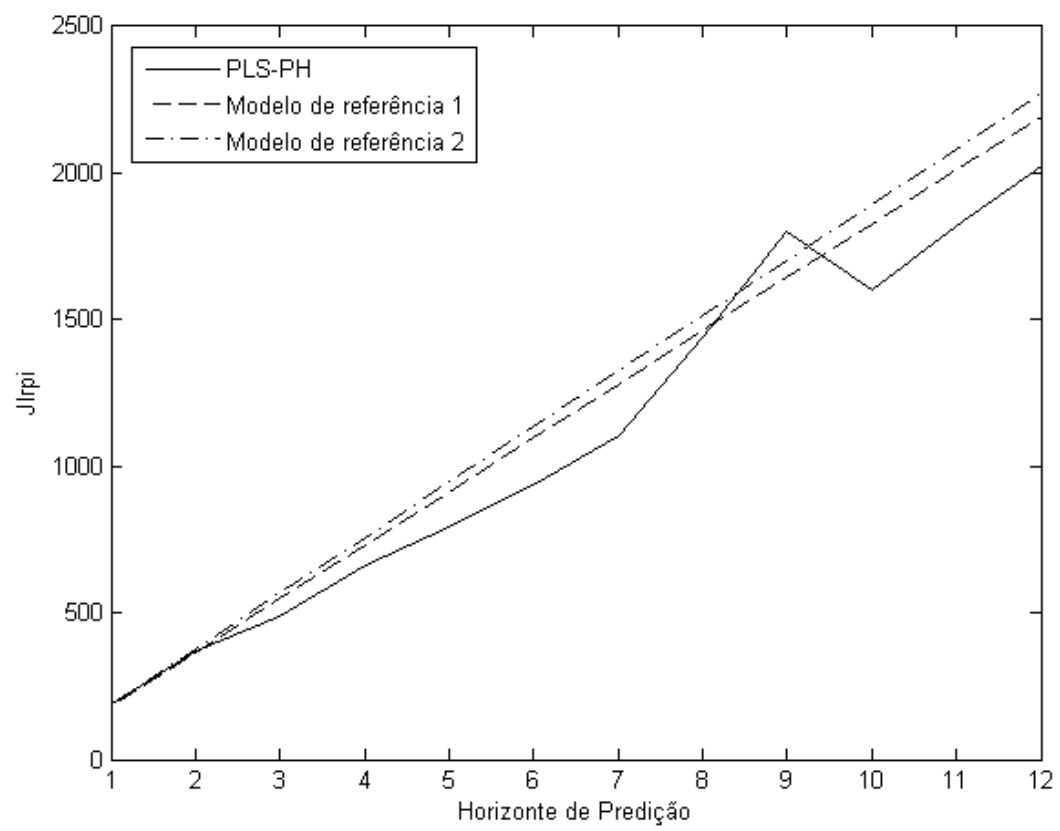

Figura 6.7 - Comparação do $J_{L R P I}$ entre os modelos de referência e os modelos identificados por PLS-PH. (Autor)

Ao analisar a figura 6.7, é possível verificar dois resultados distintos. A primeira constatação que pode ser feita é que para os horizontes de predição maiores, o algoritmo PLS-PH apresenta menores valores de $J_{L R P I}$. Esse resultado era esperado, afinal o algoritmo PLS-PH minimiza esta função custo para o horizonte de predição avaliado.

A segunda constatação decorre do resultado apresentado para os horizontes de predição 8 e 9. Conforme avaliado na primeira constatação, esperava-se que para estes dois horizontes de predição os valores de $J_{L R P I}$ obtidos pelo PLS-PH fossem inferiores aos valores obtidos pelos modelos de referência, o que não foi observado. Uma possível explicação para esse fenômeno decorre do fato de que o algoritmo PLS-PH é baseado na resolução de um problema de otimização não-linear, embora o algoritmo proposto por (LAURI, et al, 2010), implementado no presente trabalho, utilize um método de busca linear para a minimização. É importante notar que essa classe de algoritmos é aplicável para a resolução de problemas de otimização local, muito possivelmente podendo retornar o valor de mínimos locais, caso o problema de otimização não seja convexo. Assim, para os horizontes de predição 8 e 9, o algoritmo PLS-PH 
muito provavelmente está retornando valores de mínimos locais, ao invés de valores de mínimos globais.

\subsection{Conclusão}

A partir da análise apresentada neste capítulo, é possível constatar que o algoritmo PLS-PH constitui uma boa alternativa para a identificação de modelos com estrutura NARX polinomial para controladores NMPC (Nonlinear MPC).

Apesar de ser capaz de identificar modelos com relativa precisão, é importante notar que apesar de realizar a seleção de regressores, o modelo final encontrado possui o mesmo número de parâmetros que o previsto na estrutura completa. Dado que para modelos com estrutura NARX existe a explosão combinatória do número de parâmetros, os modelos identificados pelo PLS-PH apresentarão elevado número de parâmetros.

É importante também notar que existem melhorias que devem ser implementadas no algoritmo, notadamente a inclusão de restrições no problema de otimização e a utilização de algoritmos de otimização global. 


\section{CONCLUSÃO}

Por meio dos resultados apresentados ao longo da presente dissertação, observou-se que o fenômeno de multicolinearidade pode ocorrer com maior intensidade para identificação em malha fechada, justificando portanto a utilização de métodos de identificação baseados em algoritmos como o PLS$\mathrm{PH}$.

Foi possível constatar que para horizontes de predição longos, o algoritmo PLS-PH em geral apresentou melhores parâmetros fit e $J_{L R P I}$ em relação aos obtidos pelo método MPEM.

Um ponto que deve ser notado é o fato do algoritmo PLS-PH ter sido capaz de identificar modelos com desempenho satisfatório de acordo com as métricas escolhidas e elevada precisão mesmo na presença de erros na estimativa de tempo morto. Essa maior robustez em relação ao tempo morto apresenta uma grande vantagem em relação aos métodos MPEM.

Outro ponto de interesse do algoritmo PLS-PH foi a sua capacidade de identificar modelos MRI para sistemas não lineares com estrutura NARX polinomial. Todos os demais métodos de identificação MRI são baseados nas identificações PEM, sendo construídos exclusivamente para a identificação de modelos lineares. Assim, o PLS-PH é o único método de identificação facilmente adaptável para a identificação não-linear caixa preta.

Por outro lado, a necessidade de utilizar dados centrados e escalados faz com que o algoritmo PLS-PH seja incapaz de identificar com precisão os ganhos dos sistemas. Essa deficiência do algoritmo se reflete em duas características marcantes: primeiramente, os modelos possuem ganhos inadequados, de modo que, quando aplicados em controladores MPC, apresentam desempenho insatisfatório. Além disso, a presença de ganhos de pequena amplitude poderia ser indício da não existência de função de transferência para um dado par 
entrada-saída. O fato de utilizar dados centrados e escalados faz com que os ganhos do modelo identificado sejam comparáveis aos ganhos dos demais modelos, criando, portanto, um erro no modelo identificado. A fim de reverter esses problemas, deve ser aplicado um método de correção de ganho. Alternativamente, pode ser utilizado um método de detecção de modelos nulos na matriz de transferência para auxiliar na identificação exclusivamente dos pares corretos.

Outro ponto de atenção é o fato do algoritmo PLS-PH ser baseado em um método de otimização baseado em busca direta irrestrita. Esse método de otimização faz com que não existam garantias quanto à estabilidade do modelo ou identificação de resposta inversa, o que pode deteriorar o desempenho da malha de controle. Além disso, para a identificação de modelos não-lineares, diversas vezes foram encontrados modelos oriundos de mínimos locais e não globais.

Em suma, o algoritmo PLS-PH é um método de identificação MRI que apresenta boa capacidade para identificar as características dinâmicas do sistema em malha fechada, porém com grandes dificuldades para realizar a identificação do ganho dos modelos. Em virtude da grande quantidade de pontos de melhora existentes, pode-se afirmar que esse algoritmo apresenta grande potencial para a identificação de sistemas, porém ainda deve ser trabalhado para que esse potencial seja efetivamente concretizado.

\subsection{Perspectivas de Trabalhos Futuros}

Dentre as perspectivas de trabalhos futuros podem ser citadas:

- Comparação do algoritmo PLS-PH com outros métodos de identificação MRI: neste trabalho o algoritmo PLS-PH foi comparado exclusivamente com os algoritmos MPEM. Assim, uma linha de trabalho imediata seria a comparação do desempenho desse método com outros, como o método de dois passos ou o método EMPEM. 
- Melhoria nos modelos de perturbação: de acordo com (LAURI, et al., 2010) o método PLS-PH pode ser utilizado para identificar modelos CARIMA, desde que seja fornecido um modelo de perturbação do sistema. Uma maneira de explorar essa propriedade seria combinar o método PLS-PH com um método com grande capacidade de identificar modelos de perturbação, como é o caso do método de dois passos.

- Correcão dos ganhos do modelo: provavelmente o trabalho futuro mais crítico para permitir a aplicabilidade do método PLS-PH. Nessa linha de trabalho, devem ser estudadas maneiras de corrigir os ganhos identificados pelo algoritmo PLS-PH, para que estes modelos possam ser aplicados em controladores MPC.

- Melhoria da otimização do algoritmo PLS-PH: a fim de conferir maior estabilidade ao sistema e impedir problemas de convergências para mínimos locais, notadamente para identificação não-linear.

- Identificação de modelos MIMO não-lineares: esta linha de pesquisa teria por objetivo expandir os resultados obtidos no capítulo 6 para plantas multivariáveis e verificar a aplicabilidade dos modelos identificados em controladores NMPC. 


\section{REFERÊNCIAS}

AGUIRRE, L. A. Introdução a identificação de sistemas - técnicas lineares e não lineares. Disponível em: < http://www.cpdee.ufmg.br/ aguirre/livro/livro.htm >. Acesso em: 01/06/2011

AGUIRRE, L. A. Introdução a Identificação de sistemas - técnicas lineares e não lineares. $3^{\text {a }}$ ed. Belo Horizonte, Editora UFMG, 2007.

AMJAD, S.; AL-DUWAISH; H. N. Closed loop identification with model predictive control: a case study. In: SICE Annual Conference. Fukui, 2003.

ÅSTRÖM, K. J.; HÄGGLUND, T. PID controllers: theory design and tuning. ISA, 1995 apud CAMPOS, M. C. M. M., TEIXEIRA, H. C. G. Controle típico de equipamentos e processos industriais São Paulo, Editora Edgard Blucher, 2006

CAMACHO, E.F.; BORDONS, C. Model Predictive Control. $2^{\text {nd }}$ Ed, Londres, Springer Verlag, 2004.

CHEN, S.; BILLINGS, S.A.; LUO, W. Orthogonal least squares methods and their application to non-linear systems identification. International Journal of Control, v. 50, n. 5, p.1873-1896, 1989.

FORSELL, U.; LJUNG, L. Closed-loop Identification revisited. Automatica, v. 35, n. 7, p.12151241, 1999.

GARCIA, C. Modelagem e simulação de processos industriais e de sistemas eletromecânicos. $2^{\mathrm{a}}$ ed, São Paulo: Edusp, 2005

GEVERS, M. A decade of progress in iterative process control design: from theory to practice. Journal of Process Control, v. 12, n. 4, p. 519-531, 2002.

GOPALUNI, R.B.; PATWARDHAN, R. S; SHAH, S. L.; The nature of data pre-filters in MPC relevant identification - open- and closed-loop issues. Automatica, v. 39, n. 9, p.1617-1626, 2003.

GOPALUNI, R.B.; PATWARDHAN, R. S; SHAH, S. L.; The MPC relevant identification - tuning the noise models. Journal of Process Control, v.14, n.6, p.699-714, 2004.

HAYTER, A. Probability and statistics for engineers and scientists. $3^{\text {rd }}$. Ed. Belmont: Thomson Higher Education, 2007.

HÖSKULDSON, A. PLS regression methods. Journal of Chemometrics, v.2, n. 3, p. 211-228, 1988. 
HUANG, B.; WANG, Z. The role of data prefiltering for integrated identification and model predictive control. In: Proceeding of the $14^{\text {th }}$ World Congress of IFAC, Beijing, 1999 .

KAILATH, T. Linear systems. Englewood Cliffs: Prentice-Hall, 1980.

KIERS, H. A.; SMILDE, A.K.; A comparison of various methods for multivariate regression with highly collinear variables. Statistical Methods \& Applications, v. 16, n.2, p. 193-228, 2007.

LAURI, D.; MARTINEZ, M.; SALCEDO, J.V.; SANCHIS, J. PLS-based model predictive control relevant identification: PLS-PH algorithm, Chemometrics and Intelligent Laboratory Systems, v.100, n.2, p. 118-126, 2010.

LJUNG, L. Systems identification - theory for the user. $2^{\text {nd }}$ Ed. Upper Saddle River: Prentice Hall PTR, 1999.

LJUNG, L. System identification toolbox - user's guide, Mathworks, 2011, Disponível em: <http://www.mathworks.com/help/pdf_doc/allpdf.html>. Acesso em: 01/09/2011.

MARTENS, $\mathrm{H}$. Reliable and relevant modelling of real world data: a personal account of the development of PLS regression, Chemometrics and Intelligent Laboratory Systems, v.58, n. 2, p. 85-95, 2001.

QUACHIO, R.; GARCIA, C. Aplicação do método PLS-PH para identificação de modelos NARX polinomiais. In: 10 ${ }^{a}$ CONFERÊNCIA BRASILEIRA DE DINÂMICA, CONTROLE E APLICAÇÕES, 2011, Águas de Lindóia. No Prelo.

QUACHIO, R.; GARCIA, C. Application of the PLS-PH algorithm for identification of closed-loop systems. In: 9TH IEEE INTERNATIONAL CONFERENCE ON CONTROL \& AUTOMATION, 2011, Santiago Chile. No Prelo.

QIN, S; BADGWELLI, T. A survey of industrial model predictive control technology, Control Engineering Practice, v.11, n. 7, p. 733-764, 2003.

RODRIGUES, G. C.; AGUIRRE, L.A.; FREITAS, U.S.; PENA, R.T. Identificação de um forno elétrico não-linear utilizando modelos NARMAX polinomiais. In: XI CONGRESSO BRASILEIRO DE AUTOMÁTICA, 1996, São Paulo, Anais. São Paulo, 1996, p.953-958.

ROSSITER, J. A.; KOUVARITAKIS, B. Modelling and implicit modelling for predictive control, International Journal of Control, v. 74, n. 11, p. 1085-1095, 2001.

SHOOK, D.S.; MOHTADI, C.; SHAH, S.L.. Identification for long-range predictive control, IEE Proceedings-D, v. 138, n. 1, p. 75-84, 1991.

SONG, K.; JANG, P. Y.; CHO H.; JUN, C.. Partial least square-based model predictive control for large-scale manufacturing processes, IIE Transactions, v. 34, n.10, p. 881-890, 2002.

STEWART, G. W. Colinearity and least squares regression, Statistical Science, v. 2, n. 1, p. 68-84, 1987.

STOICA, P.; NEHORAI, A, On multistep prediction error methods for time series models, Journal of Forecasting, v. 8, n. 4, p.357-368, 1989.

TROPSHA, A.; GRAMATICA, P.; GOMBAR, V. K. The importance of being earnest: validation is the absolute essential for succesful application and interpretation of QSPR models. QSAR \& Combinatorial Science, v. 22, n. 1, p. 69-77, 2003. 
WOOD, R.K.; BERRY, M. W. Terminal composition control of a binary distillation column. Chemical Engineering Science, v. 28, n. 9, p. 1707-1717, 1973. 